PNNL-13381

\title{
Low-Activity Waste Glass Studies: FY2000 Summary Report
}

\author{
B. P. McGrail \\ J. P. Icenhower \\ P. F. Martin \\ D. R. Rector \\ H. T. Schaef \\ E. A. Rodriguez \\ J. L. Steele
}

November 2000

Prepared for

the U.S. Department of Energy

under Contract DE-AC06-76RLO 1830 


\title{
DISCLAIMER
}

This report was prepared as an account of work sponsored by an agency of the United States Government. Neither the United States Government nor any agency thereof, nor Battelle Memorial Institute, nor any of their employees, makes any warranty, expressed or implied, or assumes any legal liability or responsibility for the accuracy, completeness, or usefulness of any information, apparatus, product, or process disclosed, or represents that its use would not infringe privately owned rights. Reference herein to any specific commercial product, process, or service by trade name, trademark, manufacturer, or otherwise does not necessarily constitute or imply its endorsement, recommendation, or favoring by the United States Government or any agency thereof, or Battelle Memorial Institute. The views and opinions of authors expressed herein do not necessarily state or reflect those of the United States Government or any agency thereof.

\section{PACIFIC NORTHWEST NATIONAL LABORATORY operated by \\ BATTELLE MEMORIAL INSTITUTE for the \\ UNITED STATES DEPARTMENT OF ENERGY under Contract DE-AC06-76RLO 1830}

\author{
Printed in the United States of America
}

Available to DOE and DOE contractors from the Office of Scientific and Technical Information, P.O. Box 62, Oak Ridge, TN 37831; prices available from $(615) \mathbf{5 7 6 - 8 4 0 1 .}$

Available to the public from the National Technical Information Service, U.S. Department of Commerce, 5285 Port Royal Rd., Springfield, VA 22161 
PNNL-13381

\title{
Low-Activity Waste Glass Studies: FY2000 Summary Report
}

\author{
B. P. McGrail \\ J. P. Icenhower \\ P. F. Martin \\ D. R. Rector \\ H. T. Schaef \\ E. A. Rodriguez \\ J. L. Steele
}

November 2000

Prepared for the U.S. Department of Energy under Contract DE-AC06-76RLO 1830

Pacific Northwest National Laboratory

Richland, Washington 99352 


\section{SUMMARY}

Over 200 single-pass flow-through (SPFT) experiments were completed with LAWABP1 glass, the reference glass for the 2001 Immobilized Low-Activity Waste (ILAW) Performance Assessment. These data provided the kinetic rate law parameters and $\mathrm{Na}$ ion-exchange rate needed to conduct long-term performance analyses using the reactive chemical transport code STORM. Pressurized unsaturated flow (PUF) experiments with five prototypic ILAW glasses were also performed. The PUF test provides a means to dramatically accelerate the weathering process in a simulated vadose zone environment. The performance of these five next generation ILAW glasses in the PUF test (and other accelerated tests) improved markedly from earlier glass compositions that were being developed by BNFL, Inc. No autocatalytic corrosion rate accelerations were observed in tests that were conducted for over 1 year. Excellent performance was also observed for one glass that has a $23 \% \mathrm{Na}_{2} \mathrm{O}$ loading as compared with the nominal 20 mass $\% \mathrm{Na}_{2} \mathrm{O}$ loading in previously tested glasses. Improvements in glass performance resulted from the improved scientific understanding about how key glass components ( $\mathrm{Al}, \mathrm{Fe}, \mathrm{Zr}, \mathrm{Ti}, \mathrm{La}$ ) impact long-term glass behavior and the rapid feedback on product performance now available with advanced test methods such as the PUF test.

SPFT and PUF experiments were run with a commercial humic acid solution, 25 to 50 times more concentrated than expected in Hanford vadose zone pore water. No difference in glass dissolution rate versus the rate measured in deionized water could be detected within experimental error.

Initial development and testing of a parallelized lattice-Boltzmann method for solving reactive chemical transport problems in complex geometries was completed. This method is being examined as a means to dramatically decrease the computional time required to solve complex multidimensional reactive transport problems needed to predict long-term radionuclide release rates from ILAW glasses. The results showed linear speedup behavior with number of processors for a simple test problem. The code was also used to solve a 160,000 node reactive transport problem in an artificial fracture network. Additional development and testing of the model on more realistic and complex ILAW disposal problems is planned for FY01. 


\section{CONTENTS}

1.0 INTRODUCTION

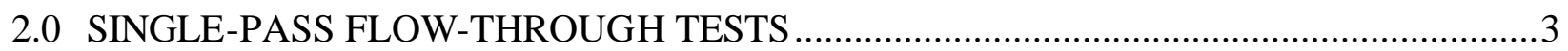

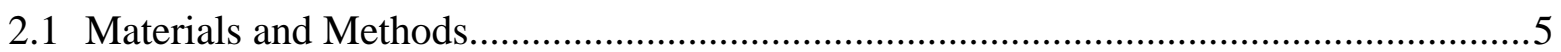

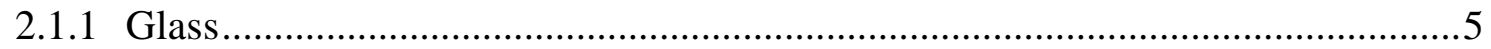

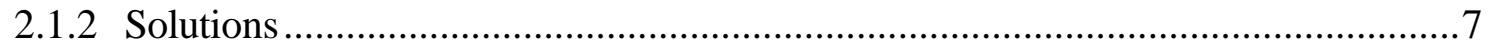

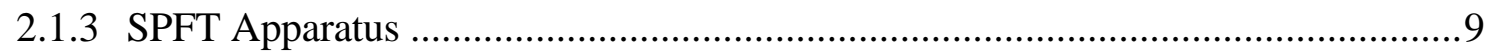

2.1.4 Dissolution Rate and Error Calculations ............................................................. 10

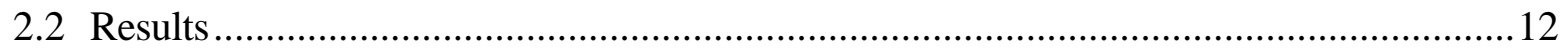

2.2.1 Achievement of Steady-State and Consistency of Results..................................12

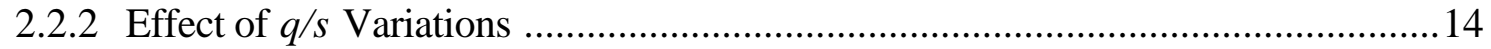

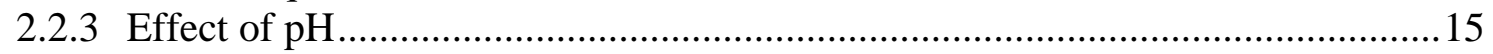

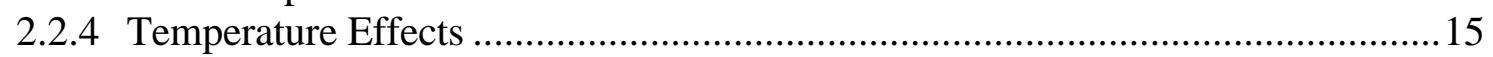

2.2.5 Effects of Additives ( $\mathrm{Si}, \mathrm{Al}, \mathrm{Humic}$ Acid) on Rates ..........................................16

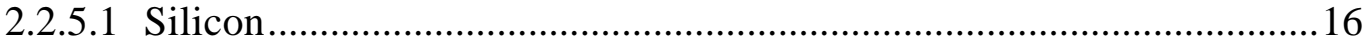

2.2.5.1.1 Rate versus silicic acid activity ………………..................... 16

2.2.5.1.2 Na-hydrogen exchange rates ..............................................17

2.2.5.2 Aluminum and aluminum plus silicon.................................................19

2.2.5.3 Effects of Humic Acid on Dissolution Rate ........................................22

2.2.5.3.1 NMR Characterization ......................................................2.

2.2.5.3.2 Dissolution Rate Results ....................................................25

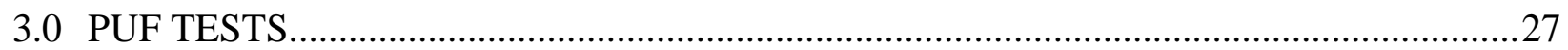

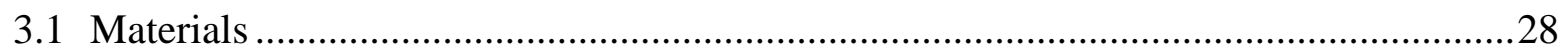

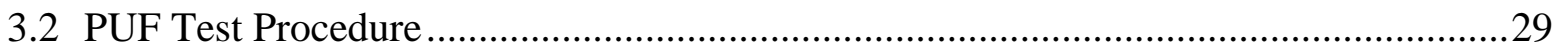

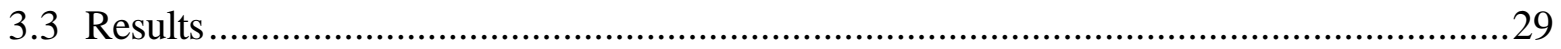

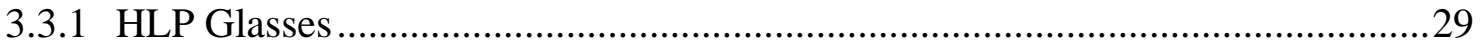

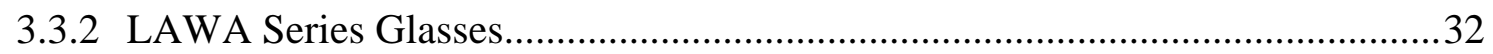

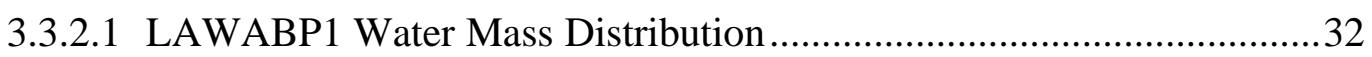

3.3.2.2 Solid Phase Analyses.............................................................................

3.3.2.3 LAWA44 Glass..................................................................................

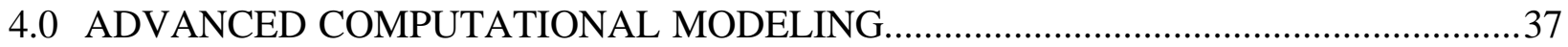

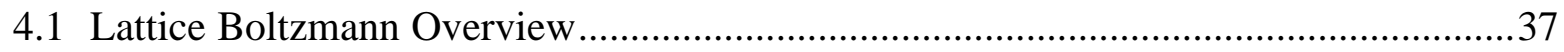

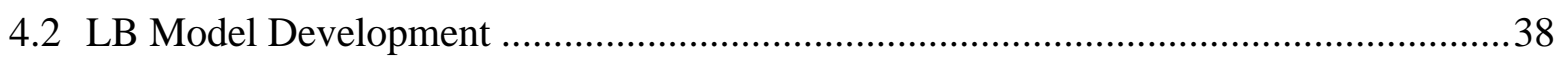

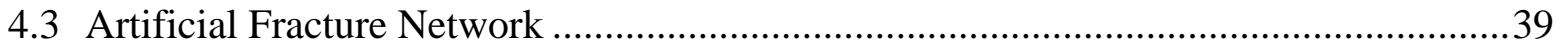

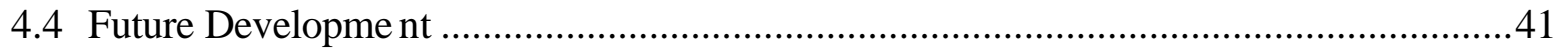

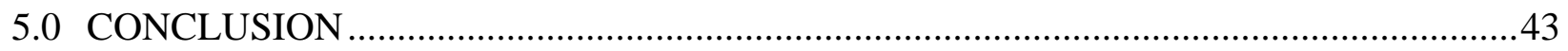

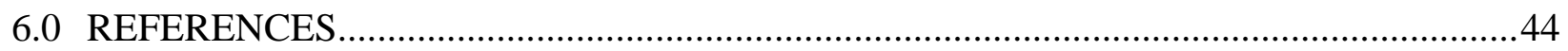





\section{FIGURES}

1. Schematic of the Single Pass Flow-Through (SPFT) Apparatus .............................................

2. Boron Concentration Versus Time for the Four Temperatures Investigated..........................13

3. Effect of Variation in the Ratio of Flow Rate, $q$, to Sample Surface Area, $s . . . \ldots \ldots \ldots \ldots \ldots \ldots . . . . . . . .14$

4. $\log _{10}$ Dissolution Rate Versus Temperature Corrected $\mathrm{pH}$ for LAWABP1 Glass .................15

5. Dissolution Rate Based on $\mathrm{B}$ and $\mathrm{Na}$ Versus the Activity of Silicic Acid at $40^{\circ} \mathrm{C}$.................16

6. Dissolution Rate with Respect to B and Na Versus Silicic Acid Activity at $70^{\circ}$ and $90^{\circ} \mathrm{C} \ldots 17$

7. Sodium-H Exchange Rate Versus Reciprocal Temperature for LAWABP1 Glass ...............18

8. Dissolution Rate Versus Activity of Aluminate Ion for LAWABP1 Glass at $40^{\circ} \mathrm{C}$...............20

9. $\log _{10}$ Activity Aluminate Versus Dissolution rate of LAWABP1 glass at $40^{\circ} \mathrm{C} \ldots \ldots \ldots \ldots \ldots \ldots . . . .20$

10. Activity of Silicic acid Versus Aluminate at 40,70 , and $90^{\circ} \mathrm{C}$............................................

11. Dissolution Rate at $40^{\circ} \mathrm{C}$ Versus Mixed Al-Si Activity Product Terms ................................22

12. Dissolution Rate at $90^{\circ} \mathrm{C}$ Versus Mixed Al-Si Activity Product Terms ................................22

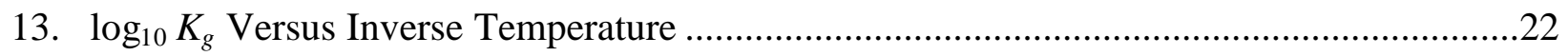

14. Dissolution Rate at $90^{\circ} \mathrm{C}$ Versus the Two Competing Al-Si Activity Product Schemes ......23

15. MAS-NMR Spectra of Aldrich Humic Acid Used in SPFT Experiments .............................25

16. Dissolution Rate (based on B, Al, or Na) Versus Time for Experiments With and Without

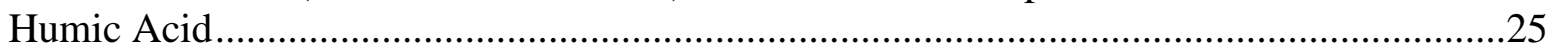

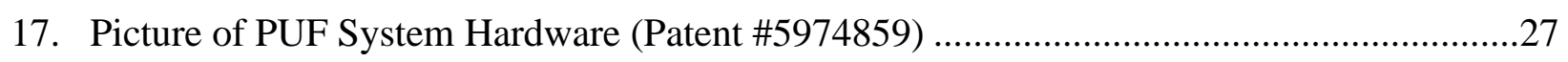

18. Computer Monitored Test Metrics From PUF Tests with HLP Series of Glasses ..................30

19. Normalized Release Rate for Selected Elements in PUF Tests with HLP Series of Glasses.........................................................................................................

20. Computer Monitored Test Metrics From PUF Tests with LAWA Series of Glasses..............32

21. Normalized Release Rate for Selected Elements in PUF Tests with LAWA

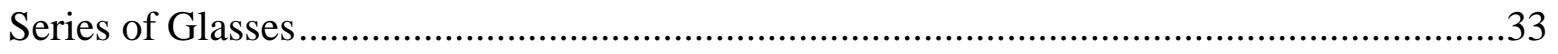

22. Water Mass Distribution in Reacted Solids From PUF Test with LAWABP1 Glass ............33

23. Optical Photos of LAWABP1 Glass Samples S4 and S9 After $190 \mathrm{~d}$ of Reaction in PUF

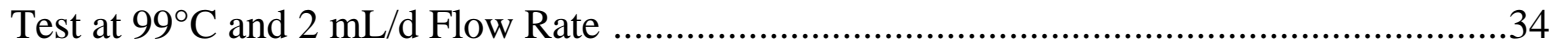

24. XRD Analyses of PUF Reacted LAWABP1 Glass Samples ....................................................34

25. SEM Photos of Reacted LAWABP1 Glass Grains From Sample S9 .....................................35

26. Kaolinite Crystals Found on PUF Reacted LAWABP1 Glass Sample S11 ……....................35

27. Aluminosilicate Phase Shown in Cross-Section in PUF Reacted LAWABP1 Sample S1 ...35

28. Speedup Performance of the LB/KEMOD Computer Program for a Simple Model System. .39 
29. LB/KEMOD Simulation of $\mathrm{pH}$ and Flow Field in Artificial Fracture Network

30. Predicted Concentration $\left(\mathrm{mol} / \mathrm{m}^{3}\right)$ of Calcite LB/KEMOD Simulation of Artificial Fracture Network.

31. Predicted Total Aqueous Concentration $\left(\mathrm{mol} / \mathrm{m}^{3}\right)$ of $\mathrm{Ca}$ in $\mathrm{LB} / \mathrm{KEMOD}$ Simulation of Artificial Fracture Network 


\subsection{INTRODUCTION}

Vitrification of low-activity tank waste at Hanford is expected to produce over $160,000 \mathrm{~m}^{3}$ of glass that will be placed in a shallow subsurface disposal facility [1]. Before the immobilized low activity waste (ILAW) can be disposed of, DOE must approve a performance assessment, which is a document that describes the long-term impacts of the disposal facility on public health and environmental resources. One of the key inputs to the performance assessment is the radionuclide release rate from the glass. A strategy to evaluate the long-term radionuclide release rate from LAW glasses has been published [2]. The purpose of this report is to describe the progress made in fiscal year (FY) 2000 toward implementing this strategy with the goal of developing an understanding of the long-term corrosion behavior of low-activity waste glasses so that a credible performance assessment can be conducted.

The emphasis in FY2000 was the completion of a large suite of single-pass flow-through (SPFT) experiments with LAWABP1 glass, which was selected as the reference glass for detailed analysis in the 2001 ILAW Performance Assessment. The results from these studies is discussed in Section 2.0. Several prototypic ILAW glasses, in addition to LAWABP1 glass, were also subjected to accelerated weathering using the pressurized unsaturated flow (PUF) system. The results from these experiments are discussed in Section 3.0. Finally, the results from initial development and testing of a new lattice-Boltzmann method for reactive chemical transport modeling are discussed in 4.0, followed by Conclusions and References. 



\subsection{SINGLE-PASS FLOW-THROUGH TESTS}

The single pass flow-through (SPFT) test is an open system experiment in which a solution flows at constant temperature and rate through a reaction cell containing the sample. This configuration precludes re-circulation of a portion of the effluent and so makes a "single-pass" through the reaction cell. Many different SPFT apparatuses have been developed, but these can all be classified as three basic types: 1) well-mixed batch, 2) packed bed, and 3) fluidized bed. The well-mixed batch type of apparatus was used for all the test data reported here.

We have quantified the dissolution kinetics of LAWABP1 glass composition through the use of SPFT experiments over a range of $\mathrm{pH}$ values (2 to 11 ), temperatures $\left(23^{\circ}\right.$ to $90^{\circ} \mathrm{C}$ ), and solution compositions (primarily Al, Si doped). Because vitreous materials, such as the LAWABP1 glass, are metastable substances, the glass sample cannot reach chemical equilibrium with the solution. Moreover, the complete dissolution and conversion of glass to more stable crystalline or amorphous materials in the repository will occur on a time scale that exceeds the period of regulatory concern (20,000 years) for the ILAW glass. Therefore, to understand the reactivity of potential waste glass candidates in subsurface environments, a full knowledge of the dissolution kinetics is necessary. While other experiments, such as static PCT or PUF tests described elsewhere in this report may more realistically mimic disposal system conditions, SPFT experiments are ideal for elucidating the kinetic rate law parameters that will be used to model radionuclide release rates into the geosphere. The SPFT test is uniquely suited for retrieving rate parameters because the system is designed to establish steady-state conditions between the glass and the aqueous solution. Steady-state conditions ensure that effluent $\mathrm{pH}$ and concentrations of elements are invariant with respect to time and that the system is maintained at constant chemical affinity.

To predict the long-term fate of glass in the subsurface over the period of regulatory concern, a mathematical model that describes glass reactivity is needed. Over the last few decades, a general rate equation has been fashioned to describe the dissolution of glass (and more ordered materials) into aqueous solution. As described below, the equation is based upon the Transition State Theory of chemical kinetics, in which the overall reaction rate is governed by the slowest elementary reaction. Elementary reactions have simple stoichiometry and can be combined as an overall reaction. In many cases, the elementary reactions can only be inferred. As an example of the elementary reaction, consider the dissolution of $\mathrm{SiO}_{2}$ polymorphs to form silicic acid: 


$$
\mathrm{SiO}_{2}(\text { solid })+2 \mathrm{H}_{2} \mathrm{O} \Leftrightarrow \mathrm{SiO}_{2} * 2 \mathrm{H}_{2} \mathrm{O}^{\ddagger} \rightarrow \mathrm{H}_{4} \mathrm{SiO}_{4}(\text { aqueous })
$$

in which $\mathrm{SiO}_{2} * 2 \mathrm{H}_{2} \mathrm{O}^{\ddagger}$ represents an activated complex of unknown stoichiometry. Note that the reactants and the activated complex in equation (1) are linked by a double-headed arrow symbolizing that the reaction is reversible such that the latter can back react to form the former. Decay of the activated complex to form the product (silicic acid) is irreversible in the TST formulation and is symbolized as a uni-directional arrow.

With these assumptions, a general equation describing the rate of reaction as a function of solid (glass, mineral, ceramic) composition, $\mathrm{pH}$, temperature, saturation state of the system, and the activities of rate-enhancing or -inhibiting entities [3] has been proposed:

$$
k_{i}=\vec{k} v_{i} a_{\mathrm{H}^{+}}^{-\eta} e \frac{-E_{a}}{\mathrm{RT}}\left[1-\left(\frac{Q}{K_{g}}\right)^{\sigma}\right] \prod_{j} a_{j}
$$

where: $k_{i} \quad=$ dissolution rate, $\mathrm{g} \mathrm{m}^{-2} \mathrm{~d}^{-1}$

$\vec{k} \quad=$ intrinsic rate constant, $\mathrm{g} \mathrm{m}^{-2} \mathrm{~d}^{-1}$

$v_{i} \quad=$ the stoichiometric coefficient of element $\mathrm{i}$ in the glass (dimensionless)

$a_{\mathrm{H}^{+}}=$hydrogen ion activity

$a_{j} \quad=$ activity of the $j^{\text {th }}$ aqueous species

$E_{a}=$ activation energy, $\mathrm{kJ} / \mathrm{mol}$

$\mathrm{R}=$ gas constant, $\mathrm{kJ} / \mathrm{mol} \cdot \mathrm{K}$

$\mathrm{T}=$ temperature, $\mathrm{K}$

$Q \quad=$ ion activity product

$K_{g} \quad=$ pseudoequilibrium constant

$\eta \quad=\mathrm{pH}$ power law coefficient

$\sigma \quad=$ Temkin coefficient.

By manipulating one experimental condition, such as temperature, flow-rate, $\mathrm{pH}$, and the concentration of additives, while keeping the others constant, the parameters within Equation (2) can be isolated and quantified.

Although equation (2) is useful, there is still some debate in the scientific community regarding the identity and values of the above parameters. For example, it is well established that dissolution rates increase with an increase in the activity of the hydronium ion (i.e., $\mathrm{pH}$ ), but it is not clear if other aqueous species (such as the aluminate ion or humic acid) inhibit or catalyze reaction rates. As discussed in more detail below, there is no consensus concerning inclusion of the effects of aluminum in equation (2). Two different schemes have been advanced for the effects 
of $\mathrm{Al}$ on rates: (i) Assigning the activity of the aluminum species as an inhibitor (as an $a_{j}$ term) [4], or (ii) As part of an activity product in the $Q / K_{g}$ term [5]. This divergence of opinion stems from disagreements surrounding the value of the pseudoequilibrium constant, $K_{g}$. Grambow [6] proposed that that the value of $K_{g}$ should be equivalent to that for one of the silica polymorphs (e.g., amorphous silica or chalcedony). Other investigators have proposed that $K_{g}$ include other species, such as aluminum, or a complicated activity product of all species found in secondary corrosion products. A final uncertainty rests with the nature and value of the Temkin coefficient, $\sigma$, which represents the net reaction order of the decay of the activated complex to the product. Investigators have reported values of $\sigma$ ranging between 0.4 and 1.0 whereas others have recommended that $\sigma$ should be ignored in the above equation. The value of $\sigma$ cannot be determined independently through experiment with any certainty, and we will follow the recommendation of Lasaga [4] and assign it a value of 1.0.

This report summarizes the findings of our experiments to date. In this fiscal year (FY 2000), we have completed over two hundred experiments on the LAWABP1 glass and have amassed data that will be used to model the long-term corrosion behavior of glass. Following a discussion of the materials and methods used, the data are discussed in detail. The data in this report can be conveniently grouped into five separate sections; (1) a discussion of the consistency of the data set and methods validation, (2) the effects of varying $q / s$ (the flow-through rate divided by the surface area of the sample), (3) solution $\mathrm{pH}$, and (4) temperature on dissolution rates, and (5) the effects of adding additives ( $\mathrm{Si}, \mathrm{Al}$, and humic acid) into the input solution.

\subsection{MATERIALS AND METHODS}

\subsubsection{Glass}

The glass composition used in this study is denoted "LAWABP1", which is a boroaluminosilicate glass characterized by relatively high concentrations of $\mathrm{TiO}_{2}$ (2.49 wt.\%), $\mathrm{ZnO}(2.60$ wt.\%), $\mathrm{ZrO}_{2}$ (5.25 wt.\%), and $\mathrm{La}_{2} \mathrm{O}_{3}(2.00 \mathrm{wt} . \%$ ) (Table 1). Inclusion of these oxides in glass is thought to promote greater corrosion resistance as well as slower $\mathrm{Na}^{+}-\mathrm{H}^{+}$exchange rates (see later section). As with other glasses considered for the ILAW program, $\mathrm{Na}_{2} \mathrm{O}$ concentrations are relatively high (20.00 wt.\%), but other oxides are either relatively low (MgO: $1.00 \mathrm{wt} . \%)$ or absent (e.g., $\mathrm{CaO}, \mathrm{Li}_{2} \mathrm{O}$ ). 
Samples of powdered glass used in this study were produced by crushing glass in a ceramic ball mill. The crushed glass was then sieved to separate the powders into a variety of size fractions; in this study, only the $<100,>200$ mesh (149 to $75 \mu \mathrm{m}$ diameter) size fraction was used. The powdered sample was then sonicated in deionized water (DIW) and rinsed in ethanol to remove any adhering particles outside the desired size fraction. After drying in a $90^{\circ} \mathrm{C}$ oven for several hours the powder was kept in a desiccator until used in an experiment. For two sets of experiments we used glass coupons $(\sim 10 \mathrm{~mm} \times 10 \mathrm{~mm} \times 2 \mathrm{~mm})$ rather than powders. Coupons were cut using an isomet saw and were then polished using 600-grit sandpaper.

The mass-normalized surface area of the powder samples was measured using the BET method [7], with $\mathrm{Kr}$ as the adsorbate. Table 2 displays the results of the BET analysis for one LAWABP1 and two LAWA33 samples. The surface area measurements, in $\mathrm{m}^{2} \mathrm{~g}^{-1}$, are all within $10 \%$ of each other, indicating the reproducibility of the results.
Table 1. Chemical Composition of LAWABP1 Glass

\begin{tabular}{lr}
\multicolumn{1}{c}{ Oxide } & mass\% \\
\hline $\mathrm{Al}_{2} \mathrm{O}_{3}$ & $10.00 \%$ \\
$\mathrm{~B}_{2} \mathrm{O}_{3}$ & $9.25 \%$ \\
$\mathrm{Cl}$ & $0.58 \%$ \\
$\mathrm{Cr}_{2} \mathrm{O}_{3}$ & $0.02 \%$ \\
$\mathrm{~F}$ & $0.04 \%$ \\
$\mathrm{Fe}_{2} \mathrm{O}_{3}$ & $2.50 \%$ \\
$\mathrm{~K}_{2} \mathrm{O}$ & $2.20 \%$ \\
$\mathrm{La}_{2} \mathrm{O}_{3}$ & $2.00 \%$ \\
$\mathrm{MgO}$ & $1.00 \%$ \\
$\mathrm{Na}_{2} \mathrm{O}$ & $20.00 \%$ \\
$\mathrm{P}_{2} \mathrm{O}_{5}$ & $0.08 \%$ \\
$\mathrm{SO}_{3}$ & $0.10 \%$ \\
$\mathrm{SiO}_{2}$ & $41.89 \%$ \\
$\mathrm{TiO}_{2}$ & $2.49 \%$ \\
$\mathrm{ZnO}^{2}$ & $2.60 \%$ \\
$\mathrm{ZrO}_{2}$ & $5.25 \%$
\end{tabular}

TOTAL $\quad 100.00 \%$ We note, however, that the values reported in Table 2 for the BET analyses are probably an overestimate of the true surface area of the sample over the duration of the experiment. This is due to the ubiquitous presence of finer-grained glass particles that adhere to the material of the desired size fraction. Because the surface of area of very fine-grained material is large, the BET analyses measurements are skewed towards higher values. When the sample powders react with aqueous solutions, the finer-grained material rapidly dissolves (probably in one to three days, depending on temperature and $\mathrm{pH}$ ) leaving behind the larger-grained sample (of the desired size range) with a lower surface area. It is this surface area that persists through the duration of the experiment as the sample and solution approaches steady-state conditions. An alternate way of assessing sample surface area is to calculate the specific surface area based on the following geome tric formula [8]:

$$
s=\frac{3}{\rho r}
$$

where $\rho$ is the glass density $\left(\mathrm{g} \mathrm{m}^{-3}\right)$, and $r$ is the average particle radius is in meters. Applying this formula for the LAWABP1 glass in this size fraction yields a specific surface area of 
$0.020 \mathrm{~m}^{2} \mathrm{~g}^{-1}$, which is nearly $3 \mathrm{X}$ smaller than the value measured by BET. In deriving this geometric formula, it is assumed that the particles are spherical, that the size distribution of grains within the fraction is normally distributed, and that surface pits, cracks, and other forms of surface roughness do not affect the
Table 2. Measured Kr BET surface areas and estimated surface area from Equation 3 for $<100,>200$ mesh size fraction glass.

\begin{tabular}{|c|c|c|c|c|}
\hline \multicolumn{5}{|c|}{ BET Surface Area } \\
\hline Sample & $\begin{array}{c}\text { Size Fraction } \\
\text { (mesh) }\end{array}$ & $\begin{array}{c}\text { \# of } \\
\text { points }\end{array}$ & $\begin{array}{c}\text { Surface Area } \\
\left(\mathrm{m}^{2} / \mathrm{g}\right)\end{array}$ & $\begin{array}{l}\text { error } \\
\left(\mathrm{m}^{2} / \mathrm{g}\right)\end{array}$ \\
\hline LAWABP1 & $(<100,>200)$ & 9 & 0.0575 & 0.0002 \\
\hline LAWA33 & $(<100,>200)$ & 6 & 0.0517 & 0.0003 \\
\hline \multirow[t]{2}{*}{ LAWA33 } & $(<100,>200)$ & 8 & 0.0567 & 0.0001 \\
\hline & & Average $=$ & 0.0553 & \\
\hline \multicolumn{5}{|c|}{ Geometric Surface Area } \\
\hline Sample & $\begin{array}{c}\text { Size Fraction } \\
(\text { mesh })\end{array}$ & $\begin{array}{l}\text { Density } \\
\left(\mathrm{g} / \mathrm{m}^{3}\right)\end{array}$ & $\begin{array}{c}\text { Surface Area } \\
\left(\mathrm{m}^{2} / \mathrm{g}\right)\end{array}$ & $\begin{array}{c}\text { error } \\
\left(\mathrm{m}^{2} / \mathrm{g}\right)\end{array}$ \\
\hline LAWABP1 & $(<100,>200)$ & $2.68 \mathrm{E}+06$ & 0.0200 & 0.0028 \\
\hline
\end{tabular}

surface area. All three of these assumptions are probably not strictly valid, yet the following line of evidence suggests that the geometric estimate best represents the true surface area. Because the surface area of glass coupons can be precisely determined from dimensional measurements, dissolution rates using glass coupons can be compared to rates measured using powders. The value of the sample surface area, measured by BET or estimated by the geome tric formula, can be plugged into the rate equation (see below) for purposes of comparison.

In an experiment using glass coupons at $90^{\circ} \mathrm{C}, \mathrm{pH}\left(25^{\circ} \mathrm{C}\right)=9$, the measured $\log _{10}$ dissolution rate is $-0.63 \mathrm{~g} \mathrm{~m}^{-2} \mathrm{~d}^{-1}$. Using the geome tric formula for surface area, the $\log _{10}$ dissolution rate is $-0.72 \mathrm{~g} \mathrm{~m}^{-2} \mathrm{~d}^{-1}$ for the powdered sample, which within the experimental uncertainty of the dissolution rate. In contrast, if the BET surface area were used in this same experiment, the resulting $\log _{10}$ dissolution rate would be $-1.20 \mathrm{~g} \mathrm{~m}^{-2} \mathrm{~d}^{-1}$, which is clearly different from the result using glass coupons. We conclude, therefore, that the geometric estimate is a more accurate appraisal of the sample surface area.

\subsubsection{Solutions}

Seven different solutions were used to control the $\mathrm{pH}$ during the experiments and are listed in Table 3. Acid solutions ( $\mathrm{pH}=2,4)$ were prepared by adding $\mathrm{HNO}_{3}$ to deionized water (DIW). Neutral to slightly basic solutions ( $\mathrm{pH}=7,8,9$, and 10) were made by adding small amounts of the organic THAM (tris hydroxymethyl aminomethane) buffer to DIW and then adding minor 
concentrations of $\mathrm{HNO}_{3}$ to bring the solution to the desired $\mathrm{pH}$ value. Alkaline solutions $(\mathrm{pH}=$ 11) were prepared by adding $\mathrm{LiCl}$ and $\mathrm{LiOH}$ to DIW. Solution compositions are summarized in Table 3. Table 3 also gives the change in $\mathrm{pH}$ with respect to the temperature of the experiment, as calculated with the EQ3NR geochemical code [9]. As one can see from Table 3, the in-situ $\mathrm{pH}$ of the experiment can change by as much as $1.5 \mathrm{pH}$ units over the temperature interval of $23^{\circ}$ to $90^{\circ} \mathrm{C}$.

Aliquots of all input solutions used in this study were analyzed by ICP-OES (inductively coupled plasma optical emission spectroscopy) methods to determine the background concentration of elements of interest ( $\mathrm{Al}, \mathrm{B}, \mathrm{Mg}, \mathrm{K}, \mathrm{Si}, \mathrm{Na}$ ). In all cases (except the humic acid solution; see below), the background concentrations of elements were below their respective detection thresholds.

For select experiments, we added $\mathrm{Al}, \mathrm{Si}$, or both to input solutions. Aluminum was added in the form of water soluble $\mathrm{Al}\left(\mathrm{NO}_{3}\right)_{3} \cdot 9 \mathrm{H}_{2} \mathrm{O}$, which rapidly dissolved leaving no residue. Silicon was added in the form of silicic acid powder $\left(\mathrm{SiO}_{2} \cdot 2 \mathrm{H}_{2} \mathrm{O}\right)$, which required heating of the silicacontaining solution to $\geq 87^{\circ} \mathrm{C}$ for at least three days to facilitate complete dissolution. These solutions were $\mathrm{pH}$-adjusted by use of $\mathrm{HNO}_{3}$ after addition of $\mathrm{Al}$ or $\mathrm{Si}$ to ensure that solutions were maintained at the appropriate $\mathrm{pH}$ value (typically $\mathrm{pH}=9$ ). The amount of $\mathrm{Al}$ or $\mathrm{Si}$ added to the solutions depended on the temperature of the experiment. Silicon was added to solution as a percentage of saturation with respect to amorphous silica. Because $\mathrm{SiO}_{2}(\mathrm{am})$ solubility increases with temperature, the range of $\mathrm{Si}$ concentrations added to solutions varied from approximately 10 to $150 \mathrm{ppm} \mathrm{Si}$. In the case of aluminum, it was difficult to add aluminum into solution without becoming supersaturated with respect to polymorphs of $\mathrm{Al}(\mathrm{OH})_{3}$ (e.g., gibbsite) or $\mathrm{Al}_{2} \mathrm{Si}_{2} \mathrm{O}_{5}(\mathrm{OH})_{4}$ (kaolinite). As in the case of silicon, the amount of aluminum added depended upon the temperature of the experiment but can be summarized as from 10 to $100 \mu$ molal Al. To achieve a wide spread in aluminum and silicon activities in solution, a subset of solutions was prepared with both added $\mathrm{Al}$ and $\mathrm{Si}$. For these experiments, four different concentrations of $\mathrm{Al}$ were used. For each Al concentration, Si was added up to near saturation with respect to amorphous silica. Again, these additions probably caused the solutions to become supersaturated with respect to one or more aluminosilicate phase. Precipitation of solid phases can be visually detected in the effluent solution composition, as is fully discussed below. For experiments in 
Table 3. Composition of solutions used in single pass flow-through experiments. TRIS $=$ THAM-based buffer. Solution $\mathrm{pH}$ values above $23^{\circ} \mathrm{C}$ were calculated with EQ3NR Code V7.2b database.

\begin{tabular}{clrrrr} 
Solution \# & Composition & $\mathrm{pH} 23^{\circ} \mathrm{C}$ & $\mathrm{pH} 40^{\circ} \mathrm{C}$ & $\mathrm{pH} 70^{\circ} \mathrm{C}$ & $\mathrm{pH} 90^{\circ} \mathrm{C}$ \\
\hline & & & & & \\
1 & $0.01 \mathrm{M} \mathrm{HNO}_{3}$ & 2.01 & 2.04 & 2.07 & 2.11 \\
2 & $0.0001 \mathrm{M} \mathrm{HNO}_{3}$ & 3.66 & 3.71 & 3.71 & 3.71 \\
3 & $0.01 \mathrm{M} \mathrm{TRIS}^{2} 0.0093 \mathrm{M} \mathrm{HNO}_{3}$ & 7.13 & 6.53 & 5.87 & 5.50 \\
4 & $0.01 \mathrm{M} \mathrm{TRIS}+0.0059 \mathrm{M} \mathrm{HNO}_{3}$ & 8.08 & 7.54 & 6.88 & 6.52 \\
5 & $0.05 \mathrm{M} \mathrm{TRIS}+0.0079 \mathrm{M} \mathrm{HNO}_{3}$ & 8.97 & 8.44 & 7.78 & 7.42 \\
6 & $0.05 \mathrm{M} \mathrm{TRIS}$ & 9.65 & 9.38 & 8.87 & 8.52 \\
7 & $0.01 \mathrm{M} \mathrm{LiCl}+0.0107 \mathrm{LiOH}$ & 11.07 & 10.94 & 10.49 & 10.12
\end{tabular}

which precipitation did not occur, the full extent to which $\mathrm{Al}$ and $\mathrm{Si}$ affect dissolution rates could be assessed.

\subsubsection{SPFT Apparatus}

The salient features of the single pass flow-through (SPFT) apparatus used in this study are illustrated in Figure 1. Either a syringe (Kloehn; model 50300) or infusion pump (either 3M AVI Micro 210A or Graseby 3000) was used to transfer solution from the reservoir bottle to a Teflon reactor. In the case of the syringe pump, up to four experiments per pump could be run using the same input solution. This configuration was especially useful when experiments with varying flow-through rates were required. Infusion pumps were used when the input solutions contained $\mathrm{Al}$ or $\mathrm{Si}$ additives. Because no part of the infusion pump comes in contact with the solution, this precluded the possibility of contaminating later experiments. Transport of solution from the pumps was accommodated by $1 / 16^{\text {th }}$ inch Teflon tubing that led to a Teflon reservoir situated within a constant temperature oven. The oven was set to the experimental temperature of interest and a digital thermocouple, accurate to $\pm 2^{\circ} \mathrm{C}$, was used to record temperature daily. An in-line reservoir situated in the oven before the reac-

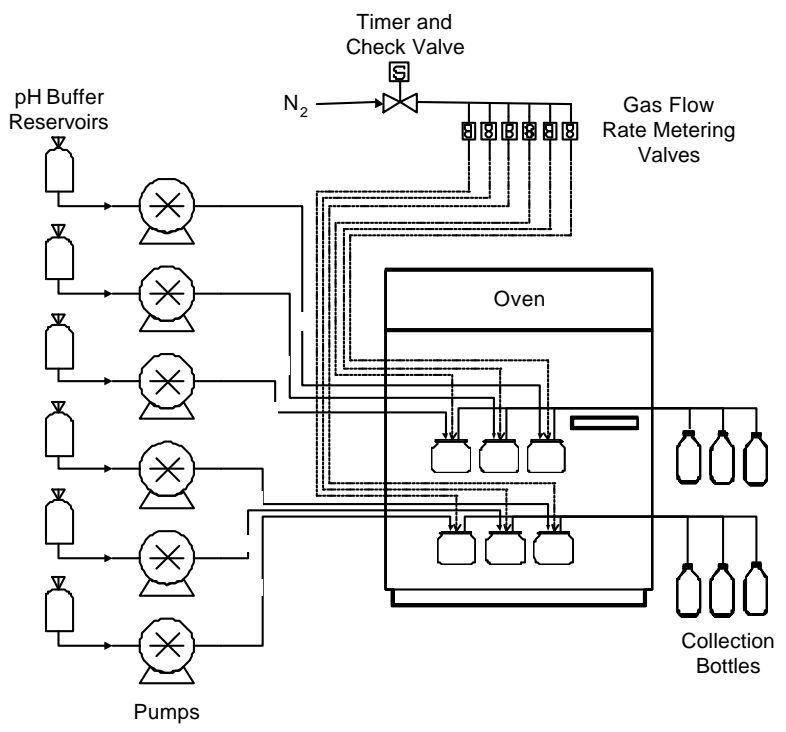

Figure 1. Schematic of the Single Pass FlowThrough (SPFT) Apparatus 
tor was also used because the typical flow-through rates were fast enough that the solution may not have had time to equilibrate at the temperature of interest before entering the reactor. The reservoir vessel contains two ports, for inflow and outflow of solution, in addition to a third port for a nitrogen gas line. A nitrogen generator continuously supplied $\mathrm{N}_{2}$ to the reservoir, ensuring that atmospheric $\mathrm{CO}_{2}$ did not cause deviations in solution $\mathrm{pH}$. A Teflon line connected the reservoir to the reactor, which housed the powdered sample. The reactors consist of two pieces that screw together with the upper half containing a port for ingress of solution and a second port for the egress of effluent solution. The powdered sample lies at the bottom of the reactor in a thin layer. Therefore, the fluid is not pumped directly through the sample, as in other reactor designs. The advantage of this design is that bubbles that form in the fluid transfer lines do not become entrained in the sample, which could alter the exposed surface area. Effluent is collected continuously in collection bottles situated outside the oven.

Aliquots of effluent solution were routinely checked to ensure that $\mathrm{pH}$ control was maintained during the experiment. The remainder of the effluent solution was acidified by high purity nitric acid and analyzed for chemical composition by inductively coupled plasma optical emi ssion spectroscopy (ICP-OES) methods. Typically, three blank solutions were drawn before glass was added to the reactor. The blank solutions were analyzed for background concentrations of elements of interest and, together with analyses of starting solution aliquots (see above), ensured us that contamination from previous experiments was not a factor.

Experiments were terminated when the concentrations of elements in the effluent solution became invariant with respect to time (steady-state conditions). Typically, this would take from one to three weeks, depending upon the temperature of the experiments. For example, in order for boron concentrations to exceed its detection threshold, flow-through rates for experiments at $23^{\circ} \mathrm{C}$ were relatively slow $\left(=20 \mathrm{~mL} \mathrm{~d}^{-1}\right)$. In contrast, the concentration of boron in experiments at $90^{\circ} \mathrm{C}$ was well above detection threshold, even with flow-through rates as fast as $100 \mathrm{~mL} \mathrm{~d}^{-1}$. Since it typically takes exchange of seven reactor volumes to achieve steady-state conditions [c.f., 6], the duration of an experiment at $23^{\circ} \mathrm{C}$ is longer than that at $90^{\circ} \mathrm{C}$.

\subsubsection{Dissolution Rate and Error Calculations}

Dissolution rates, based on steady-state concentrations of elements in the effluent, reported herein are normalized to the amount of the element present in the glass by the following formula: 


$$
\text { Normalized dissolution rate }\left(\mathrm{g} \mathrm{m}^{-2} \mathrm{~d}^{-1}\right)=\frac{\left(C_{i}-\bar{C}_{i, b}\right) q}{f_{i} S}
$$

where $C_{i}$ is the concentration of the element, $i$, in the effluent $\left(\mathrm{g} \mathrm{L}^{-1}\right), \bar{C}_{i, b}$ is the average background concentration of the element of interest $\left(\mathrm{g} \mathrm{L}^{-1}\right), q$ is the flow-through rate $\left(\mathrm{L} \mathrm{d}^{-1}\right), f_{i}$ is the mass fraction of the element in glass (dimensionless), and $S$ is the surface area of the sample $\left(\mathrm{m}^{2}\right)$. The value of $f_{i}$ can be calculated from the chemical composition of the glass. Flowthrough rates were determined by gravimetric analysis of the fluid collected in each effluent collection vessel upon sampling. The background concentration of the element of interest is determined, as previously discussed, by analyses of the starting input solution and the three blank solutions. Typically, background concentrations of elements are below their respective detection threshold. The detection threshold of any element is defined here as the lowest calibration standard that can be determined reproducibly during an analytical run within $10 \%$. Therefore, the detection threshold can be higher or lower for the same element on two separate analytical runs. For example, the detection threshold for boron may be as high as $100 \mathrm{ppb}$ (parts per billion) or as low as 5 ppb, depending how well the ICP-OES instrument operates on any particular day. In cases where the analyte is below the detection threshold, the background concentration of the element is set at the value of the detection threshold.

Dissolution rates were computed for elements whose concentrations are at least three times the detection threshold. In a few cases, concentrations were less than this and either the rate is not reported or is reported with all appropriate caveats. In the latter case, the uncertainty on the dissolution rate may be much greater than the typical $35 \%$.

Determining the experimental uncertainty of the dissolution rate takes in account all the uncertainties of each parameter in equation (4). For uncorrelated random errors the standard deviation of a function $f\left(x_{1}, x_{2}, \ldots x_{n}\right)$ is given by:

$$
\sigma_{f}=\sqrt{\sum_{i=1}^{n}\left(\frac{\partial f}{\partial x_{i}}\right)^{2} \sigma_{i}^{2}}
$$

where $\sigma_{f}=$ standard deviation of the function $f$.

$\mathrm{x}_{i}=$ parameter $i$

$\sigma_{I}=$ standard deviation of parameter $i$. 
In the case of dissolution of a solid, the function of interest is Equation (4). Substituting (4) into (5) results in:

$$
\sigma_{R_{i}}=\sqrt{\left(\frac{q}{f_{i} S}\right)^{2}\left(\sigma_{C_{i}}^{2}+\sigma_{\bar{C}_{i, b}}^{2}\right)+\left(\frac{C_{i}-\bar{C}_{i, b}}{f_{i} S}\right)^{2} \sigma_{q}^{2}+\left(\frac{\left(C_{i}-\bar{C}_{i, b}\right) q}{f_{i}^{2} S}\right)^{2} \sigma_{f}^{2}+\left(\frac{\left(C_{i}-\bar{C}_{i, b}\right) q}{f_{i} S^{2}}\right)^{2} \sigma_{S}^{2}}
$$

Errors of $5 \%, 5 \%, 10 \%, 3 \%$, and $15 \%$ were assigned to $C_{i}, \bar{C}_{i, b}, q, \mathrm{f}_{i}$, and $S$, respectively. The conservative appraisal of errors assigned to Equation (6), in addition to the practice of imputing detection threshold values to background concentrations, results in uncertainties of approximately $\pm 35 \%$ on the dissolution rate (or $\pm 0.2 \log$ units when reported as $\log _{10}$ rates).

\subsection{RESULTS}

\subsubsection{Achievement of Steady-State and Consistency of Results}

Dissolution rates and experimental conditions, including temperature, solution $\mathrm{pH}$, flowthrough rates, and sample mass and surface area, are listed in the Appendix. The majority of the rates reported are computed based on concentration of boron. Boron is typically the most reliable index for matrix dissolution since it, along with $\mathrm{Si}$ and $\mathrm{Al}$, forms the glass polymer network. In addition, when boron is released during dissolution, it is not retained either in secondary mi nerals or in "leach layers" that build up on the surface of glass. Other network forming eleme nts, such as $\mathrm{Al}$ and $\mathrm{Si}$, may be retained after initial release in experiments with slow flow-through rates (and, clearly, neither Al nor Si can be used as an index of dissolution in cases where these elements are added to input solutions). Rates based on alkali elements, in this case, $\mathrm{Na}$, are also subject to uncertainty under conditions of slow matrix dissolution rates. As discussed in more detail below, release of $\mathrm{Na}$ to solution is through two separate reactions, matrix dissolution, and alkali-hydrogen exchange. For example, when flow-through rates are slow, the concentration of $\mathrm{Si}$ in solution in contact with glass builds up, causing the dissolution rate to decrease. Relatively large amounts of $\mathrm{Na}$ are released into solution, however, because the $\mathrm{Na}^{+}-\mathrm{H}^{+}$exchange mechanism continues to operate. Thus, in this example, the calculated dissolution rate would be too fast. In many experiments, however, the $\log _{10}$ dissolution rate based upon $\mathrm{Al}, \mathrm{B}, \mathrm{Na}$, and $\mathrm{Si}$ agree to within $0.2 \mathrm{log}$ units and are reported as an average. In some extreme cases, the concen- 
tration of boron in solution is below the detection threshold and we are forced to rely on concentrations of $\mathrm{Al}, \mathrm{Na}$, and $\mathrm{Si}$ for computing dissolution rates. This may occur, for example, when flow-through rates are very fast and concentrations of elements in the effluent are dilute. However, if these rates are in disagreement with each other, for the reasons mentioned above, then dissolution rates for that experiment are not reported.

As stated earlier in this report, obtaining valid dissolution rates depends on the glasssolution system reaching steady-state conditions. Figure 2 shows that these conditions are met for typical experiments at the four temperatures $\left(23,40,70\right.$, and $\left.90^{\circ} \mathrm{C}\right)$ investigated. Concentrations of boron are invariant with respect to time after $\sim 10$ days in these experiments. The results shown in this diagram are typical of what we observed for all experiments.

For experiments performed under similar

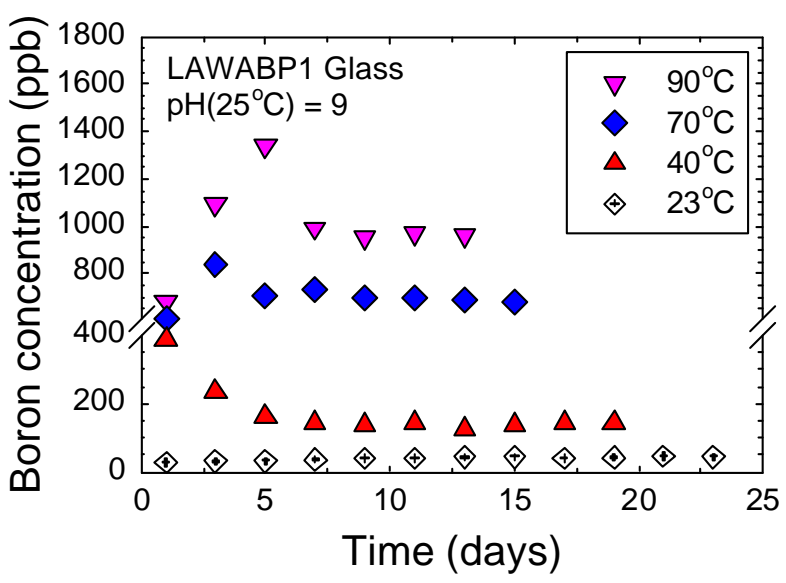

Figure 2. Boron Concentration Versus Time for the Four Temperatures Investigated. This plot illustrates that the system achieves steadystate conditions in $\sim 10$ days. Note scale break in vertical axis. conditions, the data yield generally yield consistent rate measurements. For example, experiments at $\mathrm{pH}\left(25^{\circ} \mathrm{C}\right)=9$ and flow-through rates between 80 and $100 \mathrm{~mL} \mathrm{~d}^{-1}$ gave $\log _{10}$ dissolution rates between -0.71 to $-0.84 \mathrm{~g} \mathrm{~m}^{-2} \mathrm{~d}^{-1}$ (see Appendix). The mean rate, based on 9 experiments, is $-0.784 \pm 0.108 \mathrm{~g} \mathrm{~m}^{-2} \mathrm{~d}^{-1}$ (two standard deviations). However, one experiment (\#80) is inexplicably faster than all of the others $\left(-0.59 \mathrm{~g} \mathrm{~m}^{-2} \mathrm{~d}^{-1}\right)$. Including this value, the mean rate is -0.765 $\pm 0.160 \mathrm{~g} \mathrm{~m}^{-2} \mathrm{~d}^{-1}$. We therefore conclude that the SPFT experiments are generally internally consistent with nearly all rate values within $0.2 \log _{10}$ units of each other. 


\subsubsection{Effect of $q / s$ Variations}

Figure 3 illustrates the effect of varying the ratio of flow-through rate, $q$, to sample surface area, s. Rates based on concentrations of $\mathrm{Al}, \mathrm{B}, \mathrm{Si}$, and $\mathrm{Na}$ are plotted for the conditions of $90^{\circ} \mathrm{C}$, $\mathrm{pH}\left(25^{\circ} \mathrm{C}\right)=9$ in Figure $3 \mathrm{~A}$. This figure illustrates that as the $q / s$ ratio increases, dissolution rates increase and then reach a constant value. This figure also shows that the rates based on all four elements (Al, B, Na, and Si) are nearly identical over the $q / s$ values studied. Figure 3B illustrates that the effect of $q / s$ on rates is similar at $40^{\circ}, 70^{\circ}$, and $90^{\circ} \mathrm{C}$. For all three temperatures, the rate increases to a maximum and thereafter remains constant. This rate is known as the forward rate and can be used to calculate the activation energy, $E_{a}$, of the dissolution reaction.

The reason that rates are relatively slow on the left-hand side of the diagram (toward smaller values of $q / s$ ) is that when flow-rates are low or when total surface area is high, the concentrations of elements dissolved into solution are high. As the
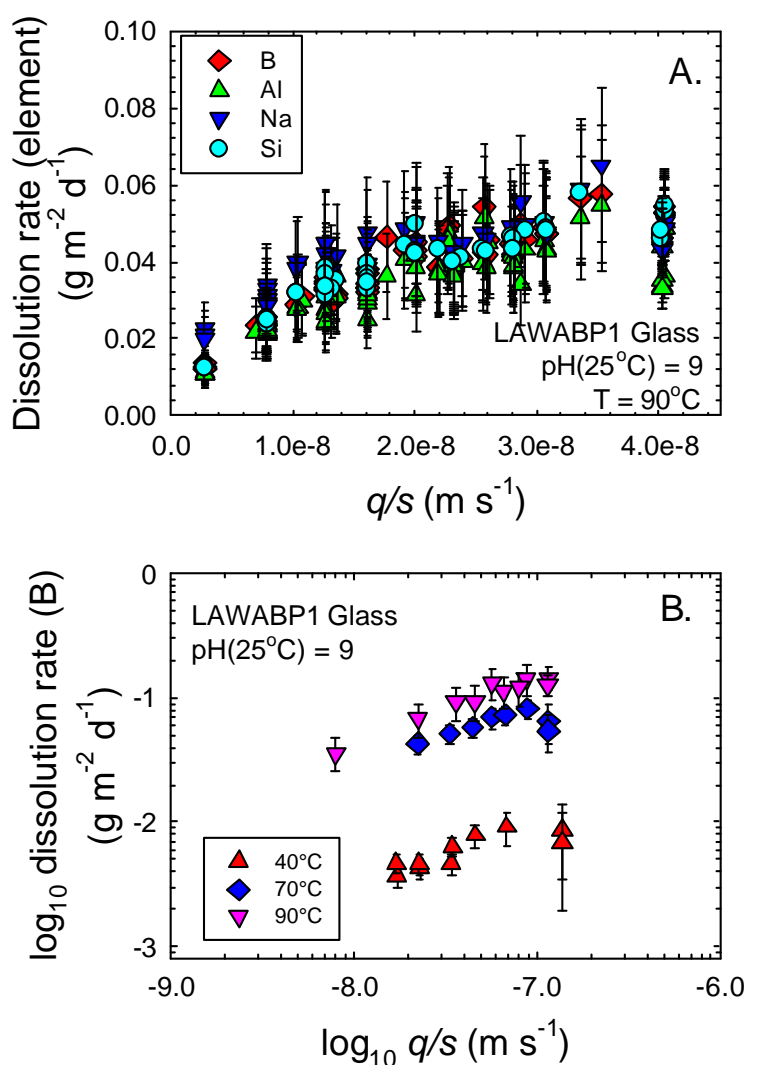

Figure 3. Effect of Variation in the Ratio of Flow Rate, $q$, to Sample Surface Area, $s$. Figure A shows the increase in rate based on $\mathrm{Al}, \mathrm{B}, \mathrm{Na}$, and $\mathrm{Si}$ for experiments at $90^{\circ} \mathrm{C}$. Note that the rates reach a constant value at higher values of $q / s$ (towards the right-hand side of the diagram). Figure B illustrates that these same effects are present for experiments at $40^{\circ}$ and $70^{\circ} \mathrm{C}$. concentration of elements rise in solution, the solution approaches saturation with respect to some solid phase or phases. Therefore, the dissolution rate slows as the chemical potential difference between glass and solution decreases. This effect is expressed mathematically as the chemical affinity of reaction:

$$
\text { Chemical affinity }=\mathrm{R} T \ln \left(\frac{K_{g}}{Q}\right)=-\Delta G_{r}
$$

where $-\Delta G_{r}$ is the free energy of reaction, and $\mathrm{R}, T, K_{g}$, and $Q$ are as defined in Equation (2). In other words, the chemical affinity is a measure of the departure from equilibrium. Therefore, as 
the ion activity product, $Q$, approaches the value of $K_{g}$, the natural $\log$ of the ratio $\frac{K_{g}}{Q} \rightarrow 0$ and the chemical affinity term goes to zero.

\subsubsection{Effect of $\mathrm{pH}$}

Solution $\mathrm{pH}$ values were varied between 2 and 11 at temperatures of $23,40,70$ and $90^{\circ} \mathrm{C}$ (see Table 3). Because the pore water solution in the disposal system is expected to be neutral to basic, only the results of the experiments for this $\mathrm{pH}$ range will be discussed. Figure 4 illustrates the effect of $\mathrm{pH}$ on the dissolution rates. Note that the in-situ $\mathrm{pH}$ has been corrected for temperature using the EQ3/6 computer code. For the four temperatures studied, the data indicate similar behav-

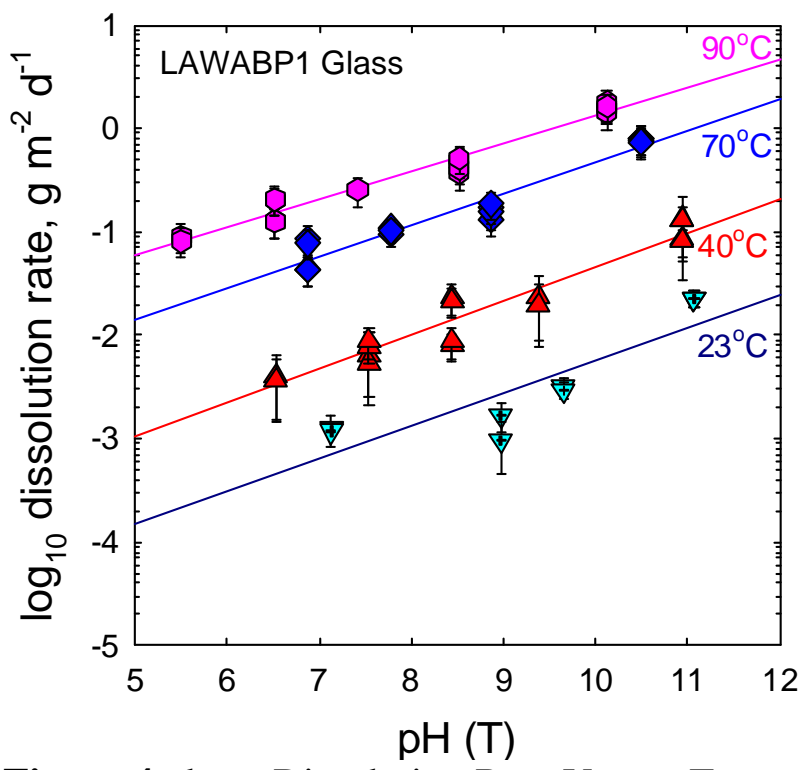

Figure 4. $\log _{10}$ Dissolution Rate Versus Temperature Corrected $\mathrm{pH}$ for LAWABP1 Glass ior with rates increasing with $\mathrm{pH}$ at a constant value. The slope of a line through the data points corresponding to each temperature is equal to $\eta$, which is one of the parameters in Equation (2). The value of the slope is $0.35 \pm 0.03$ for all four temperatures plotted. The value of $\eta$ is similar to what we determined previously on other waste glass candidates [8]. In addition, the value of $\eta$ for LAWABP1 glass is consistent with values reported for silicate minerals [10]. The apparent constant slope at all four temperatures (Figure 4) is significant because it suggests that $\eta$ is not dependent upon temperature. Therefore, we can apply the value of 0.35 to $\eta$ at $15^{\circ} \mathrm{C}$, the anticipated repository temperature, with confidence.

\subsubsection{Temperature Effects}

Figure 4 also illustrates the strong effect that temperature has on dissolution rates. Dissolution rates increase by $\sim 1,000 \mathrm{X}$ over the temperature interval of $23^{\circ}$ to $90^{\circ} \mathrm{C}$ under circum-neutral to basic $\mathrm{pH}$ values. A non-linear regression of the data set was performed to retrieve the experimental activation energy, $E_{a}$, for the LAWABP1 glass, assuming that $Q / K_{g}=0$ and fixing $\eta$ at 0.35 in Equation (2). The regression yields an activation energy of $68 \pm 3 \mathrm{~kJ} \mathrm{~mol}^{-1}$, which is similar to values reported for other borosilicate glass compositions [7, 11-12]. Note that the value of 
$E_{a}$ for glass is similar to that of silica polymorphs (quartz $=66-83 \mathrm{~kJ} \mathrm{~mol}^{-1}$ [12]; amorphous silica, $74.5 \mathrm{~kJ} \mathrm{~mol}^{-1}$ [13]; cristobalite, $68.9 \mathrm{~kJ} \mathrm{~mol}^{-1}$ [14]). These data suggest that rupture of the $\mathrm{Si}-\mathrm{O}$ bond in borosilicate glass is the rate-limiting step in dissolution.

\subsubsection{Effects of Additives ( $\mathrm{Si}, \mathrm{Al}$, Humic Acid) on Rates}

As discussed in the introduction, we doped input solutions of select experiments to determine the effects of various molecular species on the dissolution rate. The experiments were doped with $\mathrm{Si}, \mathrm{Al}$, and humic acid, as described below.

\subsubsection{Silicon}

Silicon was added to input solutions over the concentration interval of 20 to $120 \mathrm{ppm}$. As discussed in Section 2.1.2, silicon was added by dissolving powdered $\mathrm{SiO}_{2} \cdot 2 \mathrm{H}_{2} \mathrm{O}$ into a $0.05 \mathrm{M}$ THAM solution, $\mathrm{pH}$-adjusted to 9 (at $23^{\circ} \mathrm{C}$ ). The amount added to each solution is listed in the Appendix as mol/L Si in the effluent solution. The range in concentration of $\mathrm{Si}$ in the effluent is up to $95 \%$ of the saturation value with respect to amorphous silica at $40^{\circ}$ and $70^{\circ} \mathrm{C}$. In contrast, the concentration of $\mathrm{Si}$ in the effluent solutions in the $90^{\circ} \mathrm{C}$ experiments was only up to $\sim 70 \%$ with respect to saturation. This value reflects the difficulty in keeping $\mathrm{Si}$ in solution in the input reservoir (at $23^{\circ} \mathrm{C}$ ) for experiments at relatively high temperatures.

\subsection{Rate versus silicic acid activity}

Figure 5 illustrates the effect of silicon on the dissolution rate of LAWABP1 glass. Dissolution rates with respect to both boron and sodium are plotted against the activity of silicic acid at $40^{\circ} \mathrm{C}$. At the temperature and $\mathrm{pH}$ of the experiment, silicic acid $\left(\mathrm{H}_{4} \mathrm{SiO}_{4}{ }^{\circ}\right)$ is the dominant aqueous species, although smaller fractions of $\mathrm{H}_{3} \mathrm{SiO}_{4}{ }^{-}(\sim 11 \%)$ and $\mathrm{H}_{2} \mathrm{SiO}_{4}{ }^{2-}(\ll 1 \%)$ are also present. Figure 5 shows that dissolution rates based on boron decrease rapidly and then reach a constant value with increasing activity of silicic acid.

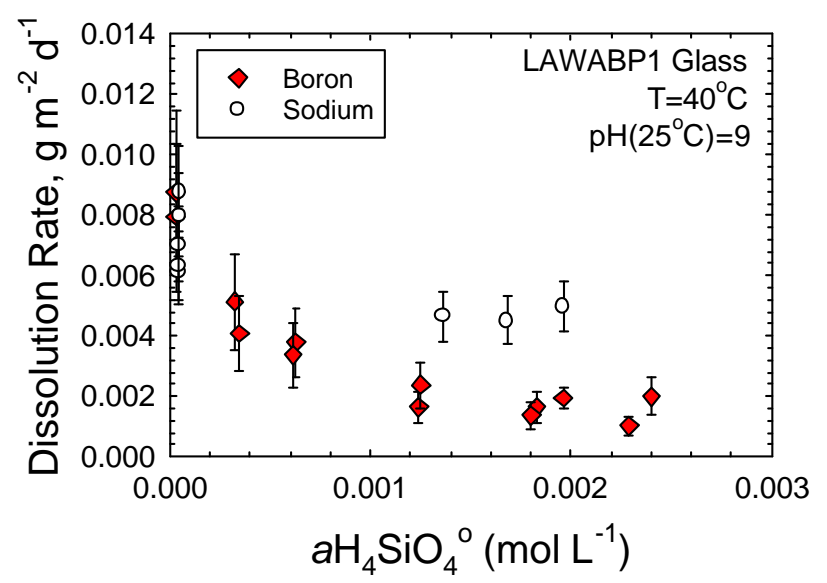

Figure 5. Dissolution Rate Based on $\mathrm{B}$ and $\mathrm{Na}$ Versus the Activity of Silicic Acid at $40^{\circ} \mathrm{C}$. This figure also illustrates that sodium rates are faster than boron rates at high $\mathrm{Si}$-concentrations due to the dominance of alkali-H exchange under these conditions (see text). 
Figures $6 \mathrm{~A}$ and $6 \mathrm{~B}$ illustrate the effects of dissolved silicon on dissolution rates at 70 and $90^{\circ} \mathrm{C}$. As in the case of Figure 5, both boron and sodium dissolution rates decrease nonlinearly with increasing silicon concentrations. Note however, that at $70^{\circ} \mathrm{C}$ (Figure 6A), the dissolution rate with respect to sodium is nearly the same as that for boron at high concentrations of dissolved silica. At $90^{\circ} \mathrm{C}$ (Figure 6B) the dissolution rates based on the two elements are identical within experimental uncertainty.

What Figures 5, 6A, and B collectively indicate is that dissolution rates decrease nonlinearly with respect to silica activity. At first glance, this contradicts the proposal of Grambow [6] in which the activity of silica is assumed to control the dissolution rate of borosilicate glass. According to this model of
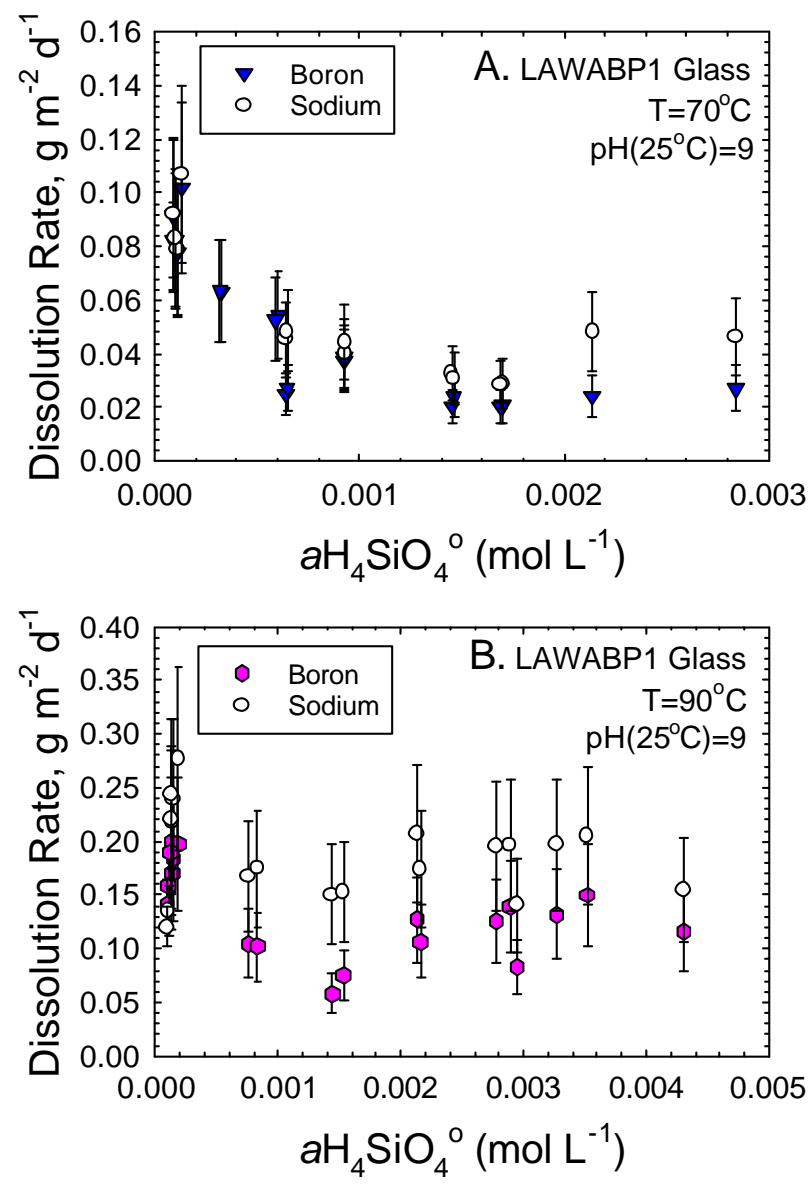

Figure 6. Dissolution Rate with Respect to B and $\mathrm{Na}$ Versus Silicic Acid Activity at $70^{\circ}$ and $90^{\circ} \mathrm{C}$.

glass dissolution, the equilibrium constant for amorphous silica can be substituted for $K_{g}$ in Equation (2). If this were true, modeling the long-term corrosion behavior of glass would be straight forward, given that the thermodynamic stability of amorphous silica is well understood as a function of temperature and $\mathrm{pH}$.

\subsection{Na-hydrogen exchange rates}

In the preceding section we showed that as silicon is added to solution, the dissolution rates decrease. Rates with respect to sodium also decrease with increasing silicic acid activity (see Figures 5 and 6A,B). Note that under dilute solution conditions (low Si concentration, left-hand side of diagram), sodium and boron rates are identical within experimental error. As the concentration of dissolved silicon increases, however, the sodium rates become statistically faster than boron rates. This divergence in rates at high silicon concentrations can be explained by the operation of two distinct mechanisms that release sodium to solution. The first mechanism is ma- 
trix dissolution and the second is alkali-H exchange. Under conditions of dilute solution compositions, the matrix dissolution mechanism dominates, so boron and sodium release rates are equal. In contrast, as silicon is added to solution, matrix dissolution rates are suppressed yet alkali-H exchange is unaffected and becomes dominant. Thus, sodium is released faster than what can be accounted for by matrix dissolution alone.

Sodium exchange rates were calculated by subtracting the boron from the sodium rate and then making the proper conversion to moles of sodium per unit area per time. In this instance, we calculated the sodium exchange rate in terms of mole $\mathrm{m}^{-2} \mathrm{~s}^{-1}$, so as not to be confused with the dissolution rate. Exchange rates for the four temperatures investigated are plotted with respect to temperature on Figure 7. We note that on an Arrhenius diagram such as this that a correction factor

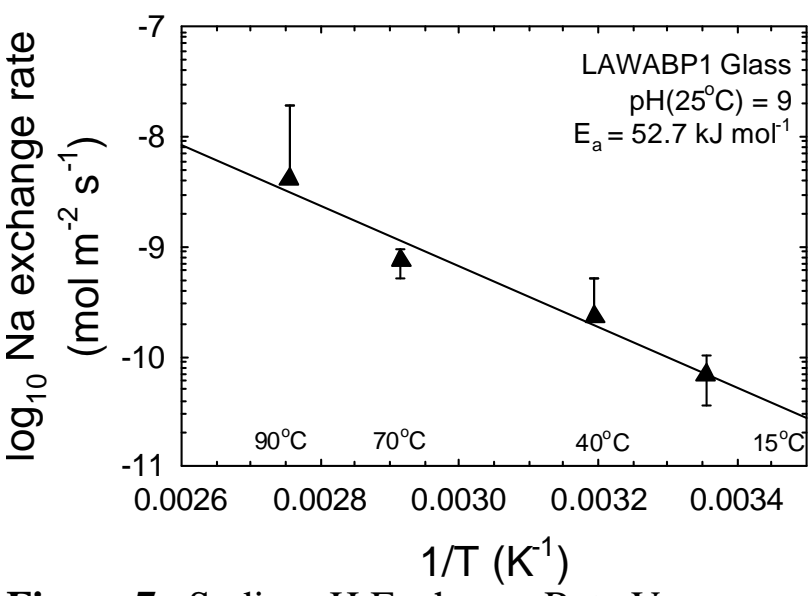

Figure 7. Sodium-H Exchange Rate Versus Reciprocal Temperature for LAWABP1 Glass. The slope of the line through the data indicate an activation energy of $52.7 \mathrm{~kJ} \mathrm{~mol}^{-1}$. for the change in solution $\mathrm{pH}$ must be applied. We have not yet determined the $\mathrm{pH}$-dependence (if any) of the ion-exchange rate so this correction could not be applied. The approximate activation energy for the Na ion-exchange reaction for LAWABP1 glass is $52.7 \mathrm{~kJ} \mathrm{~mol}^{-1}$. The activation energy is similar to the value of 47.3 $\mathrm{kJ} \mathrm{mol}^{-1}$ reported by Pederson [15] for $\mathrm{Na}^{+}-\mathrm{H}^{+}$exchange in sodium silicate glass. For a full discussion of alkali ion exchange mechanisms and the effect of glass structure on exchange rates, the reader should consult reference [16].

From this graph, we can calculate the apparent sodium exchange rate at $15^{\circ} \mathrm{C}$, the likely repository temperature. Extrapolating to this temperature, the $\mathrm{Na}^{+}-\mathrm{H}^{+}$exchange value is $3.4 \times 10^{-11}$ mol m $\mathrm{m}^{-2} \mathrm{~s}^{-1}$. Extensive exchange of $\mathrm{Na}^{+}$for $\mathrm{H}_{3} \mathrm{O}^{+}$in solution will result in an increase in solution $\mathrm{pH}$, which in turn will cause an increase in matrix dissolution. For this reason, alkali ion exchange must be included in disposal system modeling calculations.

Ion exchange may also explain why plots of rate versus silicic acid activity are non-linear (Figures 5, 6A, B). Because $\mathrm{Na}^{+}-\mathrm{H}^{+}$exchange results in hydration of one or more $\mathrm{Si}-\mathrm{O}$ bonds in 
the glass, this reaction may impact dissolution by accelerating the breakup of the silicate network to form aqueous $\mathrm{H}_{4} \mathrm{SiO}_{4}$. Because this reaction does not involve the chemical affinity term under near silica-saturated conditions, the dissolution rate becomes independent of silicic acid activity. If this is true, then Grambow's [6] model may still be strictly true, but the influence of $\mathrm{Na}-\mathrm{H}$ exchange obfuscates analysis of his model.

Other investigators, principally Gin [5] and Bourcier et al. [17], also could not model dissolution according to Grambow's model and have advocated a mixed activity product term that includes Al. In the following section, we will explore the effects of aluminum on the dissolution of LAWABP1 glass.

\subsubsection{Aluminum and aluminum plus silicon}

Aluminum was added to select experiments by dissolving aluminum trinitrate hydrate $\left[\mathrm{Al}\left(\mathrm{NO}_{3}\right)_{3} \cdot 9 \mathrm{H}_{2} \mathrm{O}\right]$ crystals into $0.05 \mathrm{M}$ THAM solutions. Solution $\mathrm{pH}$ values were then adjusted to 9 by addition of $\mathrm{HNO}_{3}$. The amount of dissolved aluminum added to the input solutions varied over a concentration range of 20 to $120 \mu \mathrm{mol} \mathrm{Al}$. The maximum amount of aluminum added depended, as in the case of silicon, on the te mperature of the experiment, but in most cases, the amount of $\mathrm{Al}$ added probably resulted in precipitation of aluminum hydroxide or aluminosilicate phases. In a subset of experiments, both $\mathrm{Al}$ and $\mathrm{Si}$ were added to the input solution. To be able to compare experiments over the temperature interval studied $\left(40^{\circ}\right.$ to $\left.90^{\circ} \mathrm{C}\right)$, we kept the range of $\mathrm{Al} / \mathrm{Si}$ ratios the same. As in the case of the $\mathrm{Al}$ only experiments, precipitation of solid phases

likely occurred over the duration of the experiments. The effects of the precipitated phases will be discussed below. 
The following figures illustrate the extent to which dissolution rates are suppressed when aluminum is added to solution. Figure 8 shows that dissolution rates decrease linearly as aluminum is progressively added to solution. These results again argue against Grambow's model [4], wherein the activity of silica alone governs the dissolution of glass. Another noteworthy feature of this diagram is that the rates are suppressed by a factor of $\sim 4 \mathrm{X}$, which is approximately the same magnitude to which addition of silicon suppresses rates at the same temperature (see Figure 6).

Addition of silicon suppresses the matrix dissolution rate, as discussed above. Likewise, addition of aluminum suppresses the matrix dissolution. Therefore, when silicon is added to the starting solution, the amount of aluminum in the effluent solution, solely from matrix dissolution, decreases in concentration and vice versa. This effect can be seen in Figure 9, which is a plot of the dissolution rate versus the activity of the aluminate ion, $\mathrm{Al}(\mathrm{OH})_{4}{ }^{-}$, at $40^{\circ} \mathrm{C}$. The activity of the aluminate ion is plotted because it is the dominant aluminum species at this $\mathrm{pH}$ and

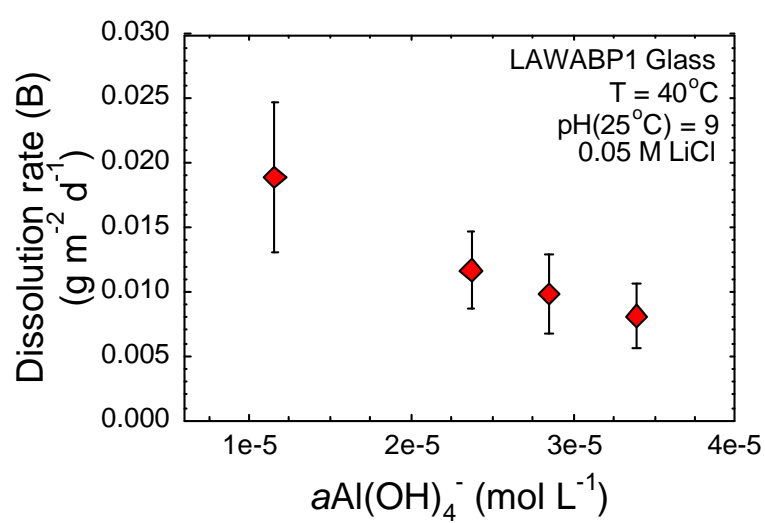

Figure 8. Dissolution Rate Versus Activity of Aluminate Ion for LAWABP1 Glass at $40^{\circ} \mathrm{C}$. The figure illustrates that dissolution rates decrease with the progressive increase in added Al. Note that the solution also contained a high concentration of $\mathrm{LiCl}$, so the rates are not directly comparable to rates in DIW.

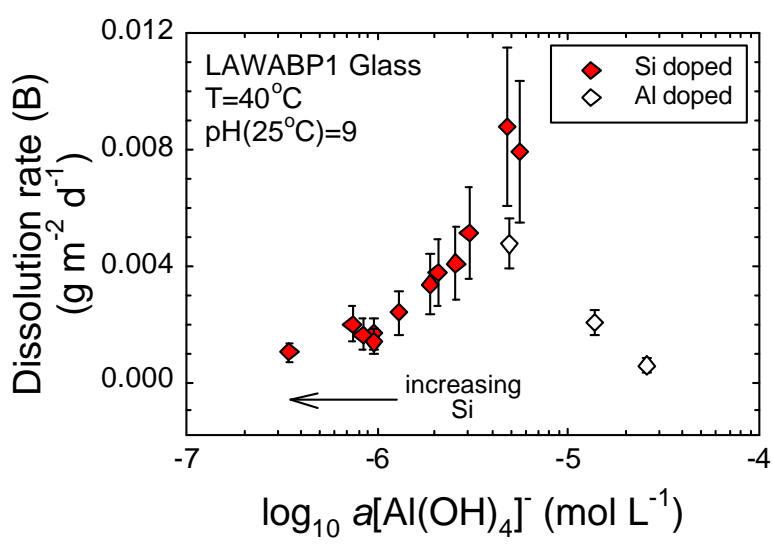

Figure 9. $\log _{10}$ Activity Aluminate Versus Dissolution rate of LAWABP1 glass at $40^{\circ} \mathrm{C}$. This figure shows that increasing silicon to the input solution decreases aluminum activity.

temperature. As the figure illustrates, addition of Si causes a decrease in the activity of aluminate. Therefore, the effects of aluminum and silicon on glass dissolution are anti-correlated. 
It is clear, then, that the activity of silicic acid alone does not govern dissolution rates. Both aluminum and silicon need to be accounted for in the ion activity product, $Q$. At present, the precise form of the activity product is a topic of debate in the geochemical literature. Gin [3] has advocated a mixed $\mathrm{Al}-\mathrm{Si}$ activity product in which the activities of $\mathrm{Al}$ and $\mathrm{Si}$ are raised to an exponent equal to their respective mole fractions in the glass. In the case of LAWABP1 glass, the exponent values are 0.136 and 0.482 for aluminum and silicon, respectively. However, there is no reason to believe that the composition of glass serves as a

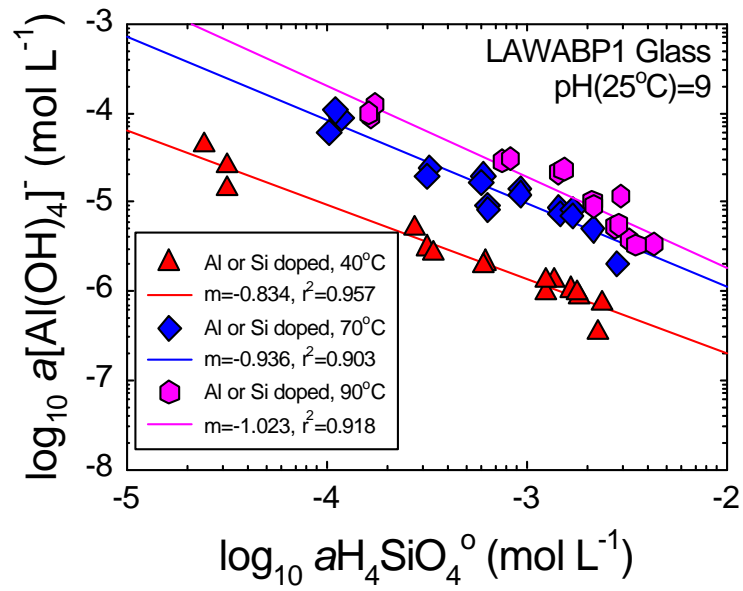

Figure 10. Activity of Silicic acid Versus Aluminate at 40,70 , and $90^{\circ} \mathrm{C}$. The slopes of the lines through the three data sets are consistent with control of $\mathrm{Al}$ and $\mathrm{Si}$ activities by a phase with a Si:Al ratio of 1:1. governor of aluminate and silicic acid activities. Alternatively, precipitation of a secondary corrosion product, either crystalline or amorphous, may control aluminate and silicic acid activities. To evaluate this possibility, Figure 10 shows $\log _{10}$ activity $\mathrm{H}_{4} \mathrm{SiO}_{4}{ }^{\circ}$ versus $\log _{10} \mathrm{Al}(\mathrm{OH})_{4}{ }^{-}$for experiments doped with $\mathrm{Al}$ or $\mathrm{Si}$. For the three temperatures considered, lines regressed through the data points are near a one-to-one ratio.

These data are consistent with aluminate and silicic acid activity control by a phase such as kaolinite, $\mathrm{Al}_{2} \mathrm{Si}_{2} \mathrm{O}_{5}(\mathrm{OH})_{4}$. Kaolinite has been observed at $99^{\circ} \mathrm{C}$ in PUF column tests, although the solids in the SPFT tests have yet to be examined. Another possibility is that the solid phase that is precipitating is a smectite, which has the formula $(\mathrm{A})_{0.7}(\mathrm{~B})_{4}\left[(\mathrm{Si}, \mathrm{Al})_{8} \mathrm{O}_{20}\right](\mathrm{OH}) 4 \cdot n \mathrm{H}_{2} \mathrm{O}$, where " $\mathrm{A}$ " is an interlayer (alkali or alkaline earth) cation, and " $\mathrm{B}$ " is an octahedral (6-fold coordinated) cation. Certain smectite phases (e.g., beidellite) have Al:Si ratios that approach 1:1. The point of this discussion is that the activities of aluminate and silicic acid are controlled by a solid phase, whose identity remains to be confirmed, with an Al:Si ratio of 1:1. Figures 11 and 12 illustrate that both the mixed Al-Si activity product proposed by Gin [3] and the activity product term for a phase with an aluminum to silicon ratio of 1:1 correlate well with boron-based dissolution rates. In all cases, lines regressed through the data points yield fairly high correlation coefficients $\left(\mathrm{r}^{2}\right)$ and the $\mathrm{y}$ - and $\mathrm{x}$-intercepts can be used to quantify the values of $k_{+}(\mathrm{T})$ and $K_{g}(\mathrm{~T})$, respectively. 

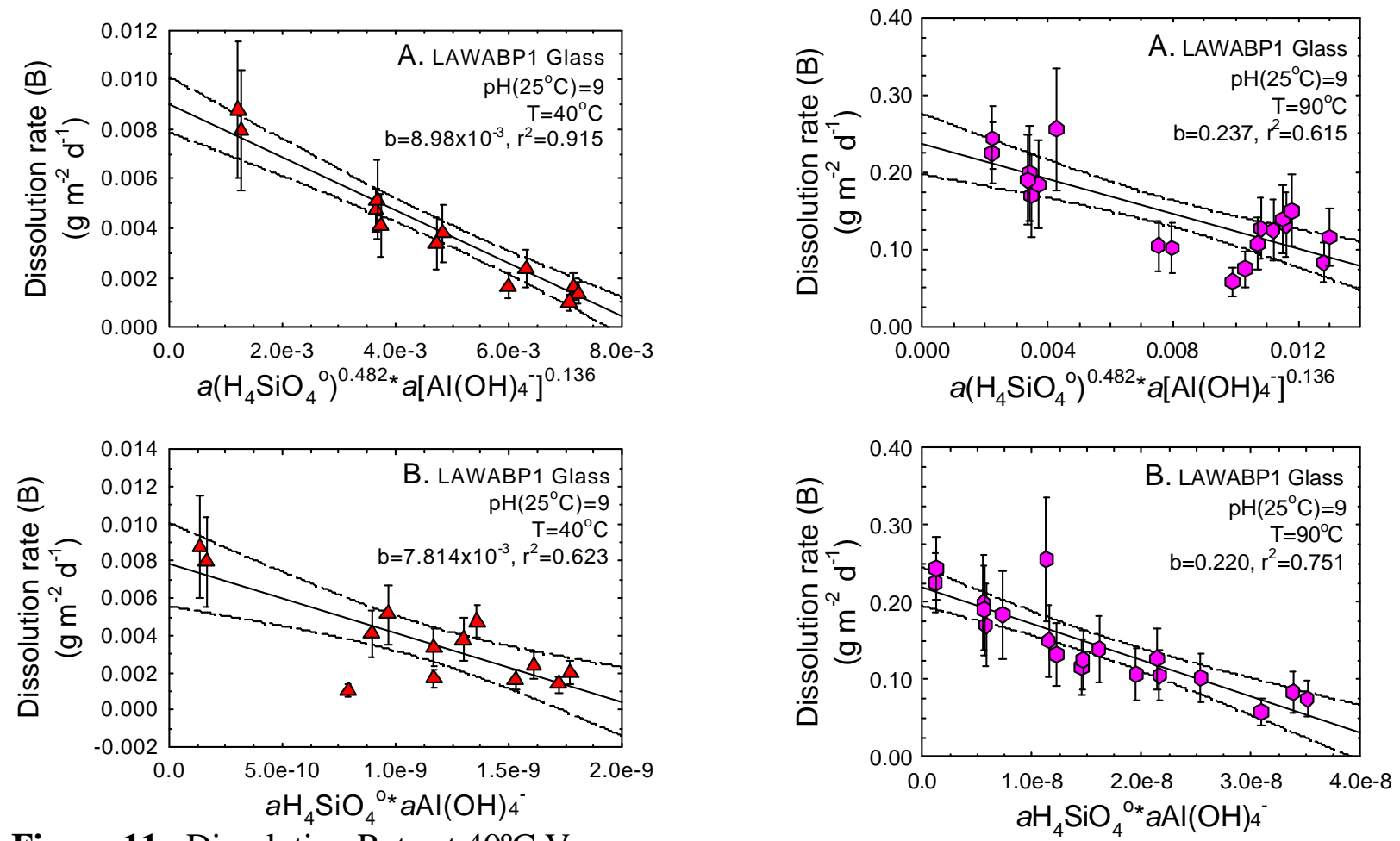

Figure 11. Dissolution Rate at $40^{\circ} \mathrm{C}$ Versus Mixed Al-Si Activity Product Terms. The solid line is the regression whereas the dashed lines represent the $95 \%$ confidence limit.

Figure 13 shows the $\log _{10} K_{g}$ versus inverse temperature for the phase with an $\mathrm{Al}$ :Si ratio of 1:1. A linear relationship is observed (although only on three data points). The slope provides a crude estimate of the reaction enthalpy at approximately $59 \mathrm{~kJ} \mathrm{~mol}^{-1}$, which is similar to values for a variety of aluminosilicate minerals [18]. The value of $K_{g}$ extrapolated to $15^{\circ} \mathrm{C}$ from these data is $2.41 \times 10^{-11}$.

When both aluminum and silicon are added to solution, the results are more difficult to interpret. Plotting dissolution rates versus the mixed $\mathrm{Al}-\mathrm{Si}$

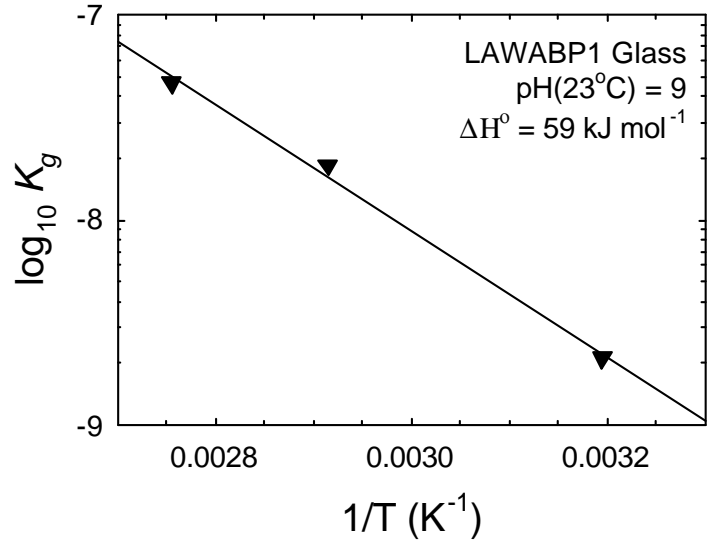

Figure 13. $\log _{10} K_{g}$ Versus Inverse Temperature. The phase assigned to $K_{g}$ is assumed to have a 1:1 Si:Al ratio. The slope of the line is proportional to the enthalpy of the reaction to form this phase and yields a value of $59 \mathrm{~kJ} \mathrm{~mol}^{-1}$. activity products discussed above, the data plot far to the right-hand side of the diagram (Figure 
14). The non-linearity of the data in Figure 14 might initially suggest that neither the Gin model nor the activity product with a 1:1 Si:Al ratio adequately describes the data set. However, the data are suspect because very fine-grained mi nerals (e.g., kaolinite, gibbsite) could have been in colloidal suspension. Because the effluent solution samples were acidified prior to analysis, any undetected precipitate would dissolve into solution. If this occurred, analyses of the effluent solution would reflect spuriously high concentrations of $\mathrm{Al}$ and $\mathrm{Si}$ in solution. We are in the process of determining whether or not precipitation occurred, but the results were not ready in time for this report. In support of this theory, we note that on a plot of activity of silica versus activity of aluminate ion, such as Figure 10 above, the data do not plot in a coherent pattern. Until we can conclusively show that the effluent samples from these experiments are free from precipitates, we will

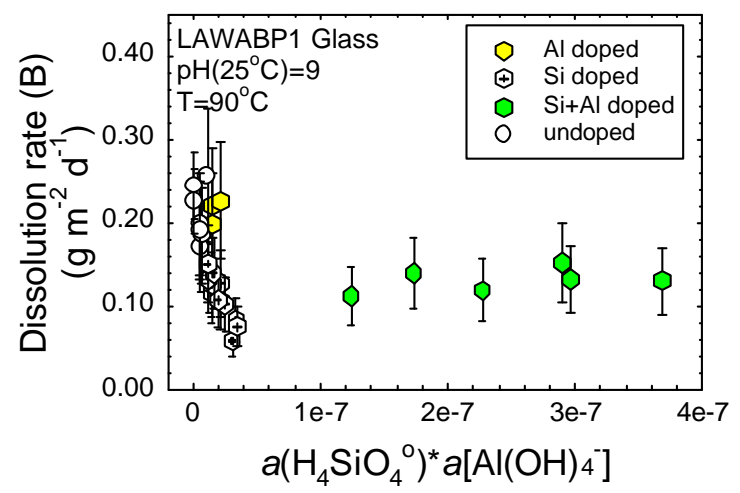

Figure 14. Dissolution Rate at $90^{\circ} \mathrm{C}$ Versus the Two Competing Al-Si Activity Product Schemes. Including data for $\mathrm{Al}+\mathrm{Si}$ doped solutions results in a distinct non-linearity in the data, possibly due to the presence of microcrystals or colloidal suspension of $\mathrm{Al}-\mathrm{Si}$ phases. regard the data with suspicion.

\subsubsection{Effects of Humic Acid on Dissolution Rate}

Humic substances constitute 70-80\% w/w of the organic matter in most soils [19]. Because humics have a strong ability to interact with metal ions, oxides, hydroxides, and minerals to form water-stable associations, investigators have suggested that humic acids may accelerate dissolution rates of silicate materials by attacking the $\mathrm{Si}-\mathrm{O}$ bond. For example, Bennett et al. [20] found that dissolution rates of quartz are faster in the presence of humic acid at $\mathrm{pH}=7$ compared to rates in solutions containing no organic acids. Gin et al. [21] conducted batch experiments with R7T7 high-level waste glass in $\mathrm{pH} 7.3$ solutions containing up to $5 \mathrm{~g} / \mathrm{L}$ humic acid (a commercial humic acid product from Fluka). Dissolution rates based on B release increased by $4 \mathrm{X}$ in a $0.5 \mathrm{~g} / \mathrm{L}$ solution and by $6 \mathrm{X}$ in a $5 \mathrm{~g} / \mathrm{L}$ solution. 
Determination of an appropriate concentration of humic acid for use in this study was hampered by an almost complete lack of pertinent data on concentrations of natural organic acids present in Hanford pore waters. Toste [22] obtained samples from a seepage trench near the NReactor and analyzed them for total organic carbon (TOC) and fractionated the carbon content into high and low molecular weight organics. Toste [22] found average TOC ranging between 2 to $3 \mathrm{mg} / \mathrm{L}$ and that most of the organic carbon (>75\%) was present as naturally occurring humic and fulvic acids.

Using Toste's study as a guide, we prepared a $50 \mathrm{mg} / \mathrm{L}$ humic acid solution from commercially-available materials (Aldrich Chemical, Inc.). Commercially available humic acid typically contains a sizeable fraction (9.3 to 33\%) of ash that contains Fe and Si among other elements. We separated the ash and humic acid by digesting the material in a concentrated $\mathrm{NaOH}-\mathrm{NaF}$ solution. The NaF is necessary to dissolve amorphous silica that may be present. Humic acid was then precipitated from solution by acidifying the solution with $\mathrm{HCl}$. Repeated washing, decanting, and centrifuging removed most of the residual $\mathrm{Na}$ from the humic acid. Aliquots of the sample were dried overnight and the precipitated humic acid crystals were collected. Humic acid solutions were made up by adding $50 \mathrm{mg}$ of the prepared humic acid to $1 \mathrm{~L}$ of deionized water. The solution $\mathrm{pH}$ was adjusted to $\mathrm{pH}=9$ using $0.05 \mathrm{M}$ THAM and a small quantity of nitric acid. Concurrent with two experiments using the humic acid solution, we ran two "control" experiments with a solution composition identical to the above, but lacking in humic acid (essentially, DIW). Analyses of the starting solutions indicated the humic acid solution contained up to 2 ppm Na, probably a residual contamination from the digestion procedure. Thus, the background correction for this element was important. The experiments were run at $90^{\circ} \mathrm{C}$ for a week using flow-rates previously determined to be appropriate.

\subsection{NMR Characterization}

The prepared humic acid was analyzed at room temperature with ${ }^{13} \mathrm{C}$ magic angle spinning nuclear magnetic resonance spectroscopy (MAS-NMR). The observed chemical shifts were referenced against an internal standard of Tetrakis (trimethylsilyl) silane. Spectra were obtained on a Varian VXR-300 spectrometer at 7.05 T using high-speed probes manufactured by Doty Scientific, Inc. Silicon nitride rotors were used to spin the samples at $5 \mathrm{kHz}$. 
Figure 15 shows the measured peak intensities versus chemical shift. The large peak between 0 to $50 \mathrm{ppm}$ is assigned to saturated aliphatic carbons, aromatic and olefinic carbons at 100 to 150 ppm, and carboxyl carbons at 165 to $190 \mathrm{ppm}$.

The MAS-NMR results are essentially identical to those reported by Malcolm and MacCarthy [23] for Aldrich humic acid. The data indicate a humic acid with relatively low population density of

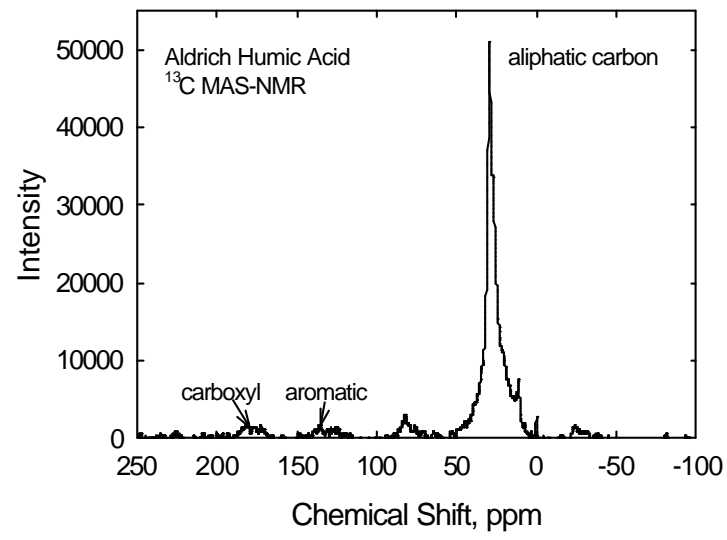

Figure 15. MAS-NMR Spectra of Aldrich Humic Acid Used in SPFT Experiments aromatic and carboxyl functional groups. This is important because the complexing power of humic and fulvic acids results largely from their content of $\mathrm{COOH}$, phenolic $\mathrm{OH}$, and $\mathrm{C}=\mathrm{O}$ groups. Humic acid is not a single pure compound but a heterogeneous mixture of organic substances [24]. Natural humic acids have wide variations in molecular weight, numbers of functional groups, and extent of polymerization [23]. We were not able to locate reported spectroscopic analyses of natural humics in Hanford soils. Consequently, the degree of departure of the characteristics of the Aldrich humic acid used in our tests from naturally occurring humics at Hanford could not be assessed.

\subsection{Dissolution Rate Results}

Figure 16 shows that dissolution rates computed from effluent concentration of $\mathrm{Al}, \mathrm{B}$, and $\mathrm{Na}$ are identical within experimental error (0.2 log units or $\sim 35 \%$ ) in the DIW and humic acid solution. Concentrations of $\mathrm{Al}$, and therefore rates based upon Al, are systematically higher in the solutions containing humic acid. This effect is probably due to chelating of $\mathrm{Al}$ by humic acids. In any event, there is no systematic difference in dissolution rates based on boron concentrations.

Although these experiments suggest that humic

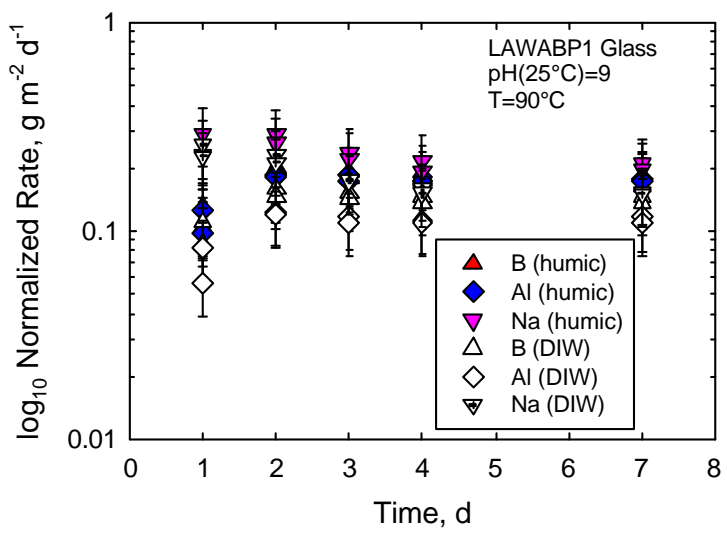

Figure 16. Dissolution Rate (Based on B, $\mathrm{Al}$, or $\mathrm{Na}$ ) Versus Time for Experiments With and Without Humic Acid. The plot illustrates that humic acid, even in concentrations of $50 \mathrm{ppm}$, does not catalyze dissolution rates.

acids do not significantly accelerate dissolution rates, the commercial humic acid used in these experiments contained few reactive functional groups, so that a natural humic acid could give 
different results. However, we compensated for this to some extent by using a much higher concentration of humic acid (50 ppm) than is likely to exist in Hanford pore waters. Consequently, we believe it unlikely that a different humic acid would have a significant effect on dissolution rates at concentrations typical of Hanford pore waters. 


\subsection{PUF TESTS}

In previous papers [25-26], equipment configurations for the PUF system have been described. A significant number of improvements have been made since these papers were published, mainly focused on consolidating the support equipment and electronics into a single unit. Still, the basic test apparatus consists of a column packed with crushed test material (or materials) of a known particle size and density, a computer data acquisition and control system, fluid pump, and electronic sensors, as illustrated in Figure 17. The column is fabricated from polyetheretherketone (PEEK), which is chemically inert so that dissolution reactions are not influenced by interaction with the column. A porous titanium plate with nominal pore size of $0.2 \mu \mathrm{m}$ is sealed in the bottom of the column to ensure an adequate pressure differential for the conductance of fluid while operating under unsaturated conditions [27]. Titanium was chosen because it is highly corrosion resistant and has excellent wetting properties. When water saturated, the porous plate allows water but not air to flow through it, as long as the applied pressure differential does not exceed the air entry relief pressure, or "bubble pressure," of the plate. The computer control system runs LabVIEW ${ }^{\mathrm{TM}}$ (National Instruments Corporation, Austin, Texas) software for logging test data to disk from several thermocouples, pressure sensors, inline sensors for effluent $\mathrm{pH}$ and conduc tivity. The column is suspended from an electronic strain gauge to accurately track water mass balance and saturation level. The column also includes a "PUF port," which is an electronically actuated valve that periodically vents the column gases. The purpose of column venting is to prevent reduction in the partial pressure of important gases, especially $\mathrm{O}_{2}$ and $\mathrm{CO}_{2}$, which may be consumed in a variety of chemical reactions.
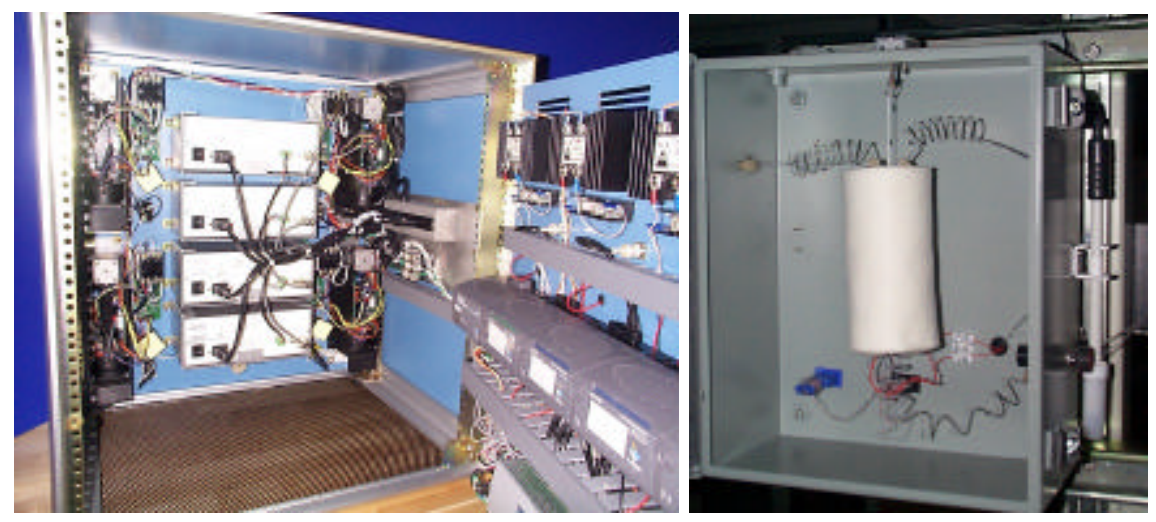

Figure 17. Picture of PUF System Hardware (Patent \#5974859) 


\section{$3.1 \quad$ MATERIALS}

Five glasses were subjected to PUF testing: HLP-9, HLP-10, HLP-31, LAWABP1, and LAWA44 glasses. The composition of four of the five glasses is given in Table 4. LAWA44 glass was considered proprietary at the time this report was published. The HLP series of glasses were prepared as part of a 56 glass composition matrix subjected to hightemperature vapor hydration testing [28]. LAWABP1 is the reference glass for the

Table 4. Composition (Mass\%) of LAW Glasses

\begin{tabular}{|c|c|c|c|c|c|}
\hline Oxide & $\underline{\text { HLP-09 }}$ & $\underline{\text { HLP-10 }}$ & $\underline{\text { HLP-31 }}$ & $\underline{\text { LAWABP1 }}$ & $\underline{\text { LAWA44 }}$ \\
\hline $\mathrm{Al}_{2} \mathrm{O}_{3}$ & 6.84 & 7.15 & 4.00 & 10.00 & \\
\hline $\mathrm{B}_{2} \mathrm{O}_{3}$ & 12.00 & 8.00 & 12.00 & 9.25 & \\
\hline $\mathrm{CaO}$ & 0.01 & 0.01 & 0.01 & 0.00 & \\
\hline $\mathrm{Cl}$ & 0.27 & 0.28 & 0.32 & 0.58 & \\
\hline $\mathrm{Cr}_{2} \mathrm{O}_{3}$ & 0.07 & 0.08 & 0.09 & 0.02 & \\
\hline $\mathrm{F}$ & 0.01 & 0.01 & 0.01 & 0.04 & \\
\hline $\mathrm{Fe}_{2} \mathrm{O}_{3}$ & 5.38 & 5.63 & 3.36 & 2.50 & \\
\hline $\mathrm{K}_{2} \mathrm{O}$ & 0.40 & 0.42 & 0.47 & 2.20 & \\
\hline $\mathrm{La}_{2} \mathrm{O}_{3}$ & 0.00 & 0.00 & 0.00 & 2.00 & \\
\hline $\mathrm{Li}_{2} \mathrm{O}$ & 0.00 & 0.00 & 0.00 & 0.00 & \\
\hline $\mathrm{MgO}$ & 1.47 & 1.53 & 0.92 & 1.00 & \\
\hline $\mathrm{Na}_{2} \mathrm{O}$ & 19.56 & 20.45 & 23.00 & 20.00 & 20.00 \\
\hline $\mathrm{P}_{2} \mathrm{O}_{5}$ & 0.05 & 0.06 & 0.06 & 0.08 & \\
\hline $\mathrm{ReO}_{2}$ & 0.01 & 0.01 & 0.01 & 0.00 & \\
\hline $\mathrm{SiO}_{2}$ & 47.98 & 50.16 & 52.00 & 41.89 & \\
\hline $\mathrm{SO}_{3}$ & 0.07 & 0.07 & 0.08 & 0.10 & \\
\hline $\mathrm{TiO}_{2}$ & 2.93 & 3.06 & 1.83 & 2.49 & \\
\hline $\mathrm{ZnO}$ & 1.47 & 1.53 & 0.92 & 2.60 & \\
\hline $\mathrm{ZrO}_{2}$ & 1.47 & 1.53 & 0.92 & 5.25 & \\
\hline
\end{tabular}
2001 ILAW PA, and LAWA44 is a representative BNFL, Inc. glass developed by Dr. Ian Pegg at the Catholic University of America. The glasses were prepared by mi xing measured amounts of dried reagent-grade chemicals (oxides, fluorides, iodides, and sulphides) in an agate mill. The mixtures were melted in a $\mathrm{Pt}(10 \%) \mathrm{Rh}$ crucible and the molten glass was poured onto a cool stainless steel plate. Each glass was then subjected to heat treatment by placing the glass in a preheated oven at $930^{\circ} \mathrm{C}$ and then cooling at $21^{\circ} \mathrm{C} / \mathrm{hr}$. This cooling rate is consistent with a computed thermal profile for a $1.2 \mathrm{~m} \times 1.2 \mathrm{~m} \times 1 \mathrm{~m}$ container that was the design being considered for LAW. The container design has since been modified to a cylinder of $1.2 \mathrm{~m}$ diameter $\times 2.3 \mathrm{~m}$ tall. Microstructural examination of LAWABP1 glass in a transmission electron microscope showed no evidence of devitrification or phase separation from the heat treatment.

Crushed glass was prepared following the procedure detailed by the American Society for Testing and Materials [29]. The glass was crushed manually and sieved to separate the 425- to $250-\mu \mathrm{m}$ size fraction (-40+60 mesh). The crushed and sieved glass was then washed ultrasonically with demineralized water and ethanol to remove fines, and then dried. Representative sam- 
ples of the crushed, sieved, and washed glass were surveyed with a scanning electron microscope (SEM) to verify that the size of the glass grains was consistent with the sieved size fraction and that fines had been removed. The specific surface area of crushed glass was estimated by assuming particles to be spheres having radii equal to the average opening of the sieves, as was discussed previously.

\subsection{PUF TEST PROCEDURE}

The PUF experiments were performed at nominal flow rate of $2.0 \mathrm{~mL} / \mathrm{d}$ and a temperature of $99^{\circ} \mathrm{C}$. Each column was packed with the crushed and cleaned glass, giving an initial porosity of approximately $0.40 \pm 0.03$, and then vacuum saturated with water at ambient temperature. A temperature controller was programmed to heat the column to $99^{\circ} \mathrm{C}$ in approximately $1 \mathrm{~h}$ $\left(1^{\circ} \mathrm{C} / \mathrm{min}\right)$. The column was allowed to initially desaturate during heating by gravity drainage and was also vented periodically to maintain an internal pressure less than the bubble pressure of the porous plate. After reaching $99^{\circ} \mathrm{C}$, the influent valve was opened, and influent and effluent were set to their respective flow rates. Column venting was set to occur once an hour. Effluent samples were collected in a receiving vessel, which was periodically drained into tared vials from which samples were extracted and acidified for elemental analysis by ICP-OES and ICPMS. The ICP-MS was calibrated with certified standards prior to each series of analyses.

At the time of this writing, only the experiments with HLP-9 and LAWABP1 glass have been terminated. After test termination, reacted solids were removed by carefully scraping material out of the column at intervals of calibrated depth. The removed solids were placed in individual containers and the samples were allowed to dry in air. Selected samples were then analyzed with SEM and x-ray diffraction (XRD). A few samples of the reacted glass particles were also mounted in an epoxy resin that was then ground using 600-grit $\mathrm{SiC}$ paper to permit viewing in cross section the particles and any surface layers.

\subsection{RESULTS}

\subsubsection{HLP Glasses}

Results from the computer monitored test metrics from the tests with HLP-9, 10, and 31 glasses are shown in Figures 16, 17, and 18. For an unknown reason, either the porous plate or 
glass near the bottom of the column in the HLP-9 test became plugged after 36 days. As can be seen in Figure 18, the water content increased rapidly after the pore plugging occurred, so the test was terminated. Results for the HLP10 and HLP-31 glasses are current as of the time this report was written; these tests are still in progress.

Because of the sensor data are noisy, the data were smoothed using a bi-square weighting method where the smoothed data point, $y_{s}$, is given by $y_{s}=\left(1-\omega^{2}\right)^{2}$. The parameter $\omega$ is a weighting coefficient calculated from a window surrounding the smoothing location in the set of the independent variables. A low-order polynomial regression (order 2 in this case) is used to compute $\omega$ for each smoothed value. The smoothed data are provided as lines in Figure 18.

Effluent $\mathrm{pH}$ and electrical con-
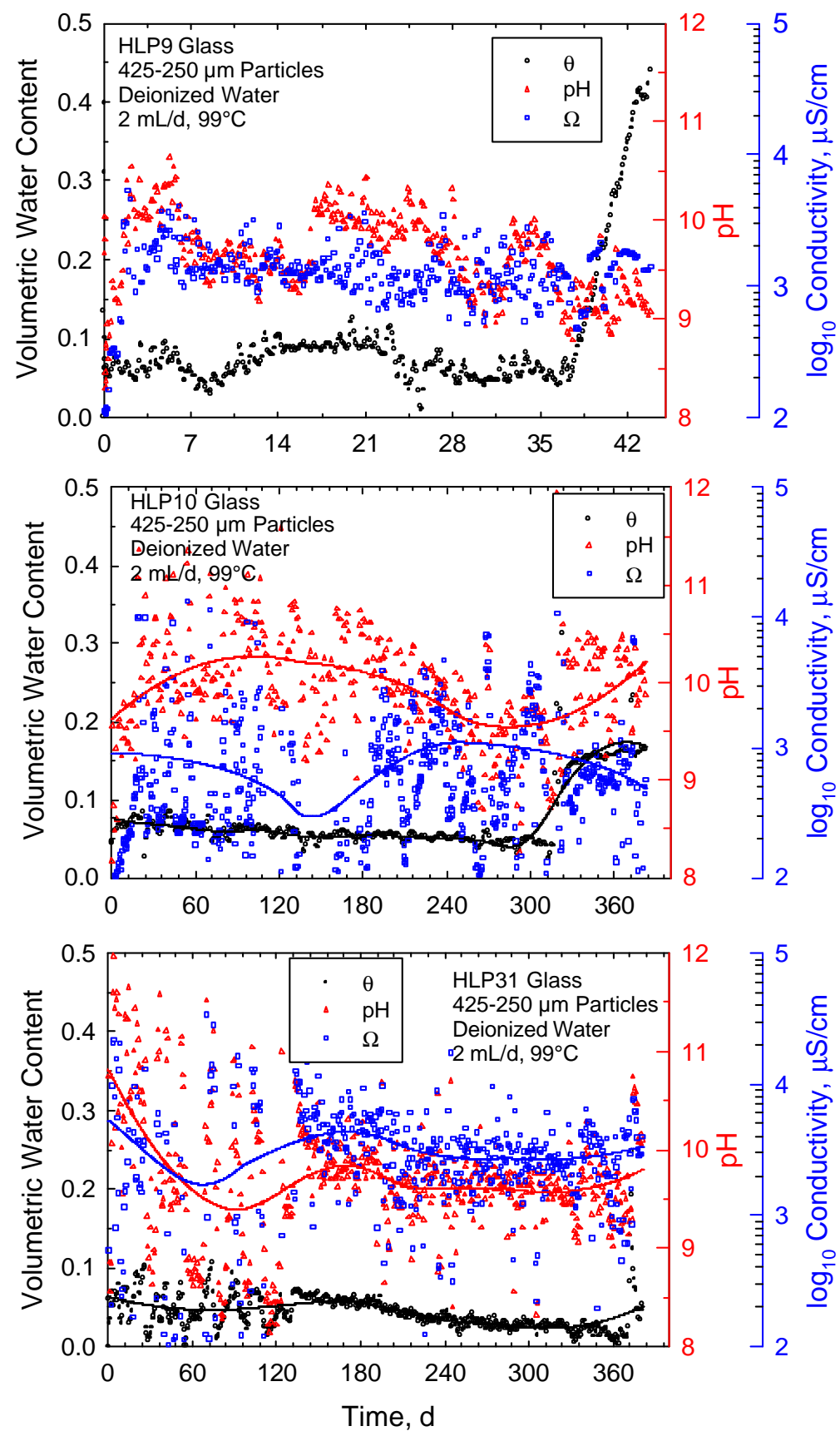

Figure 18. Computer Monitored Test Metrics From PUF Tests with HLP Series of Glasses. Lines are bi-square smoothed fits to the raw data.

ductivity are moderate for all three HLP glasses, suggesting moderate corrosion rates. Effluent electrical conductivity is highest for HLP-31 glass, suggesting that it is dissolving fastest among the three HLP glasses. This is consistent with the higher $\mathrm{Na}_{2} \mathrm{O}$ loading (23 mass\%) of HLP-31 glass as compared with the other glasses (20 mass\%). 
Results from effluent chemical analyses are shown in Figure 19.

Differential rates of release are observed for the major glass components, which reflects their

solubility behavior in water. Zinc, $\mathrm{Zr}$, and $\mathrm{Ti}$ all form very insoluble hydroxides, which controls their release rate. In contrast, $\mathrm{B}$ and $\mathrm{Na}$ are highly soluble, and so have the highest elemental release rates.

Bulk dissolution behavior is typically indexed by the rate of $\mathrm{B}$ release, as no solid phases are expected to form that would affect its solution concentration. Based on the B release data, the HLP-9 and HLP-10 glasses are reacting at approximately the same rate ( 0.1 to $0.08 \mathrm{~g} \mathrm{~m}^{-2} \mathrm{~d}^{-1}$ ) whereas HLP-31 glass is dissolving at about 0.4 $\mathrm{g} \mathrm{m}^{-2} \mathrm{~d}^{-1}$. Again, this is consistent with the electrical conductivity data in Figure 18 and the higher $\mathrm{Na}$ content in HLP-31 glass.
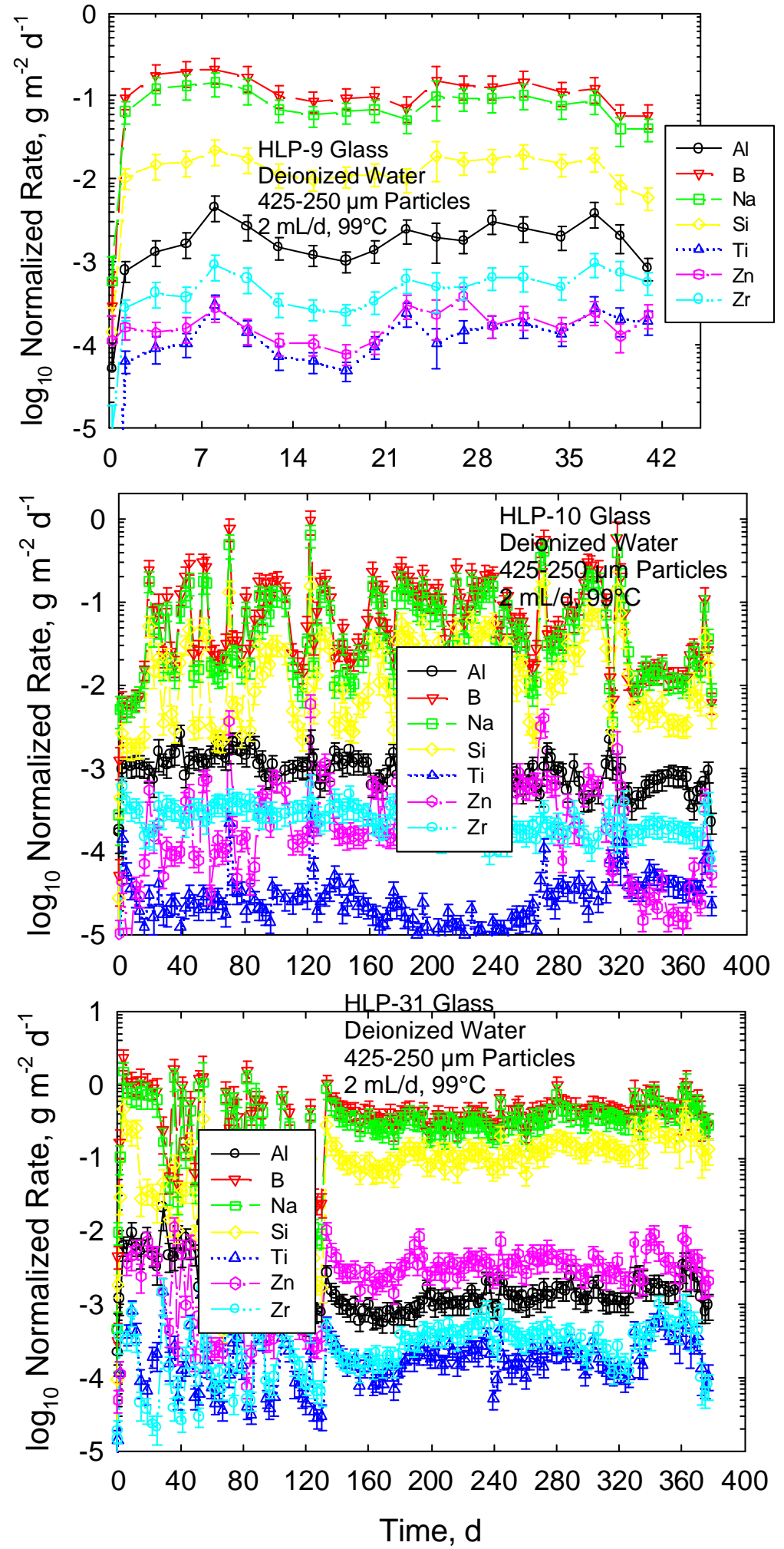

Figure 19. Normalized Release Rate for Selected Elements in PUF Tests with HLP Series of Glasses 


\subsubsection{LAWA Series Glasses}

Results from the computermonitored test metrics for

LAWABP1 and LAWA44 glasses are shown in Figure 20. At about $150 \mathrm{~d}$ in the test with LAWA44 glass, an electrical problem developed with the conductivity sensor. Consequently, the electrical conductivity data are inaccurate after this time period.

At approximately $135 \mathrm{~d}$, the deionized water influent in the PUF test with LAWA44 glass was changed out for the $50 \mathrm{mg} / \mathrm{L}$ humic acid solution, which was described previously (Section 2.2.5). As is evident in Figure 20, no change in electrical conductivity or solution $\mathrm{pH}$ occurred immediately after the
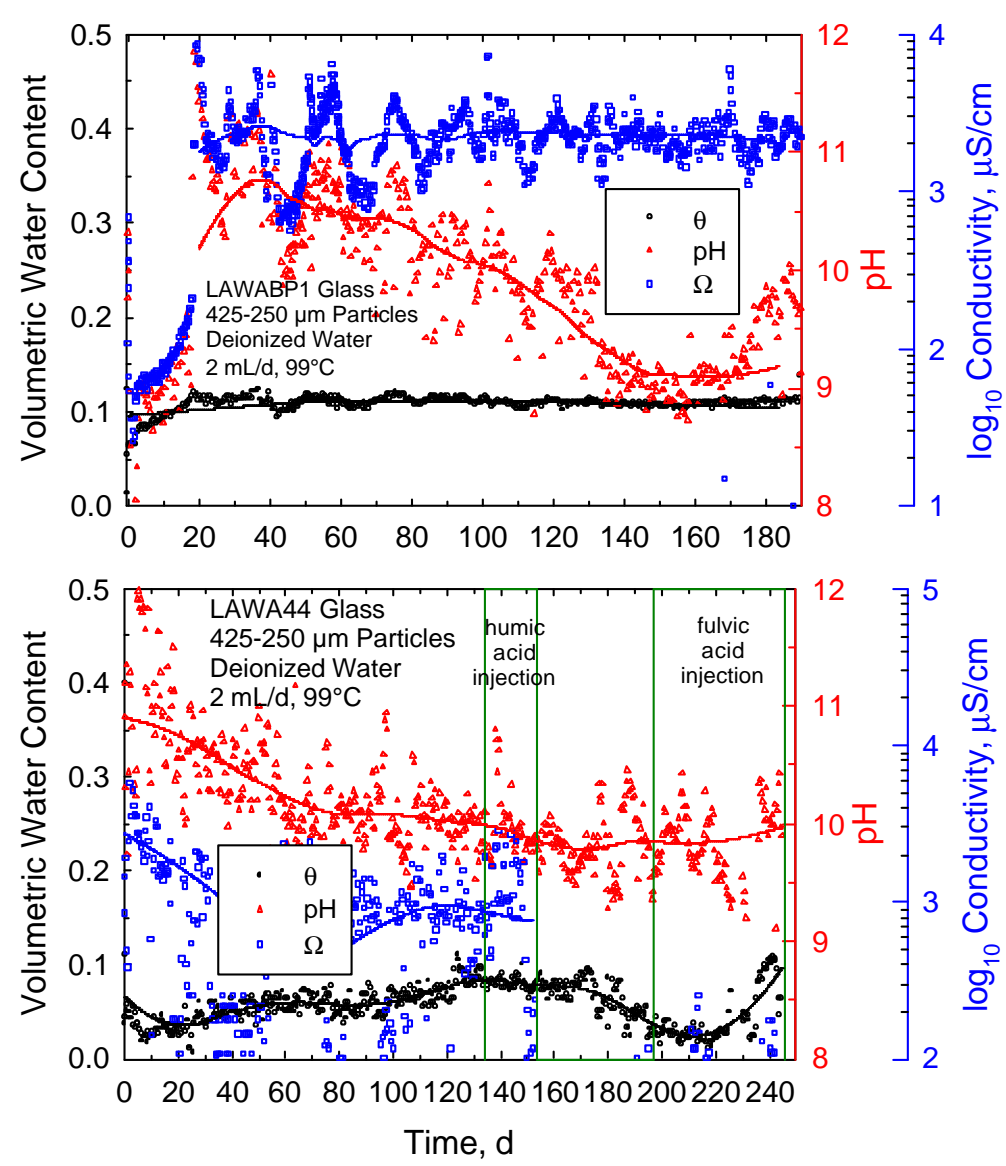

Figure 20. Computer Monitored Test Metrics From PUF Tests with LAWA Series of Glasses. Lines are bi-square smoothed fits to the raw data. The vertical lines give the period where a $50 \mathrm{mg} / \mathrm{L}$ humic acid solution was injected instead of deionized water.

change to the humic acid solution. No change in the dissolution rate of the LAWA44 glass is evident either from the effluent chemical analysis, as shown in Figure 21. A comparison of glass dissolution rates based on B release between LAWABP1 and the LAWA44 glass shows that both glasses are performing well with the rate just before the test with LAWABP1 glass was terminated at $0.1 \mathrm{~g} \mathrm{~m}^{-2} \mathrm{~d}^{-1}$ and for LAWA44 glass (test still in progress) at $0.06 \mathrm{~g} \mathrm{~m}^{-2} \mathrm{~d}^{-1}$.

\subsubsection{LAWABP1 Water Mass Distribution}

After termination of the PUF test with LAWABP1 glass, the reacted solids were subsampled as found (loose and moist particles) at $5 \mathrm{~mm}$ intervals. These samples were analyzed for moisture content by drying in glass vials at room temperature in a sealed can with $\mathrm{CaSO}_{4}$ desiccant. Samples were dried until a constant mass was obtained. The results are shown in Figure 22. 
The first three data points likely represent an imbibition profile as water drips from the fluid inlet onto the top of the porous glass bed. The data show peak water content at about $45 \mathrm{~mm}$ downstream (sample S9) from the fluid inlet. As will be shown in the next section, this sample also contains the greatest volume percentage of crystalline phases. Consequently, the larger water mass associated with the sample is likely a combination of interstitial water trapped in the tighter pore space and as waters of hydration associated with the secondary minerals formed in this region of the column. Sample S9 is indicative of a true precipitation front where water mass has accumulated in alteration products.

\subsubsection{Solid Phase Analyses}

Optical photographs (Figure 23) taken on samples S4 and S9 show how the grains from sample $\mathrm{S} 4$ appear almost pristine whereas most of the grains from sample $S 9$ are coated with alteration products. The distribution of crystalline phases as a function of position in the PUF column was examined by powder x-ray diffraction (XRD). Although this method is not very sensitive, requiring 10 vol\% or more crystallinity to produce a diffraction pattern, the results in Figure 24 clearly show the
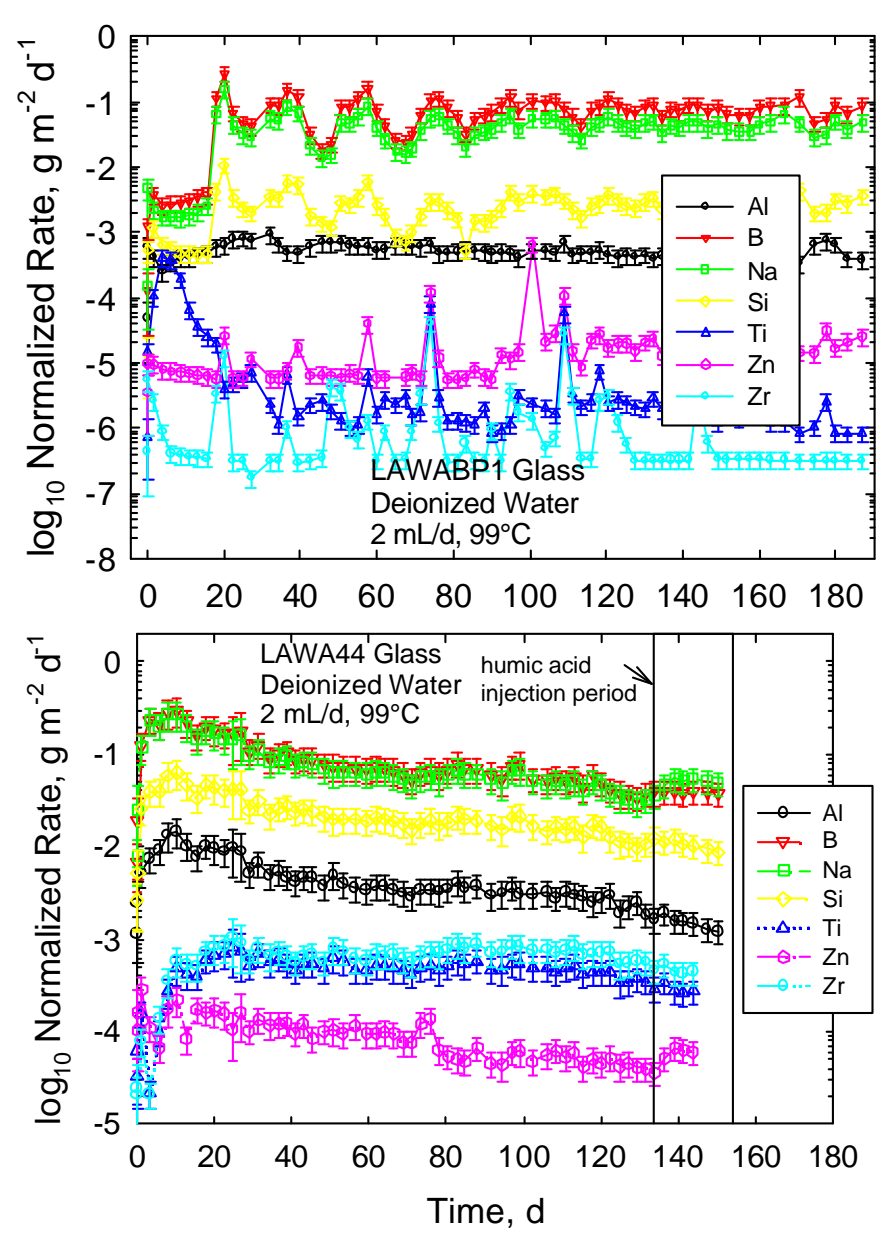

Figure 21. Normalized Release Rate for Selected Elements in PUF Tests with LAWA Series of Glasses

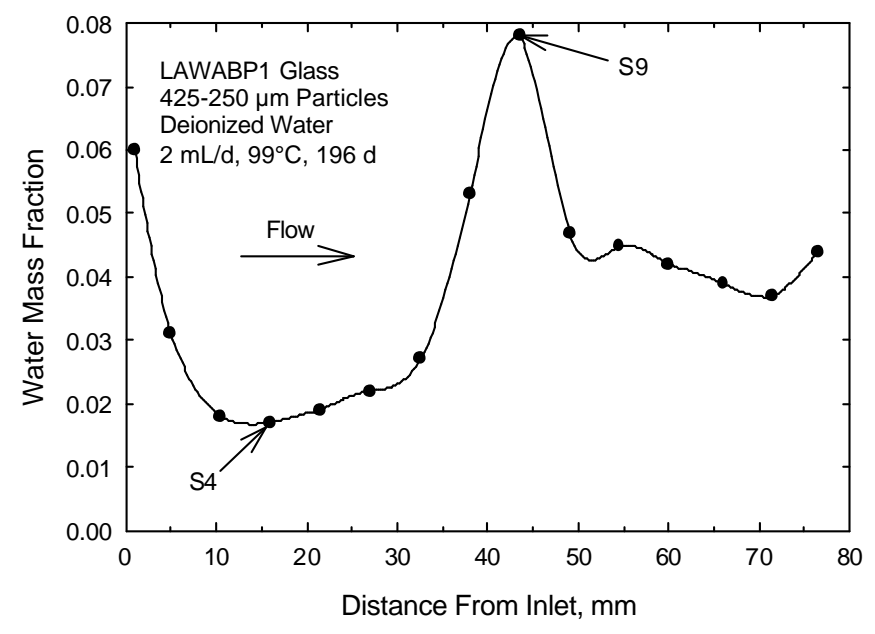

Figure 22. Water Mass Distribution in Reacted Solids From PUF Test with LAWABP1 Glass 


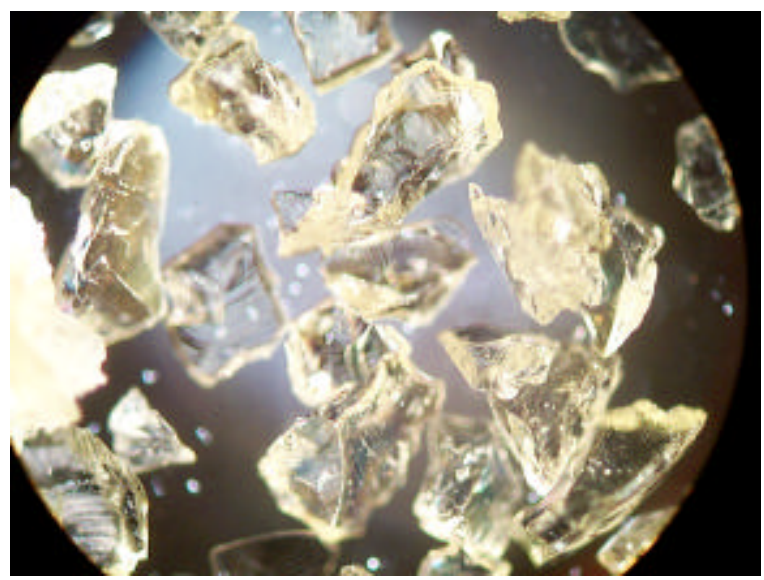

S4

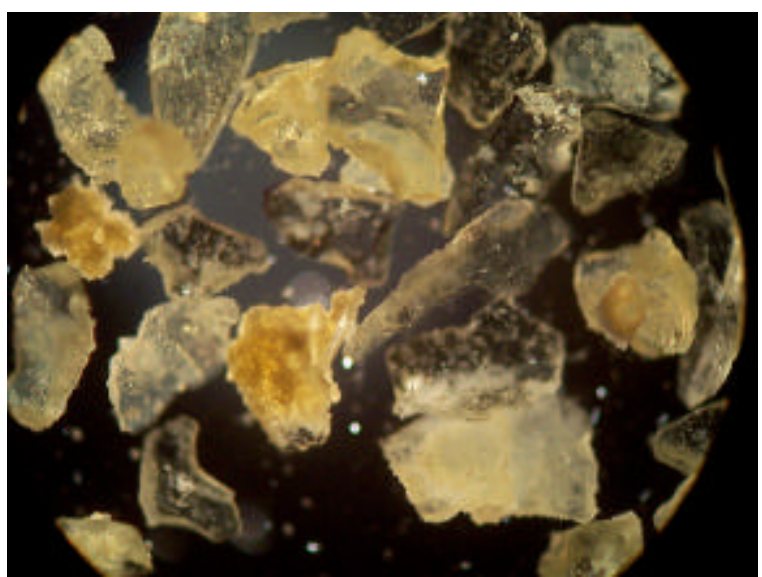

S9

Figure 23. Optical Photos of LAWABP1 Glass Samples S4 and S9 After $190 \mathrm{~d}$ of Reaction in PUF Test at $99^{\circ} \mathrm{C}$ and $2 \mathrm{~mL} / \mathrm{d}$ Flow Rate

higher concentration of crystalline phases near samples S9 and S11. Overlapping peak positions associated with a number of Na-aluminosilicate phases makes quantitative pattern matching with an individual phase difficult. However, the patterns are consistent with the presence of herschelite $\left[(\mathrm{Na}, \mathrm{K}) \mathrm{AlSi}_{2} \mathrm{O}_{6} \cdot 3 \mathrm{H}_{2} \mathrm{O}\right]$, analcime [NaAlSi $\left.{ }_{2} \mathrm{O}_{6} \mathrm{H}_{2} \mathrm{O}\right]$, and kaolinite $\left[\mathrm{Al}_{2} \mathrm{Si}_{2} \mathrm{O}_{5}(\mathrm{OH})_{4}\right]$.

SEM analyses of sample S9 reveals grains coated with an alteration layer (see highlighted area in Figure 25a) and several crystalline alteration phases. Energy dispersive spectroscopy (EDS) shows that Phase 1 is a mixed Na-K aluminosilicate and the crystal morphology clearly identifies it as herschelite. EDS analysis of Phase 2 shows it to be a pure Na-aluminosilicate and the crystal morphology is consistent with

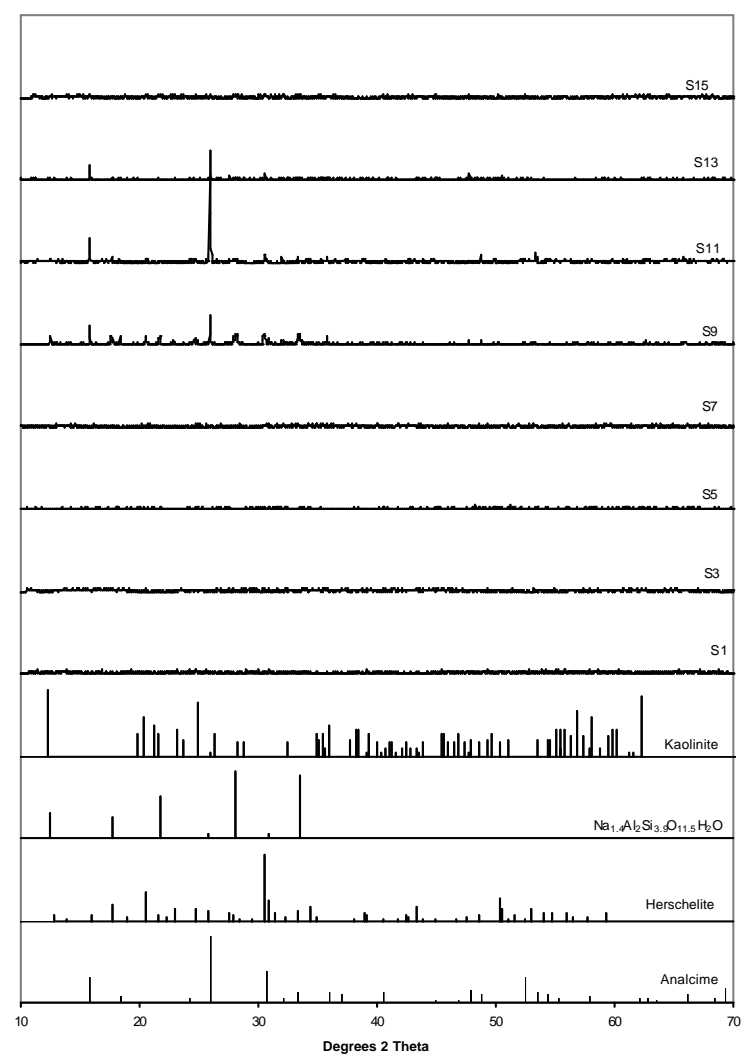

Figure 24. XRD Analyses of PUF Reacted LAWABP1 Glass Samples analcime. Phase 3 comprises the bulk of the alteration layer on the glass. EDS analysis indicates that the phase is enriched in $\mathrm{Fe}, \mathrm{Mg}, \mathrm{Zn}$, and $\mathrm{Ti}$ and is most likely a nontronitic clay. 

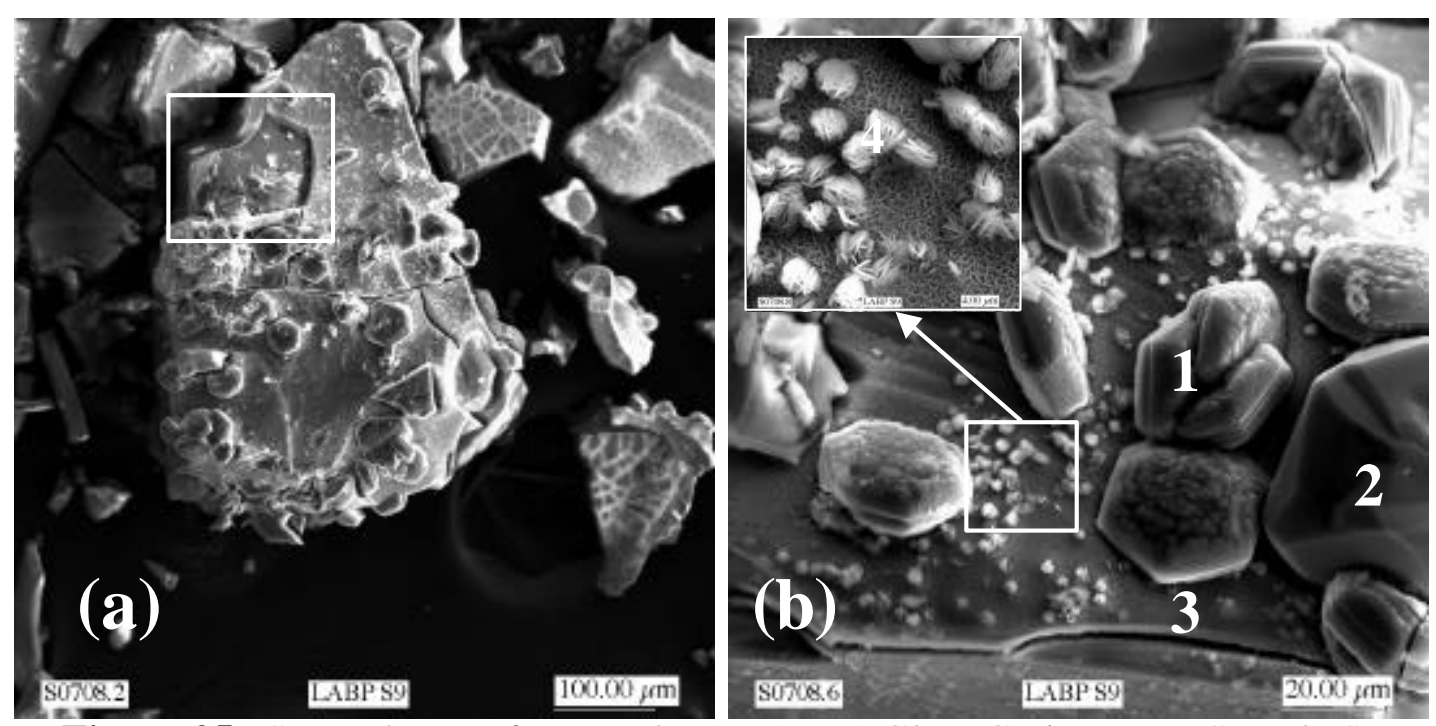

Figure 25. SEM Photos of Reacted LAWABP1 Glass Grains From Sample S9

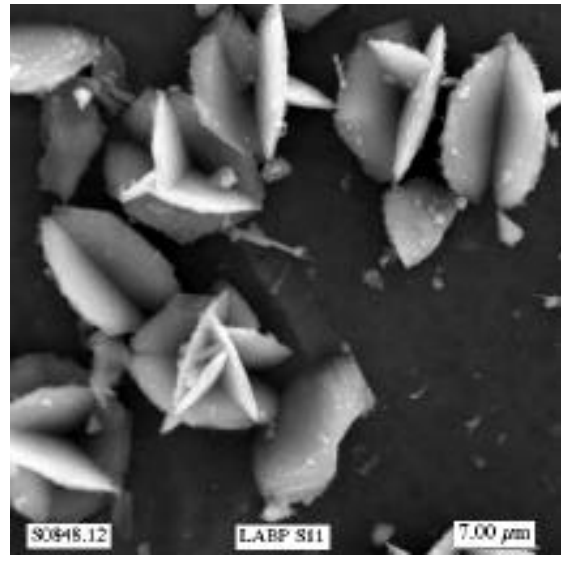

Figure 26. Kaolinite Crystals Found on PUF Reacted LAWABP1 Glass Sample S11

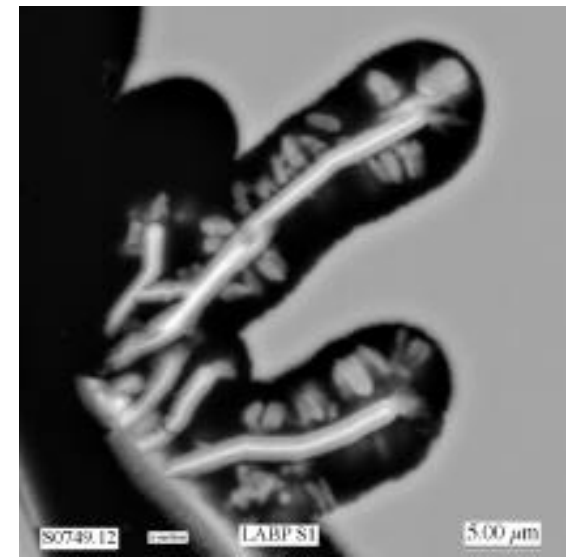

Figure 27. Aluminosilicate Phase Shown in Cross-Section in PUF Reacted LAWABP1 Sample S1

Embedded in the clay layer are also small crystals with plate-like morphology (see inset of Figure 25b). This phase was isolated in sample S11 as shown in Figure 26. The morphology of the phase and EDS analysis identify it as kaolinite $\left[\mathrm{Al}_{2} \mathrm{Si}_{2} \mathrm{O}_{5}(\mathrm{OH})_{4}\right]$, which was conclusively confirmed by the selected area electron diffraction in the TEM. TEM analyses also identified anatase $\left(\mathrm{TiO}_{2}\right)$ and sauconite $\left.\left[\mathrm{Na}_{0.3} \mathrm{Zn}_{3}(\mathrm{Si}, \mathrm{Al})_{4} \mathrm{O}_{10}(\mathrm{OH})_{2} \cdot 4 \mathrm{H}_{2} \mathrm{O}\right)\right]$ in sample $\mathrm{S} 11$.

Although the XRD analyses showed no crystalline phases in sample S1 (taken from near the top of the column), SEM analyses showed that small amounts of crystalline phases were present at isolated locations. EDS analyses showed these phases to be a Na-aluminosilicate compound. 
As is shown in Figure 27, the mode of attack in this region appears highly localized in contrast with the morphology in the other samples, which had more uniform corrosion layers of approximately constant thickness.

\subsubsection{LAWA44 Glass}

The PUF test with LAWA44 glass remains in progress at the time this report was drafted. Consequently, no reacted solid phase analyses are yet available. 


\subsection{ADVANCED COMPUTATIONAL MODELING}

In FY00, a set of reactive chemical transport calculations was conducted with the Subsurface Transport Over Reactive Multiphases (STORM) code to evaluate the long-term performance of LAWABP1 glass in a remote handled $(\mathrm{RH})$ trench conceptual design for the disposal system [30]. Both 1-D and 2-D simulations were conducted out to time periods in excess of 20,000 y. However, the RH trench design implemented several features that were not anticipated during early development and testing of STORM. In particular, the incorporation of multiple layers of waste packages and backfill (sand) with dramatically different hydraulic and chemical properties generated multiple sharp interfaces where water content and solute concentrations changed by several orders of magnitude across one or two grid nodes. The inversion algorithm (GaussSiedel) used to solve the non-linear partial differential equations (PDE) in STORM requires a strongly positive-definite matrix to achieve rapid convergence. This condition was violated in several of the simulations and so exceedingly long times (months) were sometimes required to conduct full 2-D simulations.

To address these computational issues for future PAs, improvements in execution speed and more robust numerical methods are needed in STORM. Also, the STORM code is fundame ntally based on principles derived from continuum mechanics to model flow and transport processes in porous media. However, the vitrified waste will be in the form of large glass blocks riddled with stress fractures. In STORM, the fractured blocks are treated as a continuum represented as an equivalent porous medium where the repeating fractures behave as large pores. However, this approximation breaks down once the fracture network becomes sufficiently sparse. A model is needed that is capable of handling flow and transport in both discrete fractures and porous media. Finally, the code must be adapted for operation on today's parallel processing computers. Linear speedup with the number of addressable processors is possible with highly efficient parallelized algorithms.

\subsection{LATTICE BOLTZMANN OVERVIEW}

Because several alternatives exist for decreasing the execution time of STORM, a modeling study was conducted with a new computational tool developed at PNNL that is based on a "lattice-Boltzmann" (LB) method for solving reactive chemical transport equations. The LB method 
takes a different approach to modeling fluid systems than conventional flow solvers. The spatial domain is discretized into a finite number of lattice sites, where each lattice site has a local particle distribution with values for density, pressure, flow, etc. The particle distributions define a set of displacement vectors connecting each lattice site to adjacent sites. Similar distributions are created for energy and chemical species. The solution method consists of a streaming stage and a collision stage for each time step. During the streaming stage, each lattice site transmits distribution information with adjacent neighbor sites. The incoming information is then relaxed toward an equilibrium distribution, which is determined by local conditions. This procedure is repeated for the specified number of time steps.

The advantages of this procedure center on the fact that no global solution methods are required for determining field variables. Each lattice site only requires information from adjacent sites. This makes the LB method inherently parallelizable and makes it possible to simulate complex geometries, include fracture networks, in great detail. Pore scale geometries consisting of millions of lattice nodes are typical.

\subsection{LB MODEL DEVELOPMENT}

A framework LB model developed at PNNL was fully parallelized for operation on the EMSL massively parallel IBM NWMPP1 (247 GFLOPS). A preliminary reactive chemical transport capability was added to the code using the Kinetic-Equilibrium Module (KEMOD) chemistry program developed by Prof. George Yeh at Penn State University. KEMOD provides for both kinetic and equilibrium controlled dissolution/precipitation reactions, ion exchange, adsorption, and oxidation-reduction reactions.

The modified LB/KEMOD program was tested for simple bulk systems using sample input provided for the KEMOD computer program. Timing runs were performed to assess speedup performance as a function of the number of parallel processors. The resulting performance curve is presented in Figure 28 for a uniform 16x16 node system and 100 time steps. The reaction set models the precipitation of calcium carbonate and involves three primary aqueous components, six aqueous complexes, and two solid precipitates. The runs were performed on a 14-processor SGI PowerChallenge. The results indicate nearly linear speedup (half the time for double the processors) for this system. The run times do not include the time for input and problem setup, 
which is a fixed overhead of a couple of seconds for each run. The speedup performance for more complicated systems will depend on several factors, including the rate of convergence for the chemistry solution at different locations in the system. However, these preliminary results are very encouraging.

A methodology was also established for obtaining a three-dimensional porous media geometry model from x-ray microtomography (XMT) data for use in lattice Boltzmann simulations. A series of twodimensional images produced by the $\mathrm{x}$-ray

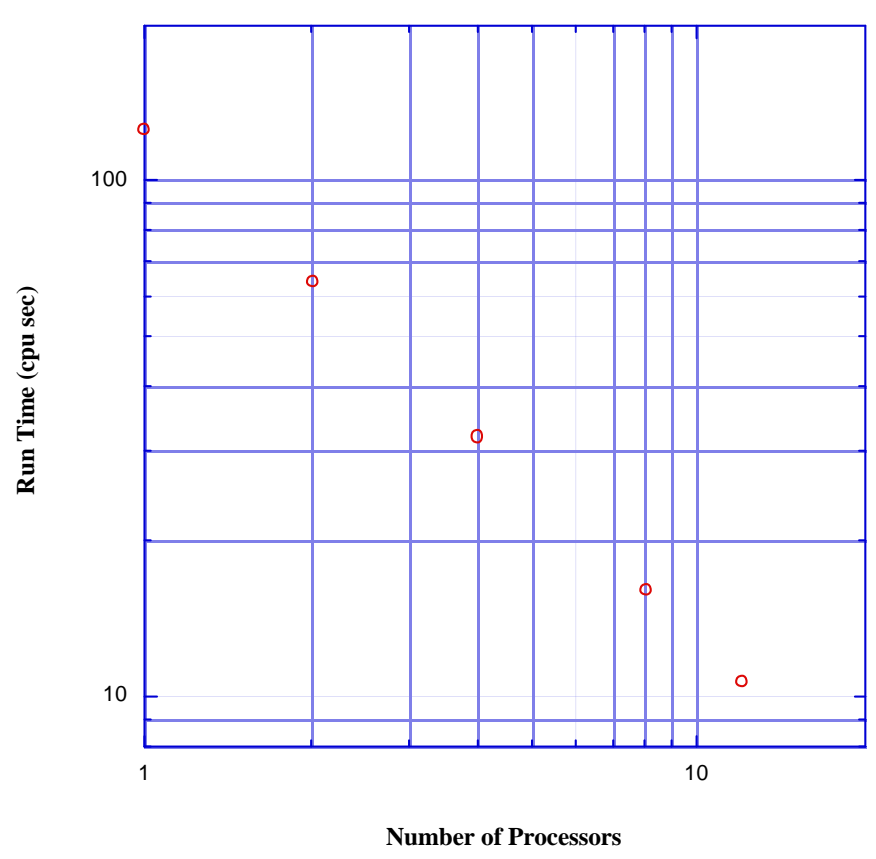

Figure 28. Speedup Performance of the LB/KEMOD Computer Program for a Simple Model System

(XMT) are digitized and geometry information between planes is obtained by interpolation. This capability will allow us to import in situ pore geometry data directly into the model from PUF columns for simulations of these experiments.

\subsection{ARTIFICIAL FRACTURE NETWORK}

A LB/KEMOD simulation was performed in a simple two-dimensional fracture network to demonstrate the capabilities of the code for modeling reactive transport phenomena in fractured glass blocks. A $4 \mathrm{~cm} \mathrm{x} 4 \mathrm{~cm}$ square block was discretized into a 400 x 400 grid of lattice points. The fractures were $0.1 \mathrm{~cm}$. wide and occupy approximately $7.5 \%$ of the total volume. The system was initialized by allowing a $10^{-6} \mathrm{~mol} / \mathrm{m}^{3}$ solution of calcium carbonate to come to equilibrium, resulting in a concentration of $1.4 \times 10^{-7} \mathrm{~mol} / \mathrm{m}^{3}$ of $\mathrm{Ca}$ in solution and $8.6 \times 10^{-7} \mathrm{~mol} / \mathrm{m}^{3}$ of $\mathrm{CaCO}_{3}$ precipitate. The inlet solution was held at equilibrium to provide a constant source boundary condition. $\mathrm{A} \mathrm{Na}^{+}-\mathrm{H}^{+}$ion-exchange reaction was mimicked by injecting a small constant flux of $\mathrm{NaOH}$ along the fracture surfaces. 


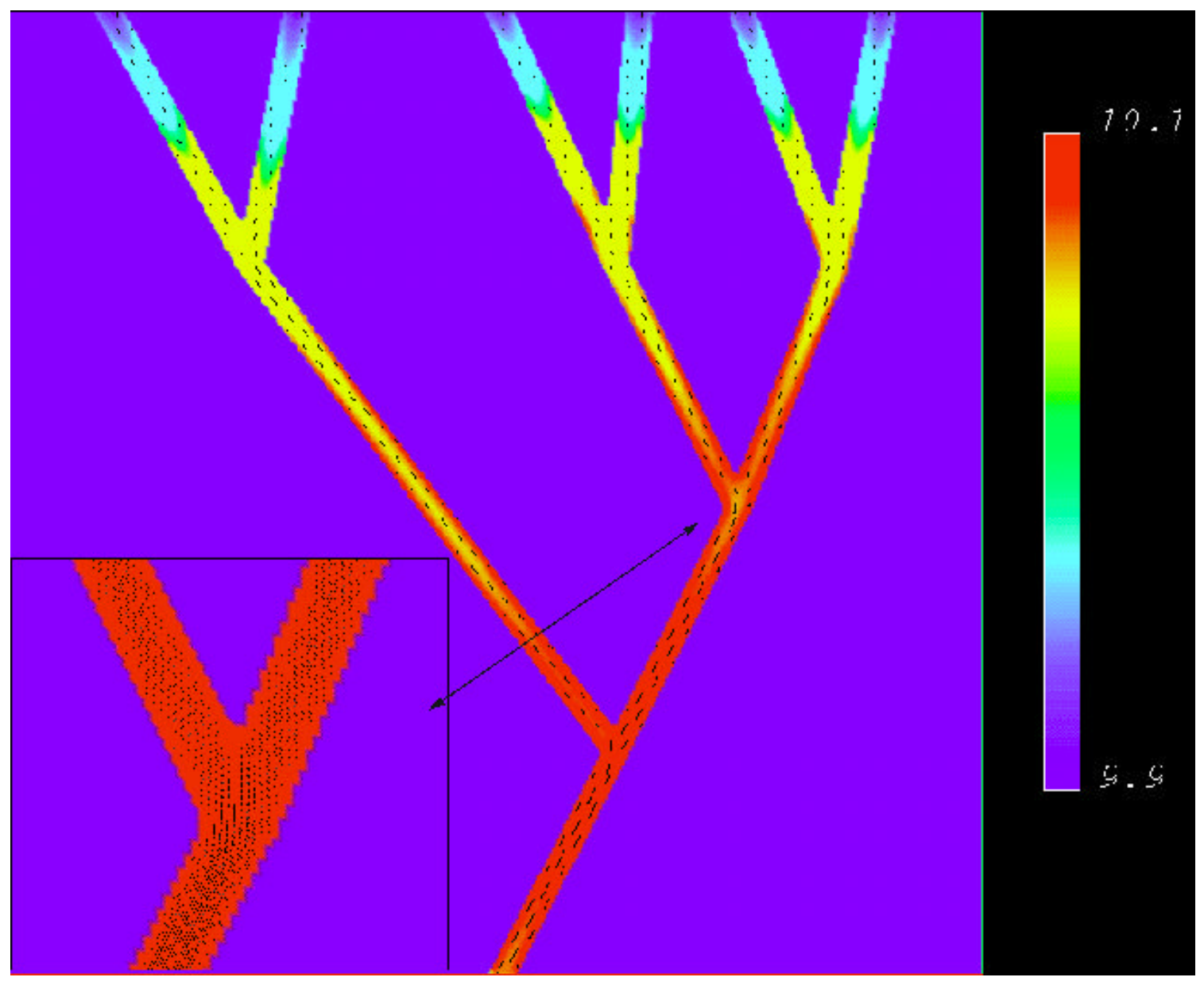

Figure 29. LB/KEMOD Simulation of $\mathrm{pH}$ and Flow Field in Artificial Fracture Network. Inset shows detailed flow solution at the bottom fracture junction

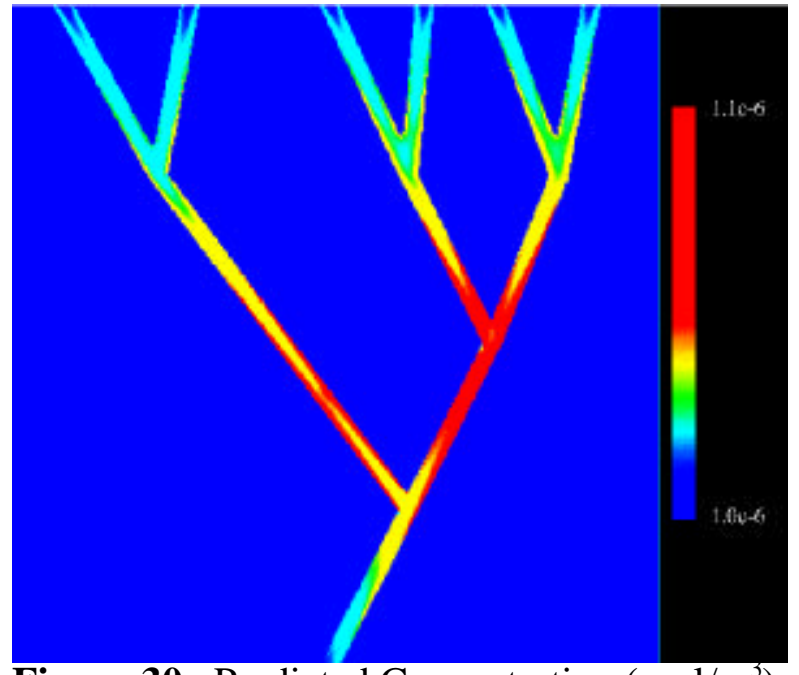

Figure 30. Predicted Concentration $\left(\mathrm{mol} / \mathrm{m}^{3}\right)$ of Calcite LB/KEMOD Simulation of Artificial Fracture Network

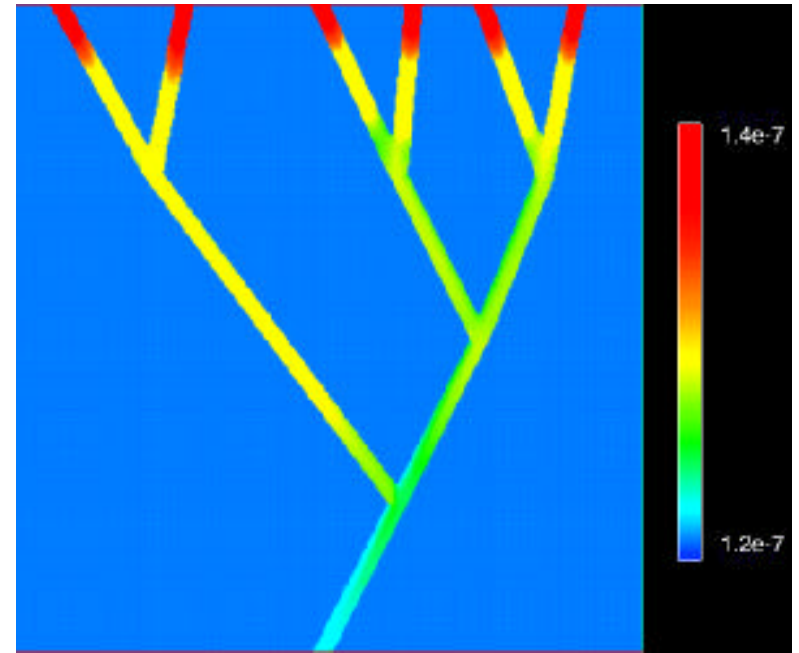

Figure 31. Predicted Total Aqueous Concentration $\left(\mathrm{mol} / \mathrm{m}^{3}\right)$ of Ca in LB/KEMOD Simulation of Artificial Fracture Network 
Figure 29 shows the calculated solution flow path and $\mathrm{pH}$ distribution after $2.2 \mathrm{hr}$ of simulation time. The maximum fluid velocity was approximately $0.005 \mathrm{~cm} / \mathrm{s}$. The code provides a very fine level of detail regarding fluid flow in the fracture network. As expected, the injection of $\mathrm{NaOH}$ along the solution flow path raises the solution $\mathrm{pH}$ from the inlet value of 9.9 to an average exit value of 10.1. Because the solubility of $\mathrm{CaCO}_{3}$ decreases with increasing $\mathrm{pH}$, a $\mathrm{CaCO}_{3}$ precipitation front develops in the fracture network, as shown in Figure 30. This in turn causes the total aqueous concentration of $\mathrm{Ca}$ to decrease from an inlet concentration of $1.4 \times 10^{-7}$ $\mathrm{mol} / \mathrm{m}^{3}$ to an exit value of $1.15 \times 10^{-7} \mathrm{~mol} / \mathrm{m}^{3}$. Although this example problem is very simple, it does illustrate the unique computational capabilities that are possible with the LB method.

\subsection{FUTURE DEVELOPMENT}

Based on the encouraging results obtained so far, additional LB model development activities are planned for FY01. Additional modifications will be made to handle irreversible reactions, which are required for modeling glass dissolution, and improvements will be made to the KEMOD time stepping procedure. We will also investigate methods to increase the accuracy of the LB method by embedding a more detailed lattice subgrid in those regions where more resolution is required. For example, multiphase flow systems typically only require greater resolution in the regions surrounding the interface. A significant portion of this work would be the passing of information between the lattice subgrid and the primary lattice through interpolation. In FY00, we began to evaluate methods for incorporating lattice subgrids into the lattice Boltzmann program. An initial implementation of an adaptive mesh algorithm has been achieved using an adaptive mesh toolkit developed at NASA, Gaithersburg. We plan to investigate whether or not the adaptive mesh refinement routines in NWGrid can be used instead to get better results. 



\subsection{CONCLUSION}

A large number of experimental studies with LAW glasses that are prototypical of those expected to be eventually produced at Hanford were completed in FY00. Over 200 SPFT experiments were completed with LAWABP1 glass, which were used to generate the kinetic rate law parameters and $\mathrm{Na}$ ion-exchange rate needed to conduct long-term performance analyses using the STORM code. PUF experiments with 5 prototypic LAW glasses were also performed. The performance of these next generation LAW glasses in the PUF test (and other accelerated tests) has improved dramatically from earlier glass compositions that were being developed by BNFL, Inc. No autocatalytic corrosion rate accelerations were observed in tests that were conducted for over 1 year. Excellent performance was also observed for one glass (HLP-31) with a 15\% higher $\mathrm{Na}_{2} \mathrm{O}$ loading than previously tested glasses. Improvements in the glass performance have been a direct result of the better scientific understanding about how key glass components ( $\mathrm{Al}, \mathrm{Fe}, \mathrm{Zr}$, $\mathrm{Ti}, \mathrm{La}$ ) impact long-term glass behavior, developed under this program and others (EMSP), and the rapid feedback on product performance now available with advanced test methods such as PUF and vapor hydration tests.

Initial development and testing of a parallelized lattice-Boltzma nn method for solving reactive chemical transport problems in complex geometries was completed. The results showed linear speedup behavior with number of processors for a simple test problem. Additional development and testing of the model on more realistic and complex ILAW disposal problems is planned for FY01.

\section{Acknowledgment}

The authors would like to gratefully acknowledge the assistance of Dr. Ian Pegg, Catholic University of America, Washington, D.C. for providing advance information regarding LAW glasses under development at his laboratory. We are grateful to Professor George Yeh (Penn State University) for supplying the KEMOD source code. We also thank Dr. Fred Mann (CH2M Hill), Ms. Carol Babel, Mr. Phil Lamont, and Dr. Neil Brown (DOE Office of River Protection) for their support of this research. 


\subsection{REFERENCES}

1. Puigh, R. J. 1999. Disposal Facility Data for the Hanford Immobilized Low-Activity Tank Waste. HNF-4950, Rev. 1, Fluor Federal Services, Richland, Washington.

2. McGrail, B. P., W. L. Ebert, D. H. Bacon, and D. M. Strachan. 1998. A Strategy to Conduct an Analysis of the Long-Term Performance of Low-Activity Waste Glass in a Shallow Subsurface Disposal System at Hanford. PNNL-11834, Pacific Northwest National Laboratory, Richland, Washington.

3. Aagard, P. and H. C. Helgeson. 1982. "Thermodynamic and Kinetic Constraints on Reaction Rates Among Minerals and Aqueous Solutions. I. Theoretical Considerations." Am. J. Sci., 282:237-285.

4. Lasaga, A. C. 1998. "Fundamental Approaches in Describing Mineral Dissolution and Precipitation Rates." In Chemical Weathering Rates of Silicate Minerals, Reviews in Mineralogy, Vol. 31, Ed. A. F. White and S. L. Brantley, Mineralogical Society of America, Washington, D. C.

5. Gin, S. 1996. "Control of R7T7 Nuclear Glass Alteration Kinetics Under Saturation Conditions.” Mat. Res. Soc. Symp. Proc. 412:189-196.

6. Grambow, B. E. 1985. "A General Rate Equation for Nuclear Waste Glass Corrosion." Mat. Res. Soc. Symp. Proc. 44:15-27.

7. Brunauer, S., P. H. Emmett, and E. Teller. 1938. "Adsorption of Gases in Multimolecular Layers." J. Phys. Chem. 60:309-319.

8. McGrail, B. P., W. L. Ebert, A. J. Bakel, and D. K. Peeler. 1997. "Measurement of Kinetic Rate Law Parameters on a Na-Ca-Al Borosilicate Glass for Low-Activity Waste.” J. Nuc. Mat. 249:175-189.

9. Wolery, T. J. 1992. EQ3NR, A Computer Program for Geochemical Aqueous SpeciationSolubility Calculations: Theoretical Manual, User's Guide, and Related Documentation (Version 7.0). UCRL-MA-110662 PT III, Lawrence Livermore National Laboratory, Livermore, California.

10. Drever, J. I. 1994. "The Effect of Land Plants on Weathering Rates of Silicate Minerals." Geochim. Cosmochim. Acta 58(10):2325-2332.

11. Cooper, G. I., and G. A. Cox. 1996. "The Aqueous Corrosion of Potash-Lime-Silica Glass in the Range 10-250C." App. Geochem. 11:511-521.

12. Dove, P. M. 1994. "The Dissolution Kinetics of Quartz in Sodium Chloride Solutions at $25^{\circ}$ to $300^{\circ}$ C." Am. J. Sci. 294: 665-712.

13. Icenhower, J. P., and P. M. Dove. 2000. "The Dissolution Kinetics of Amorphous Silica Into Sodium Chloride Solutions: Effects of Temperature and Ionic Strength." Geochim. Cosmochim. Acta, in press.

14. Renders, P. J. N., C. H. Gammons, and H. L. Barnes. 1995. "Precipitation and Dissolution Rate Constants for Cristobalite From 150 to $300^{\circ} \mathrm{C}$." Geochim. Cosmochim. Acta 59(1):77-85. 
15. Pederson, L. R. 1987. "Comparison of Sodium Leaching Rates From a $\mathrm{Na}_{2} \mathrm{O} \cdot 3 \mathrm{SiO}_{2} \mathrm{Glass}$ in $\mathrm{H}_{2} \mathrm{O}$ and $\mathrm{D}_{2} \mathrm{O}$." Phys. Chem. Glass 28(1):17-21.

16. McGrail, B. P., J. P. Icenhower, D. K. Shuh, J. G. Darab, D. R. Baer, S. Thevuthasen, V. Shutthanadan, and M. H. Englehard. 2000. "The Structure of $\mathrm{Na}_{2} \mathrm{O}-\mathrm{Al}_{2} \mathrm{O}_{3}-\mathrm{SiO}_{2}$ Glass: Impact on Sodium Ion Exchange in $\mathrm{H}_{2} \mathrm{O}$ and $\mathrm{D}_{2} \mathrm{O}$." J. Non-Cryst. Solids (submitted).

17. W. L. Bourcier, D. W. Peiffer, K. G. Knauss, K. D. McKeegan, and D. K. Smith. 1990. "A Kinetic Model for Borosilicate Glass Dissolution Based on the Dissolution Affinity of a Surface Alteration Layer.” Mat. Res. Symp. Proc. 176:209-216.

18. Langmuir, D. 1997. Aqueous Environmental Geochemistry. Prentice Hall, Upper Saddle River, New Jersey, p. 62.

19. Schnitzer, M. 1989. "Binding of Humic Substances by Soil Mineral Colloids." Interactions of Soil Minerals with Natural Organics and Microbes, SSSA Special Publication No. 17, P.M. Huang and M. Schnitzer, Eds., Madison, Wisconsin, pp. 77-101.

20. Bennett, P. C., M. E. Melcer, D. I. Siegel, J. P. Hassett. 1988. “The Dissolution of Quartz in Dilute Aqueous Solutions of Organic Acids at $25^{\circ} \mathrm{C} . "$ Geochim. Cosmochim. Acta 52:1521-1530.

21. Gin, S., N. Godon, J. P. Mestre, and E. Y. Vernaz. 1994. "Experimental Investigation of Aqueous Corrosion of R7T7 Nuclear Glass at $90^{\circ} \mathrm{C}$ in the Presence of Organic Species." Appl. Geochem. 9:255-269.

22. Toste, A. P. 1999. "A Case Study on the Role of Naturally-Occurring Organics in Subsurface Radionuclide Migration: The N Reactor's Crib-Trench System.” NUCEF'98 Symposium Working Group, Japan Atomic Energy Research Institute, Conf. 99-004, pp. 370-377.

23. Malcolm, R. L., and P. MacCarthy. 1986. "Limitations in the Use of Commercial Humic Acids in Water and Soil Research.” Environ. Sci. Tech. 20:904-911.

24. Hayes, M. H. B., and R. S. Swift. 1990. “Genesis, Isolation, Composition and Structures of Soil Humic Substances." Soil Colloids and Their Associations in Aggregates, M. F. de Boodt, M. H. B. Hayes, and A. Herbillon Eds., Plenum Press, New York, pp 245-305.

25. McGrail, B. P., C. W. Lindenmeier, P. F. C. Martin, and G. W. Gee. 1996. "The Pressurized Unsaturated Flow (PUF) Test: A New Method for Engineered-Barrier Materials Evaluation." Trans. Am. Ceram. Soc. 72:317-329.

26. McGrail, B. P., P. F. Martin, and C. W. Lindenmeier. 1997. "Accelerated Testing of Waste Forms Using a Novel Pressurized Unsaturated Flow (PUF) Method.” Mat. Res. Soc. Symp. Proc. 465:253-260.

27. Wierenga, P. J., Young, M. H., Gee, G. W., Hills, R. G., Kincaid, C. T., Nicholson, T. J., and Cady, R. E.. 1993. Soil Characterization Methods for Unsaturated Low-Level Waste Sites. PNL-8480, Pacific Northwest Laboratory, Richland, Washington.

28. Vienna, J. D., A. Jiricka, B. P. McGrail, B. M. Jorgensen, D. E. Smith, B. R. Allen, J. C. Marra, D. K. Peeler, K. G. Brown, I. A. Reamer, and W. L. Ebert. 2000. Hanford Immobilized LAW Product Acceptance Testing: Initial Data Package. PNNL-13101, Pacific Northwest National Laboratory, Richland, Washington. 
29. ASTM. 1995. Standard Test Methods for Determining Chemical Durability of Nuclear Waste Glasses: The Product Consistency Test (PCT). ASTM Standard C1285-94.

30. Bacon, D. H., and B. P. McGrail. 2000. Waste Form Release Calculations for the 2001 Immobilized Low-Activity Waste Performance Assessment. PNNL- 13369, Pacific Northwest National Laboratory, Richland, Washington. 


\section{APPENDIX}

Table A1. SPFT Experimental Conditions and Dissolution rates of LAWABP1 Glass

\begin{tabular}{|c|c|c|c|c|c|c|c|c|c|c|}
\hline Expt. \# & Description & $\begin{array}{l}\text { Temp } \\
\left({ }^{\circ} \mathrm{C}\right)\end{array}$ & $\mathrm{pH}$ & $\begin{array}{c}\operatorname{mass} \\
(\mathrm{g})\end{array}$ & $\begin{array}{c}\text { flow rate } \\
(\mathrm{mL} / \mathrm{d})\end{array}$ & $\begin{array}{c}\text { surface } \\
\text { area }\left(\mathrm{m}^{2} / \mathrm{g}\right)\end{array}$ & $\begin{array}{c}\text { Buffer } \\
\#\end{array}$ & $\begin{array}{c}\text { rate } \\
\left(\mathrm{g} \mathrm{m}^{-2} \mathrm{~d}^{-1}\right)\end{array}$ & $\begin{array}{l}\log \text { rate } \\
\left(\mathrm{g} \mathrm{m}^{-2} \mathrm{~d}^{-1}\right)\end{array}$ & Notes \\
\hline 1 & forward rate & 90 & 9.03 & 0.50 & 100 & 0.020 & 5 & $1.95 \mathrm{E}-01$ & -0.71 & 1 \\
\hline 2 & & 90 & 9.03 & 0.51 & 100 & 0.020 & 5 & $1.91 \mathrm{E}-01$ & -0.72 & \\
\hline 40 & & 90 & 9.00 & 0.50 & 100 & 0.020 & 5 & $1.58 \mathrm{E}-01$ & -0.80 & 1 \\
\hline 41 & & 90 & 9.00 & 0.50 & 100 & 0.020 & 5 & $1.41 \mathrm{E}-01$ & -0.85 & \\
\hline 42 & & 90 & 9.18 & 0.50 & 30 & $1.29 \mathrm{E}-03$ & 5 & $2.24 \mathrm{E}-01$ & -0.65 & 2 \\
\hline 43 & & 90 & 9.18 & 0.50 & 30 & $1.26 \mathrm{E}-03$ & 5 & $2.45 \mathrm{E}-01$ & -0.61 & \\
\hline 9 & q/s study & 90 & 9.18 & 0.52 & 80 & 0.020 & 5 & $1.45 \mathrm{E}-01$ & -0.84 & 1,3 \\
\hline 10 & & 90 & 9.19 & 0.50 & 70 & 0.020 & 5 & $1.23 \mathrm{E}-01$ & -0.91 & \\
\hline 11 & & 90 & 9.08 & 0.50 & 60 & 0.020 & 5 & $1.15 \mathrm{E}-01$ & -0.94 & \\
\hline 12 & & 90 & 9.08 & 0.51 & 50 & 0.020 & 5 & $1.32 \mathrm{E}-01$ & -0.88 & \\
\hline 13 & & 90 & 9.13 & 0.52 & 40 & 0.020 & 5 & $9.55 \mathrm{E}-02$ & -1.02 & \\
\hline 14 & & 90 & 9.13 & 0.51 & 30 & 0.020 & 5 & $9.33 \mathrm{E}-02$ & -1.03 & \\
\hline 15 & & 90 & 9.19 & 0.50 & 20 & 0.020 & 5 & $6.92 \mathrm{E}-02$ & -1.16 & \\
\hline 16 & & 90 & 9.19 & 0.51 & 10 & 0.020 & 5 & $3.63 \mathrm{E}-02$ & -1.44 & \\
\hline 3 & forward rate & 70 & 9.11 & 0.53 & 100 & 0.020 & 5 & $6.46 \mathrm{E}-02$ & -1.19 & 1 \\
\hline 4 & & 70 & 9.11 & 0.52 & 100 & 0.020 & 5 & $5.50 \mathrm{E}-02$ & -1.26 & \\
\hline 92 & q/s study & 70 & 9.00 & 0.52 & 20 & 0.020 & 5 & 4.27E-02 & -1.37 & 1 \\
\hline 93 & & 70 & 9.00 & 0.52 & 30 & 0.020 & 5 & $5.13 \mathrm{E}-02$ & -1.29 & \\
\hline 94 & & 70 & 9.00 & 0.52 & 40 & 0.020 & 5 & $5.75 \mathrm{E}-02$ & -1.24 & \\
\hline 95 & & 70 & 9.00 & 0.51 & 50 & 0.020 & 5 & $6.92 \mathrm{E}-02$ & -1.16 & \\
\hline 96 & & 70 & 9.00 & 0.52 & 60 & 0.020 & 5 & 7.24E-02 & -1.14 & \\
\hline 97 & & 70 & 9.00 & 0.52 & 80 & 0.020 & 5 & 8.32E-02 & -1.08 & \\
\hline
\end{tabular}

1. Glass specimen in $<100,>200$ mesh size fraction; specific surface area by geometric calculation.

2. Glass coupons, $\sim 10 \times 10 \times 1.5 \mathrm{~mm}$ dimensions.

3. $\mathrm{q} / \mathrm{s}$ is the flow-through rate, $\mathrm{q}\left(\mathrm{m}^{3} / \mathrm{s}\right)$, divided by the surface area, $\mathrm{s}\left(\mathrm{m}^{2}\right)$. 
Table A2. SPFT Experimental Conditions and Dissolution rates of LAWABP1 Glass

\begin{tabular}{|c|c|c|c|c|c|c|c|c|c|c|}
\hline Expt. \# & Description & $\begin{array}{l}\text { Temp } \\
\left({ }^{\circ} \mathrm{C}\right)\end{array}$ & $\mathrm{pH}$ & $\begin{array}{c}\operatorname{mass} \\
(\mathrm{g})\end{array}$ & $\begin{array}{c}\text { flow rate } \\
(\mathrm{mL} / \mathrm{d})\end{array}$ & $\begin{array}{c}\text { surface } \\
\text { area }\left(\mathrm{m}^{2} / \mathrm{g}\right)\end{array}$ & $\begin{array}{c}\text { Buffer } \\
\#\end{array}$ & $\begin{array}{c}\text { rate } \\
\left(\mathrm{g} \mathrm{m}^{-2} \mathrm{~d}^{-1}\right) \\
\end{array}$ & $\begin{array}{c}\log \text { rate } \\
\left(\mathrm{g} \mathrm{m}^{-2} \mathrm{~d}^{-1}\right)\end{array}$ & Notes \\
\hline 68 & $\mathrm{q} / \mathrm{s}$ study & 40 & 8.96 & 1.02 & 60 & 0.020 & 5 & $4.27 \mathrm{E}-03$ & -2.37 & 1 \\
\hline 69 & & 40 & 8.96 & 0.76 & 60 & 0.020 & 5 & $3.98 \mathrm{E}-03$ & -2.40 & \\
\hline 70 & & 40 & 8.96 & 0.51 & 60 & 0.020 & 5 & $4.47 \mathrm{E}-03$ & -2.35 & \\
\hline 71 & & 40 & 8.93 & 0.25 & 60 & 0.020 & 5 & $5.50 \mathrm{E}-03$ & -2.26 & \\
\hline 72 & & 40 & 8.93 & 1.01 & 40 & 0.020 & 5 & $3.89 \mathrm{E}-03$ & -2.41 & \\
\hline 73 & & 40 & 8.93 & 1.01 & 30 & 0.020 & 5 & $3.72 \mathrm{E}-03$ & -2.43 & \\
\hline 74 & & 40 & 8.91 & 1.01 & 60 & 0.020 & 5 & $3.72 \mathrm{E}-03$ & -2.43 & \\
\hline 75 & & 40 & 8.91 & 0.75 & 60 & 0.020 & 5 & $6.46 \mathrm{E}-03$ & -2.19 & \\
\hline 76 & & 40 & 8.91 & 0.51 & 60 & 0.020 & 5 & 7.94E-03 & -2.10 & \\
\hline 77 & & 40 & 8.90 & 0.25 & 60 & 0.020 & 5 & & & \\
\hline 78 & & 40 & 8.90 & 1.01 & 40 & 0.020 & 5 & $4.27 \mathrm{E}-03$ & -2.37 & \\
\hline 79 & & 40 & 8.90 & 1.02 & 30 & 0.020 & 5 & $4.07 \mathrm{E}-03$ & -2.39 & \\
\hline 146 & q/s study & 23 & 9.03 & 0.50 & 5 & 0.020 & 5 & $1.72 \mathrm{E}-03$ & -2.76 & 1 \\
\hline 147 & & 23 & 9.03 & 0.51 & 10 & 0.020 & 5 & $2.11 \mathrm{E}-03$ & -2.68 & \\
\hline 148 & & 23 & 9.03 & 0.51 & 15 & 0.020 & 5 & $2.24 \mathrm{E}-03$ & -2.65 & \\
\hline 149 & & 23 & 9.03 & 0.51 & 20 & 0.020 & 5 & $1.22 \mathrm{E}-03$ & -2.91 & \\
\hline 150 & & 23 & 9.03 & 0.51 & 25 & 0.020 & 5 & & & \\
\hline 151 & & 23 & 9.03 & 0.51 & 30 & 0.020 & 5 & & & \\
\hline 134 & pH sweep & 90 & 2.19 & 0.51 & 80 & 0.020 & 1 & $2.04 \mathrm{E}+00$ & 0.31 & 1 \\
\hline 135 & & 90 & 3.78 & 0.51 & 80 & 0.020 & 2 & & & \\
\hline 136 & & 90 & 6.83 & 0.51 & 80 & 0.020 & 3 & $3.55 \mathrm{E}-01$ & -0.45 & \\
\hline 137 & & 90 & 8.07 & 0.52 & 80 & 0.020 & 4 & $1.26 \mathrm{E}-01$ & -0.90 & \\
\hline 138 & & 90 & 10.00 & 0.51 & 80 & 0.020 & 6 & $3.72 \mathrm{E}-01$ & -0.43 & \\
\hline 139 & & 90 & 11.06 & 0.52 & 80 & 0.020 & 7 & $1.55 \mathrm{E}+00$ & 0.19 & \\
\hline 140 & & 90 & 2.19 & 0.51 & 80 & 0.020 & 1 & $2.63 \mathrm{E}+00$ & 0.42 & \\
\hline 141 & & 90 & 3.78 & 0.50 & 80 & 0.020 & 2 & & & \\
\hline 142 & & 90 & 6.83 & 0.50 & 80 & 0.020 & 3 & $2.88 \mathrm{E}-01$ & -0.54 & \\
\hline 143 & & 90 & 8.07 & 0.51 & 80 & 0.020 & 4 & $1.26 \mathrm{E}-01$ & -0.90 & \\
\hline 144 & & 90 & 10.00 & 0.52 & 80 & 0.020 & 6 & 4.79E-01 & -0.32 & \\
\hline 145 & & 90 & 11.06 & 0.51 & 80 & 0.020 & 7 & $1.78 \mathrm{E}+00$ & 0.25 & \\
\hline
\end{tabular}

1. Glass specimen in $<100,>200$ mesh size fraction; specific surface area by geometric calculation. 
Table A3. SPFT Experimental Conditions and Dissolution rates of LAWABP1 Glass

\begin{tabular}{|c|c|c|c|c|c|c|c|c|c|c|}
\hline Expt. \# & Description & $\begin{array}{l}\text { Temp } \\
\left({ }^{\circ} \mathrm{C}\right)\end{array}$ & $\mathrm{pH}$ & $\begin{array}{c}\operatorname{mass} \\
(\mathrm{g})\end{array}$ & $\begin{array}{c}\text { flow rate } \\
(\mathrm{mL} / \mathrm{d})\end{array}$ & $\begin{array}{c}\text { surface } \\
\text { area }\left(\mathrm{m}^{2} / \mathrm{g}\right)\end{array}$ & $\begin{array}{c}\text { Buffer } \\
\#\end{array}$ & $\begin{array}{c}\text { rate } \\
\left(\mathrm{g} \mathrm{m}^{-2} \mathrm{~d}^{-1}\right)\end{array}$ & $\begin{array}{c}\text { log rate } \\
\left(\mathrm{g} \mathrm{m}^{-2} \mathrm{~d}^{-1}\right)\end{array}$ & Notes \\
\hline 118 & pH sweep & 70 & 2.11 & 0.50 & 60 & 0.020 & 1 & $1.70 \mathrm{E}+00$ & 0.23 & 1 \\
\hline 119 & & 70 & 3.76 & 0.50 & 60 & 0.020 & 2 & 7.41E-02 & -1.13 & \\
\hline 120 & & 70 & 7.09 & 0.52 & 60 & 0.020 & 3 & $5.25 \mathrm{E}-02$ & -1.28 & \\
\hline 121 & & 70 & 8.06 & 0.51 & 60 & 0.020 & 4 & $3.31 \mathrm{E}-02$ & -1.48 & \\
\hline 122 & & 70 & 10.01 & 0.50 & 60 & 0.020 & 6 & $1.23 \mathrm{E}-01$ & -0.91 & \\
\hline 123 & & 70 & 10.99 & 0.51 & 60 & 0.020 & 7 & 7.94E-01 & -0.10 & \\
\hline 124 & & 70 & 2.11 & 0.51 & 60 & 0.020 & 1 & $2.45 \mathrm{E}+00$ & 0.39 & \\
\hline 125 & & 70 & 3.76 & 0.51 & 60 & 0.020 & 2 & $8.13 \mathrm{E}-02$ & -1.09 & \\
\hline 126 & & 70 & 7.09 & 0.51 & 60 & 0.020 & 3 & $5.13 \mathrm{E}-02$ & -1.29 & \\
\hline 127 & & 70 & 8.06 & 0.51 & 60 & 0.020 & 4 & $3.24 \mathrm{E}-02$ & -1.49 & \\
\hline 128 & & 70 & 10.01 & 0.50 & 60 & 0.020 & 6 & $1.58 \mathrm{E}-01$ & -0.80 & \\
\hline 129 & & 70 & 10.99 & 0.51 & 60 & 0.020 & 7 & 7.94E-01 & -0.10 & \\
\hline 102 & pH sweep & 40 & 2.15 & 0.51 & 40 & 0.020 & 1 & $1.29 \mathrm{E}+00$ & 0.11 & 1 \\
\hline 103 & & 40 & 3.68 & 0.51 & 40 & 0.020 & 2 & $1.38 \mathrm{E}-02$ & -1.86 & \\
\hline 164 & & 40 & 6.96 & 1.00 & 14 & 0.020 & 3 & $3.55 \mathrm{E}-03$ & -2.45 & \\
\hline 105 & & 40 & 7.99 & 0.50 & 40 & 0.020 & 4 & $6.92 \mathrm{E}-03$ & -2.16 & \\
\hline 106 & & 40 & 9.62 & 0.50 & 40 & 0.020 & 6 & $1.78 \mathrm{E}-02$ & -1.75 & \\
\hline 107 & & 40 & 11.07 & 0.51 & 40 & 0.020 & 7 & $1.29 \mathrm{E}-01$ & -0.89 & \\
\hline 108 & & 40 & 2.15 & 0.51 & 40 & 0.020 & 1 & $1.12 \mathrm{E}+00$ & 0.05 & \\
\hline 109 & & 40 & 3.68 & 0.50 & 40 & 0.020 & 2 & $1.20 \mathrm{E}-02$ & -1.92 & \\
\hline 170 & & 40 & 6.96 & 1.00 & 14 & 0.020 & 3 & $3.16 \mathrm{E}-03$ & -2.50 & \\
\hline 111 & & 40 & 7.99 & 0.50 & 40 & 0.020 & 4 & $7.08 \mathrm{E}-03$ & -2.15 & \\
\hline 112 & & 40 & 9.62 & 0.52 & 40 & 0.020 & 6 & $1.35 \mathrm{E}-02$ & -1.87 & \\
\hline 113 & & 40 & 11.07 & 0.50 & 40 & 0.020 & 7 & 7.94E-02 & -1.10 & \\
\hline
\end{tabular}

1. Glass specimen in $<100,>200$ mesh size fraction; specific surface area by geometric calculation. 
Table A4. SPFT Experimental Conditions and Dissolution rates of LAWABP1 Glass

\begin{tabular}{|c|c|c|c|c|c|c|c|c|c|c|}
\hline Expt. \# & Description & $\begin{array}{l}\text { Temp } \\
\left({ }^{\circ} \mathrm{C}\right)\end{array}$ & $\mathrm{pH}$ & $\begin{array}{c}\text { mass } \\
(\mathrm{g})\end{array}$ & $\begin{array}{c}\text { flow rate } \\
(\mathrm{mL} / \mathrm{d})\end{array}$ & $\begin{array}{c}\text { surface } \\
\text { area }\left(\mathrm{m}^{2} / \mathrm{g}\right)\end{array}$ & $\begin{array}{c}\text { Buffer } \\
\#\end{array}$ & $\begin{array}{c}\text { rate } \\
\left(\mathrm{g} \mathrm{m}^{-2} \mathrm{~d}^{-1}\right) \\
\end{array}$ & $\begin{array}{c}\log \text { rate } \\
\left(\mathrm{g} \mathrm{m}^{-2} \mathrm{~d}^{-1}\right)\end{array}$ & Notes \\
\hline 176 & pH sweep & 23 & 2.13 & 0.50 & 20 & 0.020 & 1 & $1.02 \mathrm{E}+00$ & 0.01 & 1 \\
\hline 177 & & 23 & 2.13 & 0.51 & 20 & 0.020 & 1 & $6.92 \mathrm{E}-01$ & -0.16 & \\
\hline 178 & & 23 & 2.13 & 0.50 & 20 & 0.020 & 1 & 8.32E-01 & -0.08 & \\
\hline 179 & & 23 & 6.78 & 0.51 & 20 & 0.020 & 3 & $1.23 \mathrm{E}-03$ & -2.91 & \\
\hline 180 & & 23 & 6.78 & 0.51 & 20 & 0.020 & 3 & $1.17 \mathrm{E}-03$ & -2.93 & \\
\hline 181 & & 23 & 6.78 & 0.51 & 20 & 0.020 & 3 & $1.45 \mathrm{E}-03$ & -2.84 & \\
\hline 182 & & 23 & 9.04 & 0.50 & 20 & 0.020 & 5 & $1.05 \mathrm{E}-03$ & -2.98 & \\
\hline 183 & & 23 & 9.04 & 0.50 & 20 & 0.020 & 5 & $1.35 \mathrm{E}-03$ & -2.87 & \\
\hline 184 & & 23 & 9.04 & 0.50 & 20 & 0.020 & 5 & $9.55 \mathrm{E}-04$ & -3.02 & \\
\hline 193 & & 23 & 8.08 & 1.01 & 20 & 0.020 & 4 & & & \\
\hline 194 & & 23 & 8.08 & 1.01 & 20 & 0.020 & 4 & & & \\
\hline 195 & & 23 & 8.08 & 1.00 & 20 & 0.020 & 4 & & & \\
\hline 196 & & 23 & 10.04 & 1.01 & 20 & 0.020 & 6 & $3.24 \mathrm{E}-03$ & -2.49 & \\
\hline 197 & & 23 & 10.04 & 1.01 & 20 & 0.020 & 6 & $2.88 \mathrm{E}-03$ & -2.54 & \\
\hline 198 & & 23 & 10.04 & 1.01 & 20 & 0.020 & 6 & $2.95 \mathrm{E}-03$ & -2.53 & \\
\hline 199 & & 23 & 11.05 & 1.00 & 20 & 0.020 & 7 & $2.29 \mathrm{E}-02$ & -1.64 & \\
\hline 200 & & 23 & 11.05 & 1.01 & 20 & 0.020 & 7 & $2.29 \mathrm{E}-02$ & -1.64 & \\
\hline \multirow[t]{2}{*}{201} & & 23 & 11.05 & 1.00 & 20 & 0.020 & 7 & $2.40 \mathrm{E}-02$ & -1.62 & \\
\hline & $\mathrm{Q} / \mathrm{K}$ study & & & & & & & & & \\
\hline 152 & $1.56 \mathrm{E}-04$ & 90 & 8.95 & 0.51 & 80 & 0.020 & 5 & $1.70 \mathrm{E}-01$ & -0.77 & 1,4 \\
\hline 153 & 8.71E-04 & 90 & 8.95 & 0.51 & 80 & 0.020 & 5 & $1.05 \mathrm{E}-01$ & -0.98 & \\
\hline 154 & $1.66 \mathrm{E}-03$ & 90 & 9.04 & 0.50 & 80 & 0.020 & 5 & $5.75 \mathrm{E}-02$ & -1.24 & \\
\hline 155 & $2.45 \mathrm{E}-03$ & 90 & 9.09 & 0.51 & 80 & 0.020 & 5 & $1.26 \mathrm{E}-01$ & -0.90 & \\
\hline 156 & $3.20 \mathrm{E}-03$ & 90 & 9.05 & 0.51 & 80 & 0.020 & 5 & $1.26 \mathrm{E}-01$ & -0.90 & \\
\hline 157 & $3.77 \mathrm{E}-03$ & 90 & 8.97 & 0.52 & 80 & 0.020 & 5 & $1.32 \mathrm{E}-01$ & -0.88 & \\
\hline 158 & $1.71 \mathrm{E}-04$ & 90 & 8.95 & 0.50 & 80 & 0.020 & 5 & $1.86 \mathrm{E}-01$ & -0.73 & \\
\hline 159 & $9.59 \mathrm{E}-04$ & 90 & 8.95 & 0.51 & 80 & 0.020 & 5 & $1.02 \mathrm{E}-01$ & -0.99 & \\
\hline 160 & $1.76 \mathrm{E}-03$ & 90 & 9.04 & 0.51 & 80 & 0.020 & 5 & 7.41E-02 & -1.13 & \\
\hline 161 & $2.49 \mathrm{E}-03$ & 90 & 9.09 & 0.51 & 80 & 0.020 & 5 & $1.07 \mathrm{E}-01$ & -0.97 & \\
\hline 162 & 3.33E-03 & 90 & 9.05 & 0.50 & 80 & 0.020 & 5 & $1.38 \mathrm{E}-01$ & -0.86 & \\
\hline 163 & $4.05 \mathrm{E}-03$ & 90 & 8.97 & 0.51 & 80 & 0.020 & 5 & $1.51 \mathrm{E}-01$ & -0.82 & \\
\hline 185 & $3.72 \mathrm{E}-03$ & 90 & 9.03 & 0.58 & 20 & 0.020 & 5 & $1.51 \mathrm{E}-01$ & -0.82 & \\
\hline 186 & $2.83 \mathrm{E}-03$ & 90 & 9.03 & 0.59 & 40 & 0.020 & 5 & $1.55 \mathrm{E}-01$ & -0.81 & \\
\hline 187 & $1.80 \mathrm{E}-03$ & 90 & 9.03 & 0.58 & 60 & 0.020 & 5 & $1.29 \mathrm{E}-01$ & -0.89 & \\
\hline 188 & 8.81E-04 & 90 & 9.03 & 0.59 & 80 & 0.020 & 5 & $9.33 \mathrm{E}-02$ & -1.03 & \\
\hline 189 & $3.61 \mathrm{E}-03$ & 90 & 9.08 & 0.59 & 20 & 0.020 & 5 & $1.20 \mathrm{E}-01$ & -0.92 & \\
\hline 190 & $3.45 \mathrm{E}-03$ & 90 & 9.08 & 0.58 & 40 & 0.020 & 5 & $1.35 \mathrm{E}-01$ & -0.87 & \\
\hline 191 & $2.74 \mathrm{E}-03$ & 90 & 9.08 & 0.59 & 60 & 0.020 & 5 & $1.29 \mathrm{E}-01$ & -0.89 & \\
\hline 192 & $2.42 \mathrm{E}-03$ & 90 & 9.08 & 0.59 & 80 & 0.020 & 5 & $1.62 \mathrm{E}-01$ & -0.79 & \\
\hline
\end{tabular}

1. Glass specimen in $<100,>200$ mesh size fraction; specific surface area by geometric calculation.

4. Average concentrations of $\mathrm{Si}(\mathrm{mol} \mathrm{L}-1)$ in effluent samples are listed under "Q/K". 
Table A5. SPFT Experimental Conditions and Dissolution rates of LAWABP1 Glass

\begin{tabular}{|c|c|c|c|c|c|c|c|c|c|c|}
\hline Expt. \# & Description & $\begin{array}{l}\text { Temp } \\
\left({ }^{\circ} \mathrm{C}\right)\end{array}$ & $\mathrm{pH}$ & $\begin{array}{c}\operatorname{mass} \\
(\mathrm{g})\end{array}$ & $\begin{array}{c}\text { flow rate } \\
(\mathrm{mL} / \mathrm{d})\end{array}$ & $\begin{array}{c}\text { surface } \\
\text { area }\left(\mathrm{m}^{2} / \mathrm{g}\right)\end{array}$ & $\begin{array}{c}\text { Buffer } \\
\#\end{array}$ & $\begin{array}{c}\text { rate } \\
\left(\mathrm{g} \mathrm{m}^{-2} \mathrm{~d}^{-1}\right) \\
\end{array}$ & $\begin{array}{c}\log \text { rate } \\
\left(\mathrm{g} \mathrm{m}^{-2} \mathrm{~d}^{-1}\right)\end{array}$ & Notes \\
\hline & Q/K study & & & & & & & & & \\
\hline 98 & $3.77 \mathrm{E}-04$ & 70 & 9.02 & 0.52 & 50 & 0.020 & 5 & $6.33 \mathrm{E}-02$ & -1.20 & 1,4 \\
\hline 99 & $3.66 \mathrm{E}-04$ & 70 & 9.02 & 0.51 & 60 & 0.020 & 5 & $6.34 \mathrm{E}-02$ & -1.20 & \\
\hline 100 & $6.96 \mathrm{E}-04$ & 70 & 9.12 & 0.52 & 50 & 0.020 & 5 & $5.42 \mathrm{E}-02$ & -1.27 & \\
\hline 101 & $6.80 \mathrm{E}-04$ & 70 & 9.12 & 0.52 & 60 & 0.020 & 5 & $5.29 \mathrm{E}-02$ & -1.28 & \\
\hline 114 & $1.07 \mathrm{E}-03$ & 70 & 9.05 & 0.51 & 50 & 0.020 & 5 & $3.72 \mathrm{E}-02$ & -1.43 & 1 \\
\hline 115 & $1.07 \mathrm{E}-03$ & 70 & 9.05 & 0.51 & 60 & 0.020 & 5 & $3.89 \mathrm{E}-02$ & -1.41 & \\
\hline 116 & 7.35E-04 & 70 & 9.05 & 0.51 & 50 & 0.020 & 5 & $2.51 \mathrm{E}-02$ & -1.60 & \\
\hline 117 & 7.42E-04 & 70 & 9.05 & 0.51 & 60 & 0.020 & 5 & $2.69 \mathrm{E}-02$ & -1.57 & \\
\hline 130 & $1.67 \mathrm{E}-03$ & 70 & 9.29 & 0.50 & 60 & 0.020 & 5 & $2.04 \mathrm{E}-02$ & -1.69 & 1 \\
\hline 131 & $1.68 \mathrm{E}-03$ & 70 & 9.29 & 0.50 & 60 & 0.020 & 5 & $2.40 \mathrm{E}-02$ & -1.62 & \\
\hline 132 & $1.95 \mathrm{E}-03$ & 70 & 9.29 & 0.50 & 60 & 0.020 & 5 & $2.09 \mathrm{E}-02$ & -1.68 & \\
\hline 133 & $1.94 \mathrm{E}-03$ & 70 & 9.29 & 0.51 & 60 & 0.020 & 5 & $2.04 \mathrm{E}-02$ & -1.69 & \\
\hline 206 & $4.56 \mathrm{E}-03$ & 70 & 9.03 & 0.51 & 60 & 0.020 & 5 & $2.51 \mathrm{E}-02$ & -1.60 & \\
\hline \multirow[t]{2}{*}{207} & $4.58 \mathrm{E}-03$ & 70 & 9.03 & 0.51 & 60 & 0.020 & 5 & $2.34 \mathrm{E}-02$ & -1.63 & \\
\hline & $\mathrm{Q} / \mathrm{K}$ study & & & & & & & & & \\
\hline 17 & $3.40 \mathrm{E}-05$ & 40 & 9.10 & 0.50 & 30 & 0.020 & 5 & $7.94 \mathrm{E}-03$ & -2.10 & 1 \\
\hline 18 & $3.69 \mathrm{E}-04$ & 40 & 9.09 & 0.50 & 30 & 0.020 & 5 & $5.13 \mathrm{E}-03$ & -2.29 & \\
\hline 19 & $7.24 \mathrm{E}-04$ & 40 & 9.08 & 0.51 & 30 & 0.020 & 5 & $3.72 \mathrm{E}-03$ & -2.43 & \\
\hline 20 & $1.43 \mathrm{E}-03$ & 40 & 9.04 & 0.52 & 30 & 0.020 & 5 & $1.66 \mathrm{E}-03$ & -2.78 & \\
\hline 21 & $2.10 \mathrm{E}-03$ & 40 & 8.72 & 0.50 & 30 & 0.020 & 5 & $1.95 \mathrm{E}-03$ & -2.71 & \\
\hline 22 & $2.77 \mathrm{E}-03$ & 40 & 9.08 & 0.51 & 30 & 0.020 & 5 & $1.95 \mathrm{E}-03$ & -2.71 & \\
\hline 23 & $3.27 \mathrm{E}-05$ & 40 & 9.07 & 0.50 & 30 & 0.020 & 5 & $8.71 \mathrm{E}-03$ & -2.06 & \\
\hline 24 & $3.97 \mathrm{E}-04$ & 40 & 9.06 & 0.51 & 30 & 0.020 & 5 & 4.07E-03 & -2.39 & \\
\hline 25 & $7.06 \mathrm{E}-04$ & 40 & 9.04 & 0.50 & 30 & 0.020 & 5 & $3.39 \mathrm{E}-03$ & -2.47 & \\
\hline 26 & $1.43 \mathrm{E}-03$ & 40 & 9.06 & 0.50 & 30 & 0.020 & 5 & $2.34 \mathrm{E}-03$ & -2.63 & \\
\hline 27 & $2.08 \mathrm{E}-03$ & 40 & 9.06 & 0.50 & 30 & 0.020 & 5 & $1.35 \mathrm{E}-03$ & -2.87 & \\
\hline 28 & 2.64E-03 & 40 & 9.09 & 0.50 & 30 & 0.020 & 5 & $1.00 \mathrm{E}-03$ & -3.00 & \\
\hline \multirow[t]{2}{*}{ E24 } & $2.26 \mathrm{E}-03$ & 40 & 8.00 & 1.00 & 10 & 0.020 & 4 & $1.95 \mathrm{E}-03$ & -2.71 & 1 \\
\hline & Al-sweep & & & & & & & & & \\
\hline 5 & $0 \mu \mathrm{M} \mathrm{Al}$ & 40 & 9.05 & 0.51 & 30 & 0.020 & 5 & $1.91 \mathrm{E}-02$ & -1.72 & 1 \\
\hline 6 & $20 \mu \mathrm{M} \mathrm{Al}$ & 40 & 9.03 & 0.50 & 30 & 0.020 & 5 & $1.17 \mathrm{E}-02$ & -1.93 & \\
\hline 7 & $35 \mu \mathrm{M} \mathrm{Al}$ & 40 & 9.04 & 0.52 & 30 & 0.020 & 5 & $9.77 \mathrm{E}-03$ & -2.01 & \\
\hline 8 & $50 \mu \mathrm{M} \mathrm{Al}$ & 40 & 9.01 & 0.51 & 30 & 0.020 & 5 & $8.13 \mathrm{E}-03$ & -2.09 & \\
\hline
\end{tabular}

1. Glass specimen in $<100,>200$ mesh size fraction; specific surface area by geometric calculation.

4. Average concentrations of $\mathrm{Si}(\mathrm{mol} \mathrm{L-1})$ in effluent samples are listed under " $\mathrm{Q} / \mathrm{K}$ ". 
Table A6. SPFT Experimental Conditions and Dissolution rates of LAWABP1 Glass

\begin{tabular}{|c|c|c|c|c|c|c|c|c|c|c|}
\hline Expt. \# & Description & $\begin{array}{l}\text { Temp } \\
\left({ }^{\circ} \mathrm{C}\right)\end{array}$ & $\mathrm{pH}$ & $\begin{array}{l}\operatorname{mass} \\
(\mathrm{g})\end{array}$ & $\begin{array}{c}\text { flow rate } \\
(\mathrm{mL} / \mathrm{d})\end{array}$ & $\begin{array}{c}\text { surface } \\
\text { area }\left(\mathrm{m}^{2} / \mathrm{g}\right)\end{array}$ & $\begin{array}{c}\text { Buffer } \\
\#\end{array}$ & $\begin{array}{l}\mathrm{r} \quad \text { rate } \\
\left(\mathrm{g} \mathrm{m}^{-2} \mathrm{~d}^{-1}\right)\end{array}$ & $\begin{array}{c}\log \text { rate } \\
\left(\mathrm{g} \mathrm{m}^{-2} \mathrm{~d}^{-1}\right)\end{array}$ & Notes \\
\hline & Al/Si sweep & & & & & & & & & \\
\hline 80 & $0 \mathrm{Si} 0 \mu \mathrm{M} \mathrm{Al}$ & 90 & 8.86 & 0.51 & 80 & 0.020 & 5 & $2.57 \mathrm{E}-01$ & -0.59 & 1,5 \\
\hline 81 & $0 \mathrm{Si} 40 \mu \mathrm{M} \mathrm{Al}$ & 90 & 8.97 & 0.51 & 80 & 0.020 & 5 & 2.19E-01 & -0.66 & \\
\hline 82 & $0 \mathrm{Si} 75 \mu \mathrm{M} \mathrm{Al}$ & 90 & 8.96 & 0.50 & 80 & 0.020 & 5 & $2.24 \mathrm{E}-01$ & -0.65 & \\
\hline 83 & 0 Si $100 \mu \mathrm{M}$ Al & 90 & 8.96 & 0.51 & 80 & 0.020 & 5 & $2.00 \mathrm{E}-01$ & -0.70 & \\
\hline 84 & 40\% Si $0 \mu \mathrm{M} \mathrm{Al}$ & 90 & 8.88 & 0.50 & 80 & 0.020 & 5 & 8.32E-02 & -1.08 & \\
\hline 85 & $40 \%$ Si $40 \mu \mathrm{M} \mathrm{Al}$ & 90 & 8.89 & 0.50 & 80 & 0.020 & 5 & $1.12 \mathrm{E}-01$ & -0.95 & \\
\hline 86 & $40 \%$ Si $75 \mu \mathrm{M} \mathrm{Al}$ & 90 & 8.88 & 0.51 & 80 & 0.020 & 5 & $1.17 \mathrm{E}-01$ & -0.93 & \\
\hline 87 & $40 \%$ Si $100 \mu \mathrm{M} \mathrm{Al}$ & 90 & 8.87 & 0.51 & 80 & 0.020 & 5 & $1.48 \mathrm{E}-01$ & -0.83 & \\
\hline 88 & $60 \%$ Si $0 \mu \mathrm{M} \mathrm{Al}$ & 90 & 9.07 & 0.50 & 80 & 0.020 & 5 & $1.15 \mathrm{E}-01$ & -0.94 & \\
\hline 89 & $60 \% \mathrm{Si} 40 \mu \mathrm{M} \mathrm{Al}$ & 90 & 9.12 & 0.51 & 80 & 0.020 & 5 & $1.38 \mathrm{E}-01$ & -0.86 & \\
\hline 90 & $60 \%$ Si $75 \mu \mathrm{M} \mathrm{Al}$ & 90 & 9.06 & 0.51 & 80 & 0.020 & 5 & $1.32 \mathrm{E}-01$ & -0.88 & \\
\hline \multirow[t]{2}{*}{91} & $60 \%$ Si $100 \mu \mathrm{M} \mathrm{Al}$ & 90 & 9.05 & 0.51 & 80 & 0.020 & 5 & $1.29 \mathrm{E}-01$ & -0.89 & \\
\hline & $\mathrm{Al} / \mathrm{Si}$ & & & & & & & & & \\
\hline 56 & $0 \mathrm{Si}, 0 \mu \mathrm{M} \mathrm{Al}$ & 70 & 9.02 & 0.50 & 60 & 0.020 & 5 & $1.02 \mathrm{E}-01$ & -0.99 & 1,5 \\
\hline 57 & $0 \mathrm{Si}, 35 \mu \mathrm{M} \mathrm{Al}$ & 70 & 8.93 & 0.50 & 60 & 0.020 & 5 & 7.76E-02 & -1.11 & \\
\hline 58 & $0 \mathrm{Si}, 60 \mu \mathrm{M} \mathrm{Al}$ & 70 & 8.88 & 0.51 & 60 & 0.020 & 5 & $9.55 \mathrm{E}-02$ & -1.02 & \\
\hline 59 & $0 \mathrm{Si}, 90 \mu \mathrm{M} \mathrm{Al}$ & 70 & 8.97 & 0.51 & 60 & 0.020 & 5 & 8.32E-02 & -1.08 & \\
\hline 60 & $40 \% \mathrm{Si}, 0 \mu \mathrm{M} \mathrm{Al}$ & 70 & 8.88 & 0.51 & 60 & 0.020 & 5 & $2.40 \mathrm{E}-02$ & -1.62 & \\
\hline 61 & $40 \% \mathrm{Si}, 35 \mu \mathrm{M} \mathrm{Al}$ & 70 & 9.09 & 0.50 & 60 & 0.020 & 5 & $1.55 \mathrm{E}-02$ & -1.81 & \\
\hline 62 & $40 \% \mathrm{Si}, 60 \mu \mathrm{M} \mathrm{Al}$ & 70 & 9.06 & 0.50 & 60 & 0.020 & 5 & $8.13 \mathrm{E}-03$ & -2.09 & \\
\hline 63 & $40 \% \mathrm{Si}, 90 \mu \mathrm{M} \mathrm{Al}$ & 70 & 9.04 & 0.50 & 60 & 0.020 & 5 & $1.32 \mathrm{E}-02$ & -1.88 & \\
\hline 64 & $60 \% \mathrm{Si}, 0 \mu \mathrm{M} \mathrm{Al}$ & 70 & 8.87 & 0.50 & 60 & 0.020 & 5 & 2.69E-02 & -1.57 & \\
\hline 65 & $60 \% \mathrm{Si}, 35 \mu \mathrm{M} \mathrm{Al}$ & 70 & 9.05 & 0.51 & 60 & 0.020 & 5 & $2.45 \mathrm{E}-02$ & -1.61 & \\
\hline 66 & $60 \% \mathrm{Si}, 60 \mu \mathrm{M} \mathrm{Al}$ & 70 & 9.06 & 0.51 & 60 & 0.020 & 5 & $2.14 \mathrm{E}-02$ & -1.67 & \\
\hline 67 & $60 \% \mathrm{Si}, 90 \mu \mathrm{M} \mathrm{Al}$ & 70 & 9.02 & 0.50 & 60 & 0.020 & 5 & $2.75 \mathrm{E}-02$ & -1.56 & \\
\hline
\end{tabular}

1. Glass specimen in $\langle 100,>200$ mesh size fraction; specific surface area by geometric calculation.

5. Si concentration as percentage of saturation value with respect to amorphous silica. 
Table A7. SPFT Experimental Conditions and Dissolution rates of LAWABP1 Glass

\begin{tabular}{|c|c|c|c|c|c|c|c|c|c|c|}
\hline Expt. \# & Description & $\begin{array}{l}\text { Temp } \\
\left({ }^{\circ} \mathrm{C}\right)\end{array}$ & $\mathrm{pH}$ & $\begin{array}{l}\text { mass } \\
(\mathrm{g})\end{array}$ & $\begin{array}{c}\text { flow rate } \\
(\mathrm{mL} / \mathrm{d})\end{array}$ & $\begin{array}{c}\text { surface } \\
\text { area }\left(\mathrm{m}^{2} / \mathrm{g}\right)\end{array}$ & $\begin{array}{c}\text { Buffer } \\
\#\end{array}$ & $\begin{array}{l}\mathrm{r} \text { rate } \\
\left(\mathrm{g} \mathrm{m}^{-2} \mathrm{~d}^{-1}\right)\end{array}$ & $\begin{array}{c}\text { log rate } \\
\left(\mathrm{g} \mathrm{m}^{-2} \mathrm{~d}^{-1}\right)\end{array}$ & Notes \\
\hline & Al/Si sweep & & & & & & & & & \\
\hline 44 & $0 \mathrm{Si}, 0 \mu \mathrm{M} \mathrm{Al}$ & 40 & 9.00 & 1.00 & 30 & 0.020 & 5 & 8.71E-03 & -2.06 & 1,5 \\
\hline 45 & $0 \mathrm{Si}, 20 \mu \mathrm{M} \mathrm{Al}$ & 40 & 9.00 & 1.00 & 30 & 0.020 & 5 & 4.79E-03 & -2.32 & \\
\hline 46 & $0 \mathrm{Si}, 35 \mu \mathrm{M} \mathrm{Al}$ & 40 & 9.00 & 1.01 & 30 & 0.020 & 5 & 4.79E-03 & -2.32 & \\
\hline 47 & $0 \mathrm{Si}, 50 \mu \mathrm{M} \mathrm{Al}$ & 40 & 9.00 & 1.02 & 30 & 0.020 & 5 & $4.79 \mathrm{E}-03$ & -2.32 & \\
\hline 48 & $40 \% \mathrm{Si}, 0 \mu \mathrm{M} \mathrm{Al}$ & 40 & 9.00 & 1.02 & 30 & 0.020 & 5 & 4.79E-03 & -2.32 & \\
\hline 49 & $40 \% \mathrm{Si}, 20 \mu \mathrm{M} \mathrm{Al}$ & 40 & 9.00 & 1.01 & 30 & 0.020 & 5 & $4.79 \mathrm{E}-03$ & -2.32 & \\
\hline 50 & $40 \% \mathrm{Si}, 35 \mu \mathrm{M} \mathrm{Al}$ & 40 & 9.00 & 1.00 & 30 & 0.020 & 5 & 4.79E-03 & -2.32 & \\
\hline 51 & $40 \% \mathrm{Si}, 50 \mu \mathrm{M} \mathrm{Al}$ & 40 & 9.00 & 1.02 & 30 & 0.020 & 5 & 4.79E-03 & -2.32 & \\
\hline 52 & $60 \% \mathrm{Si}, 0 \mu \mathrm{M} \mathrm{Al}$ & 40 & 9.00 & 1.01 & 30 & 0.020 & 5 & 4.79E-03 & -2.32 & \\
\hline 53 & $60 \% \mathrm{Si}, 20 \mu \mathrm{M} \mathrm{Al}$ & 40 & 9.00 & 1.00 & 30 & 0.020 & 5 & 4.79E-03 & -2.32 & \\
\hline 54 & $60 \% \mathrm{Si}, 35 \mu \mathrm{M} \mathrm{Al}$ & 40 & 9.00 & 1.01 & 30 & 0.020 & 5 & 4.79E-03 & -2.32 & \\
\hline 55 & $60 \% \mathrm{Si}, 50 \mu \mathrm{M} \mathrm{Al}$ & 40 & 9.00 & 1.00 & 30 & 0.020 & 5 & 4.79E-03 & -2.32 & \\
\hline 202 & $50 \mathrm{ppm}$ humic & 90 & 9.03 & 0.51 & 80 & 0.020 & 5 & $1.85 \mathrm{E}-01$ & -0.73 & 1 \\
\hline 203 & $50 \mathrm{ppm}$ humic & 90 & 9.03 & 0.50 & 80 & 0.020 & 5 & $1.73 \mathrm{E}-01$ & -0.76 & \\
\hline 204 & 0 ppm humic & 90 & 9.05 & 0.50 & 80 & 0.020 & 5 & $1.55 \mathrm{E}-01$ & -0.81 & \\
\hline 205 & 0 ppm humic & 90 & 9.05 & 0.51 & 80 & 0.020 & 5 & $1.49 \mathrm{E}-01$ & -0.83 & \\
\hline
\end{tabular}

1. Glass specimen in $<100,>200$ mesh size fraction; specific surface area by geometric calculation

5. Si concentration as percentage of saturation value with respect to amorphous silica. 


\section{DISTRIBUTION}

No. of

Copies

\section{OFFSITE}

1 Argonne National Laboratory

Building 205

9700 South Cass Avenue

Argonne, IL 60439-4837

Attn: William L. Ebert

2 Westinghouse Savannah River Company

P. O. Box 616

Aiken, SC 29802

Attn: E. W. Holtzscheiter

D. K. Peeler

1 Catholic University of America

Vitreous State Laboratory

Washington D.C. 20064

Attn: Ian L. Pegg

1 Dr. Harry Babad

2540 Cordoba $\mathrm{Ct}$

Richland, WA 99352
No. of

$\underline{\text { Copies }}$

ONSITE

$4 \quad$ U.S. Department of Energy Richland Operations Office

N. R. Brown, H6-60

P. E. Lamont, H6-60

C. A. Babel, H6-60

Public Reading Room, H2-53

$4 \quad$ Fluor Federal Services

R. Khaleel, B4-43

F. M. Mann, H0-22 (2)

R. J. Puigh, B4-43

\section{CH2M Hill}

C. N. Wilson, H4-02

29 Pacific Northwest National Laboratory

D. H. Bacon, K9-33

M. J. Fayer, K9-33

J. P. Icenhower, K6-81 (2)

P. F. Martin, P8-37

B. P. McGrail, K6-81 (10)

P. D. Meyer, BPO

D. R. Rector, K7-15

E. A. Rodriguez, K6-81

H. T. Schaef, K6-81

R. J. Serne, K6-81

J. L. Steele, K6-81

J. D. Vienna, K6-24

Information Release Office, K1-06 (7) 